\title{
Conferring specificity in redox pathways by enzymatic thiol/disulfide exchange reactions
}

\section{Luis Eduardo S. Netto, Marcos Antonio de Oliveira, Carlos A. Tairum \& José Freire da Silva Neto}

To cite this article: Luis Eduardo S. Netto, Marcos Antonio de Oliveira, Carlos A. Tairum \& José Freire da Silva Neto (2016) Conferring specificity in redox pathways by enzymatic thiol/disulfide exchange reactions, Free Radical Research, 50:2, 206-245, DOI: 10.3109/10715762.2015.1120864

To link to this article: https://doi.org/10.3109/10715762.2015.1120864

Accepted author version posted online: 16

Nov 2015.

Published online: 08 Jan 2016.

Submit your article to this journal \lceil

Џll Article views: 727

View Crossmark data \lceil

Citing articles: 24 View citing articles ¿ 


\title{
Conferring specificity in redox pathways by enzymatic thiol/disulfide exchange reactions
}

\author{
Luis Eduardo S. Netto ${ }^{a}$, Marcos Antonio de Oliveira ${ }^{b}$, Carlos A. Tairum $^{b}$ and José Freire da Silva Neto ${ }^{c}$ \\ ${ }^{a}$ Departamento de Genética e Biologia Evolutiva, Instituto de Biociências, Universidade de São Paulo, São Paulo, Brazil; ${ }^{\circ}$ Departamento de \\ Biologia, Universidade Estadual Paulista Júlio de Mesquita Filho, Campus do Litoral Paulista São Vicente, Brazil; 'Departamento de Biologia \\ Celular e Molecular e Bioagentes Patogênicos, Faculdade de Medicina de Ribeirão Preto, Universidade de São Paulo, Ribeirão Preto, \\ São Paulo, Brazil
}

\begin{abstract}
Thiol-disulfide exchange reactions are highly reversible, displaying nucleophilic substitutions mechanism $\left(\mathrm{S}_{N} 2\right.$ type). For aliphatic, low molecular thiols, these reactions are slow, but can attain million times faster rates in enzymatic processes. Thioredoxin (Trx) proteins were the first enzymes described to accelerate thiol-disulfide exchange reactions and their high reactivity is related to the high nucleophilicity of the attacking thiol. Substrate specificity in Trx is achieved by several factors, including polar, hydrophobic, and topological interactions through a groove in the active site. Glutaredoxin (Grx) enzymes also contain the Trx fold, but they do not share amino acid sequence similarity with Trx. A conserved glutathione binding site is a typical feature of Grx that can reduce substrates by two mechanisms (mono and dithiol). The high reactivity of Grx enzymes is related to the very acid $\mathrm{p} K_{\mathrm{a}}$ values of reactive $C y s$ that plays roles as good leaving groups. Therefore, although distinct oxidoreductases catalyze similar thiol-disulfide exchange reactions, their enzymatic mechanisms vary. PDI and DsbA are two other oxidoreductases, but they are involved in disulfide bond formation, instead of disulfide reduction, which is related to the oxidative environment where they are found. PDI enzymes and DsbC are endowed with disulfide isomerase activity, which is related with their tetra-domain architecture. As illustrative description of specificity in thioldisulfide exchange, redox aspects of transcription activation in bacteria, yeast, and mammals are presented in an evolutionary perspective. Therefore, thiol-disulfide exchange reactions play important roles in conferring specificity to pathways, a required feature for signaling.
\end{abstract}

\section{ARTICLE HISTORY}

Received 20 August 2015

Revised 11 November 2015

Accepted 11 November 2015

Published online

14 December 2015

\section{KEYWORDS}

Disulfide reductases; glutathione; glutathione peroxidase; peroxiredoxin; thiols; thioredoxin

\section{Introduction}

Many redox proteins rely on non-proteic cofactors (such as $\mathrm{NAD}^{+}$; $\mathrm{FAD}$; heme; $\mathrm{Cu}, \mathrm{Fe}$, or other transition metals) for their activity. In contrast, other proteins use Cys residues for electron transfer processes (reviewed in Ref. [1]). The free amino acid cysteine presents low reactivity for redox transitions [2,3]. However, protein folding can generate environments in which cysteine residues become redox active.

Thiol and selenol groups are the most easily oxidizable residues in proteins. Distinct Cys-based proteins are specifically oxidized by different agents. For instance, peroxiredoxins, thioredoxins, and methionine sulfoxide reductase are efficiently oxidized by hydroperoxides, proteins disulfides, and methionine sulfoxide, respectively [1]. Probably, folding in each protein is adapted to stabilize distinct transition states. One of the most common forms of oxidized cysteine in these proteins is the disulfide bond, which is generated from thiols by a two electron oxidation process from two sulfhydryl groups separated apart by distances in the $2.00 \AA$ range:

$$
\left.2 \mathrm{Cys}-\mathrm{SH} \rightarrow \mathrm{Cys}-\mathrm{SS}-\mathrm{Cys}+2 \mathrm{H}^{+}+2 \mathrm{e}^{-} \quad \text { (Reaction } 1\right)
$$

Disulfides are stable covalent bonds with dissociation energy of around $60 \mathrm{kcal} / \mathrm{mole}(251 \mathrm{~kJ} / \mathrm{mol})$, being $40 \%$ weaker than $\mathrm{C}-\mathrm{C}$ and $\mathrm{C}-\mathrm{H}$ bonds (reviewed in Ref. [4]). The disulfide bond length is about $2.05 \AA$ and its stability is related to the C-S-S-C dihedral angles (Figure 1). Disulfides with dihedral angles close to $90^{\circ}$ present low energy levels. In contrast, when the angle goes far from this value $\left(0^{\circ}\right.$ or $\left.180^{\circ}\right)$, the disulfide is in a strain condition, becoming more unstable and consequently presenting significantly better oxidant properties [5]. For instance, five-membered cyclic disulfides that are strained with a $\mathrm{C}-\mathrm{S}-\mathrm{S}-\mathrm{C}$ angle of around $30^{\circ}$ are more 


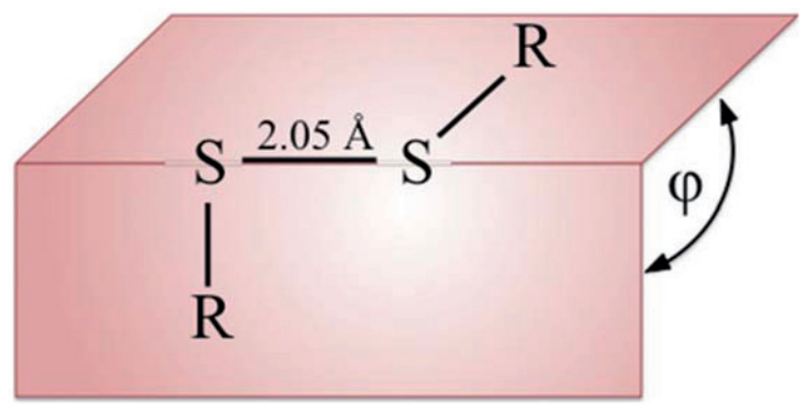

Figure 1. Dihedral angle $\phi$-determined from the two planes containing a disulfide bond. When the dihedral angle is equivalent to $90^{\circ}$ the corresponding disulfide bond is in the most stable form [5].

unstable and play a role as an oxidizing agent in bioenergetics processes. Accordingly, lipoamide is a biological five-membered cyclic disulfide that is involved in oxidizing substrates in bio-energetic pathways (section "Txn-T(SH) 2 system"). Taking advantage of the large number of structures whose coordinates were deposited into the protein data bank, we analyzed the dihedral angles of disulfides bonds in several proteins. The global analyses indicated that there is no evident correlation of proteins with reducing and oxidizing capacities $\left(E^{0}\right.$ values) and their dihedral angles (Table I). Other factors affect the redox properties of proteins and are further discussed below.

In some proteins, disulfides play a role in increasing their overall stability, especially in the case of extracellular proteins that have to cope with the harsh conditions of the extra-cellular environment [29]. In contrast, disulfide bonds can be reversible interconverted into dithiols, a redox process that can play roles in enzymatic catalysis, transport of reducing or oxidizing equivalents, and antioxidant defense, among other processes. In some cases, dithiol-disulfide inter-conversion is one of the several steps of the overall enzymatic mechanism. For example, thiol-disulfide exchange reactions are involved in the regeneration of the reduced states in enzymes such as ribonucleotide reductase [30], methionine sulfoxide reductase [31,32], and Prxs [33].

In other cases, reduction of disulfide to dithiol is not only a step in the catalytical cycle per se, but also its occurrence enhances (or diminishes) the enzymatic activities, by an allosteric-like mechanism. This kind of mechanism is well described for several chloroplastic enzymes and the reductive power comes from photodependent processes (reviewed in Ref. [4]). Also within this category are the reductive reactions of disulfides in some proteins that are components of cell receptors. Reductions of these disulfides to dithiols activate the binding of agonists (reviewed in Ref. [4]).
A third category of enzymes, whose activities are also affected by thiol-based redox processes comprise proteins that a sulfhydryl group is essential for their activities, but thiol-disulfide exchange per se is not part of the catalytical cycle. Examples are thiol proteases (papain and bromelain), $\beta$-ketoacylthiolase, creatine kinase, glyceraldehyde-3-phosphate dehydrogenase, and protein tyrosine phosphatase. These enzymes can be reactivated using reducing agents, such as dithiothreitol and TCEP.

Therefore, thiols and disulfides can be interconverted back and forward in conditions that reflect environmental state. In a basal condition, with no oxidative insult, about $90 \%$ of the total sulfur atoms in mammalian cells are in the thiol (or thiolate) form; whereas $10 \%$ are engaged in disulfide bonds $(0.1 \%$ in the protein-glutathione mixed disulfide). From the reduced pool, about $75 \%$ are proteic thiol, whereas $25 \%$ are low molecular weight thiols, mostly reduced glutathione [34].

Since inter-conversions of thiols into disulfides are central processes in biology, it is relevant to fully comprehend the fundamentals of the reaction that control these processes: thiol-disulfide exchange (also called thiol-disulfide interchange).

\section{Physico-chemical factors affecting thiol-disulfide exchange reaction for low molecular weight compounds}

Thiol-disulfide exchange reaction involves the reduction of a disulfide bond by a thiolate anion $\left(\mathrm{RS}^{-}\right)$, resulting in the formation of a new disulfide and a new thiolate (see the "Reaction 3" below). It is unique in the sense that reagents and products contain the same functional groups. Therefore, in this reaction, a strong covalent bond (the $\mathrm{S}-\mathrm{S}$ bond; bond energy about $60 \mathrm{kcal} / \mathrm{mol}$ ) is cleaved and another bond is formed. It occurs reversibly at physiological conditions, but the non-catalyzed process is very slow, with second order rate constants in the $0.1-10 \mathrm{M}^{-1} \mathrm{~s}^{-1}$ range, in the case of aliphatic thiols (reviewed in Ref. [4]). The half-life for alkane thiols is about $2 \mathrm{~h}$ for a reaction containing thiol and disulfide at millimolar concentrations.

Therefore, it is important to consider the equilibrium of thiolate protonation to thiol in aqueous solution, according to the Reaction 2. The corresponding aciddissociation constants (the $\mathrm{p} K_{\mathrm{a}}$ values) vary among low molecular weight and protein thiols, affecting the reaction rates.

$$
\mathrm{RSH} \rightleftarrows \mathrm{RS}^{-}+\mathrm{H}^{+}
$$

(Reaction 2) 
Table I. List of some thiol-disulfide exchange enzymes that present 3D-structure in the disulfide form.

\begin{tabular}{|c|c|c|c|c|c|c|}
\hline Enzymes & Organisms & $\begin{array}{l}\text { Dihedral } \\
\text { angle }\left(^{\circ}\right)\end{array}$ & $\begin{array}{c}\text { S-S distance } \\
(\AA) \\
\end{array}$ & $\begin{array}{l}\text { PDB } \\
\text { File }\end{array}$ & $\mathrm{p} K_{\mathrm{a}}$ & $\begin{array}{l}\text { Redox potential } \\
\left(E^{\circ}, \mathrm{mV}\right)\end{array}$ \\
\hline Alkyl hydroperoxide reductase C (AhpC) & S. typhimurium & -93.20 & 2.04 & 1YEP & $5.94[6]$ & $-178[7]$ \\
\hline Alkyl hydroperoxide reductase F (NTD domain) & S. typhimurium & 93.22 & 2.10 & $1 Z Y N$ & $5.1[8]$ & $-265[8]$ \\
\hline Disulfide bond protein a (Dsba) & E. coli & 90.34 & 2.03 & $1 \mathrm{~A} 2 \mathrm{M}$ & $3.5[9,10]$ & $-125[11]$ \\
\hline FTR-Ferredoxin thioredoxin reductase (chloroplast) & S. oleracea (spinach) & -84.93 & 2.05 & 1DJ7 & - & $-320[12]$ \\
\hline Glutaredoxin (Grx) & E. coli & 108.34 & 2.02 & $1 \mathrm{EGO}$ & $5.0[13]$ & $-198[14]$ \\
\hline Glutaredoxin 1 (Grx1) & S. cerevisiae & 66.12 & 2.06 & $3 \mathrm{D} 4 \mathrm{M}$ & $3.2-4.0[15]$ & - \\
\hline Glutaredoxin 2 (Grx2) & S. cerevisiae & 71.37 & 2.08 & $3 C 1 R$ & $3.1-3.5[15]$ & - \\
\hline Glutathione reductase (GR) & E. coli & 127.41 & 2.05 & 1GER & $8.5[16]$ & $-243[16]$ \\
\hline Glutathione reductase (GR) & H. sapiens & -133.43 & 2.10 & $3 G R S$ & $7.6[16]$ & $-227[16]$ \\
\hline Glutathione reductase (GR) & S. cerevisiae & -126.76 & 2.10 & $2 \mathrm{HQM}$ & $7.4[16]$ & $-237[16]$ \\
\hline Lipoamide dehydrogenase & E. coli & 28.95 & 1.96 & 4JDR & $6.7[17]$ & - \\
\hline Mercuric reductase & P. aeruginosa & -116.32 & 2.01 & $1 Z X 9$ & $5.2[18]$ & $-269[19]$ \\
\hline Protein disulfide isomerase (PDI) & H. sapiens & 91.77 & 2.21 & 4EL1 & $4.81[20]$ & -162 to $169[21]$ \\
\hline Thioredoxin A (TrxA) & E.coli & 81.02 & 2.09 & $2 \mathrm{TRX}$ & $6.4-7.45[22,23]$ & $-270[24]$ \\
\hline Thioredoxin 1 (Trx1) & S. cerevisiae & 72.4 & 2.05 & $3 F 3 Q$ & - & $-275[25]$ \\
\hline Thioredoxin 2 (Trx2) & S. cerevisiae & 84.17 & 2.10 & 2FA4 & - & $-265[25]$ \\
\hline Thioredoxin $f(\operatorname{Trx} f)$ & S. oleracea (spinach) & 74.18 & 2.03 & 1FAA & - & $-290[12]$ \\
\hline Thioredoxin $\mathrm{m}(\operatorname{Trx} m)$ & S. oleracea (spinach) & 87.05 & 2.03 & $1 F B 6$ & - & $-300[12]$ \\
\hline Thioredoxin reductase (TrxR) (FAD)-enzyme-(S)2/(SH)2 & E. coli & 73.90 & 2.01 & $1 T D E$ & - & $-254[26,27]$ \\
\hline Thioredoxin reductase (TrxR) (FADH2)-enzyme-(S)2/(SH)2 & E. coli & 73.90 & 2.01 & $1 T D E$ & - & $-271[26,27]$ \\
\hline Tryparedoxin (TXN) & T. brucei & 80.01 & 2.00 & 1073 & $7.2[28]$ & $-249[28]$ \\
\hline $\begin{array}{l}\text { Yeast activator protein 1-Redox Domain } \\
\text { (Yap1-RD) (Cys 303-Cys 598) }\end{array}$ & S. cerevisiae & -67.20 & 2.02 & 1SSE & - & $-155[25]$ \\
\hline $\begin{array}{l}\text { Yeast activator protein 1-Redox Domain } \\
\text { (Yap1-RD) (Cys 310-Cys 629) }\end{array}$ & S. cerevisiae & 64.44 & 2.02 & 1SSE & - & $-330[25]$ \\
\hline
\end{tabular}

The respective dihedral angles and disulfide sulfurs distance of each enzyme are listed. pKa and redox potential data were compiled from the discriminate references. The structure models were obtained from PDB database and determination of the distances and angles were performed using PyMol software (The PyMOL Molecular Graphics System, Version 1.7.4 Schrödinger, LLC.)

Thiol-disulfide exchange is a second-order reaction: first order for the thiolate and first order for the disulfide (reviewed in Refs. [4,35,36]). It is a nucleophilic substitution reaction of the $\mathrm{S}_{N} 2$ type, in which as one bond is broken and the new bond is formed in one step, with the inversion of the symmetry. As expected for a $\mathrm{S}_{N} 2$ reaction, there is a single transition state. In this specific case, the transition state complex is composed of an intermediate with three sulfur atoms (Figure 2), with a negative charge delocalized among them.

At this point, it is convenient to name the three sulfur atoms for a general thiol-disulfide exchange reaction: (i) the attacking sulfur atom, corresponding to the thiolate anion is the nucleophilic sulfur $\left(\mathrm{RS}_{\text {nuc }}\right.$ ), (ii) the central sulfur $\left(\mathrm{RS}_{\mathrm{c}}\right)$ as the one that will take part in the new disulfide, and (iii) the sulfur leaving group as $\mathrm{RS}_{\mathrm{lg}}$. Therefore, for a general thiol-disulfide exchange reaction:

$$
\mathrm{RS}_{\text {nuc }}^{-}+\mathrm{RS}_{\mathrm{c}}-\mathrm{S}_{\mathrm{lg}} \mathrm{R} \rightarrow \mathrm{RS}_{\text {nuc }}-\mathrm{S}_{\mathrm{c}} \mathrm{R}+\mathrm{RS}_{\mathrm{lg}}^{-} \quad(\text { Reaction 3) }
$$

As mentioned before, for aliphatic thiols and disulfides this is a very slow reaction $\left(0.1-10 \mathrm{M}^{-1} \mathrm{~s}^{-1}\right)$ (reviewed in Refs. $[4,36]$ ). Anyway, it is important to understand the factors that affect the kinetics of these reactions, in order to understand how enzymes can accelerate them.

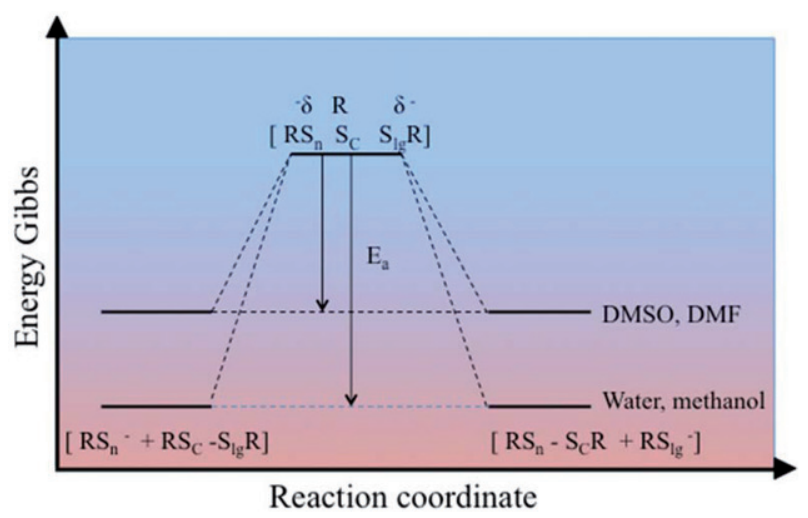

Figure 2. Free energy diagram for a generic thiol disulfide exchange reaction. $E_{\mathrm{a}}=$ Activation energy. There is a kinetic barrier, which can be alleviated by aprotic solvents and/or hydrophobic environments such as the active site pockets of the enzymes (reviewed in Ref. [4]).

\section{Electrostatic effects}

Knowing that the thiolate and not the corresponding thiol is the nucleophilic agent in thiol-disulfide exchange reactions, sulfhydryl compounds with low $\mathrm{p} K_{\mathrm{a}}$ values would be more efficient as attacking sulfur compounds. This is because the fraction of total thiol group present as thiolate will be higher for those thiols having acidic $\mathrm{p} K_{\mathrm{a}}$ values. However, the picture is more complex, as it will be described below. 
The acid dissociation for all three sulfur atoms interfere with the speed of this reaction, therefore, it is relevant to analyze the $\mathrm{p} K_{\mathrm{a}}$ values for all of them. Brønsted base coefficients are convenient parameters to correlate ionization state of the sulfur atoms and their effects on the reaction rates. The log of the real rate constants or rate constant $\mathrm{pH}$-independent $\left(k_{\mathrm{RS}-}\right)$ of a series of thiol-disulfide exchange reactions follows a Brønsted correlation as a function of their $\mathrm{p} K_{\mathrm{a}}$ values for the three sulfur atoms (reviewed in Ref. [4]).

Before describing this equation, it is important to distinguish the real second order rate constant $(\mathrm{pH}$ independent) that is distinct from the apparent $\left(k_{\text {obs }}\right)$ rate constant ( $\mathrm{pH}$ dependent). The fraction of available thiolate at a given $\mathrm{pH}$, for a given thiol is calculated to account for its reactivity toward the electrophilic species $[37,38]$. Consequently, $\mathrm{pH}$ independent rate constant $\left(k_{\mathrm{RS}-}\right)$ corresponds to the specific reactivity of the thiolate fraction of total sulfhydryl pool against the electrophile (in this case the disulfide) is given by:

$$
k_{\mathrm{obs}}=k_{\mathrm{s}-} /\left(1+10^{\left(\mathrm{p} K_{\mathrm{a}}-\mathrm{pH}\right)}\right)
$$

Therefore, the Brønsted relation for a thiol-disulfide exchange reaction is given by:

$$
\log k_{\mathrm{RS}}-=c+\beta_{\mathrm{nuc}} \mathrm{p} K_{\mathrm{a}(\mathrm{nuc})}+\beta_{\mathrm{c}} \mathrm{p} K_{\mathrm{a}(\mathrm{c})}+\beta_{\mathrm{lg}} \mathrm{p} K_{\mathrm{a}(\mathrm{lg})}
$$

where $\beta_{\text {nuc, }} \beta_{c}$, and $\beta_{\text {lg }}$ are the Brønsted base coefficients for the nucleophile, central group, and leaving group, respectively $[4,39,40]$.

For didactic reasons, let us initially consider only the first term of the overall Equation (2).

$$
\log k_{\mathrm{RS}}-=c+\beta_{\mathrm{nuc}} \mathrm{p} K_{\mathrm{a}(\mathrm{nuc})}
$$

Once formed, the reactivity of the thiolate is itself influenced by electrostatic effects. A plot of the log $k$ against $\mathrm{p} K_{\mathrm{a}}$ of the $\mathrm{pH}$-independent rate constants for a series of thiol-disulfide exchange reactions give raise to a straight line with slopes between 0.4 and $0.6[40,41,76]$ that corresponds to the $\beta_{\text {nuc }}$. This positive correlation implies that the enhancement of the thiol basicity (higher $\mathrm{p} K_{\mathrm{a}}$ ) favor its nucleophilic ability to displace the sulfur atom $\left(\mathrm{RS}_{\mathrm{C}}\right)$ of the disulfide bond. This is a wellknown phenomenon for organic chemists in other $\mathrm{S}_{N} 2$ type of reactions, which indicates that those factors that favor the transfer of electron density from the thiolate to a proton (basicity), also favor the transfer of negative charge to other atoms (such as sulfur atoms in the transition state for thiol-disulfide exchange reaction).

Therefore, the reactivity of the nucleophilic thiol $\left(\mathrm{RS}_{\text {nuc }}\right)$ is determined by two opposite factors related with the $p K_{a}$ values $[42,43]$. Thiols with high $p K_{a}$ values are expected to be stronger nucleophiles. However, as the reacting species is believed to be the thiolate anion, acidic thiols (with low $\mathrm{p} K_{\mathrm{a}}$ values) would be favored at physiological $\mathrm{pH}$, as a larger fraction of anionic thiolate would be available to react. From the balance between these two factors it emerges that the most reactive thiols (in terms $k_{\text {obs }}$ ) are those with a $\mathrm{p} K_{\mathrm{a}}$ close to the $\mathrm{pH}$ of the solution. As it will be discussed later, thioredoxin enzymes appear to take advantage of this property to act as a catalyst in thiol-disulfide exchange reactions.

Besides the attacking thiol $\left(\mathrm{RS}_{\text {nuc }}\right)$, the ionizations of the $\mathrm{RS}_{\mathrm{C}}$ and of the $\mathrm{RS}_{\mathrm{Ig}}$ also affect the rates of thioldisulfide exchange reactions $[39,40,44]$. Implicit in Equation (1) is the concept that the substituents attached to the three sulfur atoms influence the reaction rate independently. However, analysis of thiol-disulfide exchange employing a redox fluorescent protein indicates that there is some dependence among the three sulfur atoms [44]. Moreover, there is considerable uncertainty in the values of the Brønsted coefficients, but it appears that $\beta_{\mathrm{c}}$ and $\beta_{\mathrm{lg}}$ lie in the range of -0.5 to $-0.3[39,40]$. Therefore, the more acidic $p K_{a}$ values for $\mathrm{RS}_{\mathrm{C}}$ and $\mathrm{RS}_{\mathrm{Ig}}$, higher the rates of the thiol-disulfide exchange reaction, indicating that thiolate is not only a strong nucleophile, but also a good leaving group, which is related with its high polarizability and low degree of solvation, among other factors [4]. Therefore, analysis of the ionization of the $\mathrm{RS}_{\mathrm{Ig}}$ deserves further attention. For a set of similar thiol-disulfide exchange reactions, the second-order rate constant increases by a factor of four for each unit decrease in the $\mathrm{p} K_{\mathrm{a}}$ of the leaving group $[29,40]$. Furthermore, electrostatic factors that increase the electrophilicity of the disulfide formed by $R S_{C}$ and $R S_{\text {Ig }}$ will lead to a decrease of the activation energy and thereby activate the reaction rate $[36,39,44-47]$.

The limited data available indicated that electronic density is evenly distributed among the three sulfur atoms in the transition state [39 and references therein]. However, some theoretical studies appoint for higher absolute values of Brønsted coefficients for the $\mathrm{RS}_{\text {nuc }}$ and $\mathrm{RS}_{\mathrm{Ig}}$, indicating that these atoms have the greater contribution to the overall reaction. Through quantum mechanical calculations, it was observed that peripheral sulfur atoms $\left(\mathrm{RS}_{\text {nuc }}\right.$ and $\mathrm{RS}_{\mathrm{lg}}$ ) should have the most negative charge at the transition state, with zero or small negative charge at $\mathrm{RS}_{\mathrm{C}}$. It appears that along the course of the reaction, the negative charge is transferred directly from $\mathrm{RS}_{\text {nuc }}$ to $\mathrm{RS}_{\mathrm{Ig}}$ without accumulating at $\mathrm{RS}_{\mathrm{C}}[43]$.

\section{Solvent effects}

Hydrophobic environments accelerate the rate of thioldisulfide exchange reactions $[43,48]$. Molecular dynamics 
of a reaction between methylthiol and the disulfide of dithiothreitol (DTT) using a dielectric constant compatible with the hydrophobic pocket of ribonucleotide reductase produced a reaction rate 1000 times faster than the similar reaction in water [43]. Indeed, rates of dithiol-disulfide exchange reaction in polar aprotic solvents are 1000 times faster than similar reaction in polar protic solvents. In contrast, the nature of the counter cation has no effect on such reaction in DMSO $[48,76]$.

It appears that polar solvents stabilize the reactants in relation to the transition state, increasing the activation energy barrier (Figure 2). This effect is related with the negative charge distribution in the transition state described above. Extensive hydrophobic portions in Mia40 and PDI are probably related with the ability of these enzymes to catalyze thiol-disulfide exchange reactions $[43,48,49]$. In fact, a common feature among thiol-disulfide oxidoreductases is the presence of hydrophobic patches around the active site pocket (Figure 3), which may help to speed up the thiol-disulfide exchange reactions.

\section{Steric effects}

Transition state in thiol-disulfide exchange reaction is crowded and presents a linear geometry as expected for a $\mathrm{S}_{N} 2$ type process. Therefore, bulky substituents in carbon $\alpha$ of all three sulfur atoms can profoundly affect reaction rates [4]. Alkyl substituents for the carbon $\beta$ of all three sulfur atoms induced less pronounced effects.

In enzymes, steric factors probably are associated with the selectivity towards their targets, as will be discussed later. It was proposed that steric factors might create a strain of a disulfide, making its dihedral angle distant from $90^{\circ}$ (Figure 1). However, our analysis of dihedral angles in available structures indicated that is not the case (Table I). There is no clear apparent correlation among dihedral angles, S-S bond distance, $E^{0}(\mathrm{mV})$ and $\mathrm{p} K_{\mathrm{a}}$ values (Table I). Probably the diversity of structural
(A)

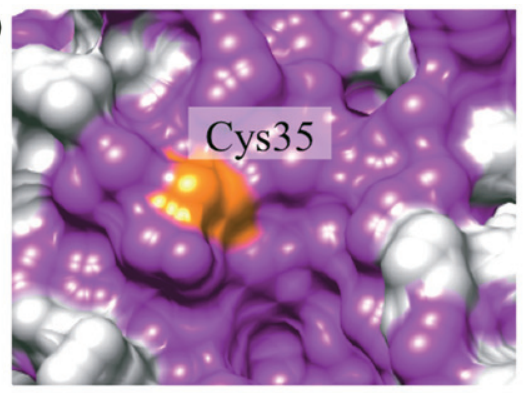

(C)

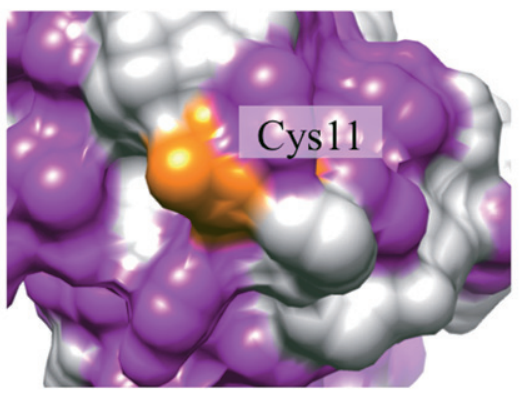

(E)

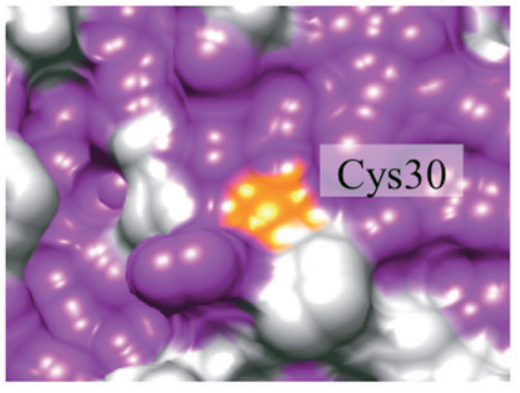

(B)

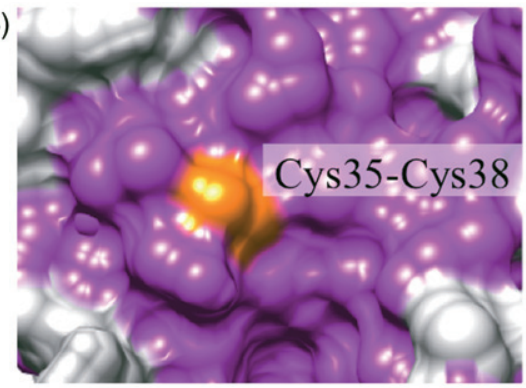

(D)

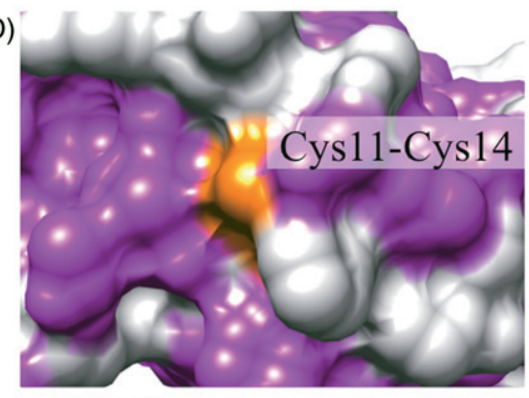

(F)

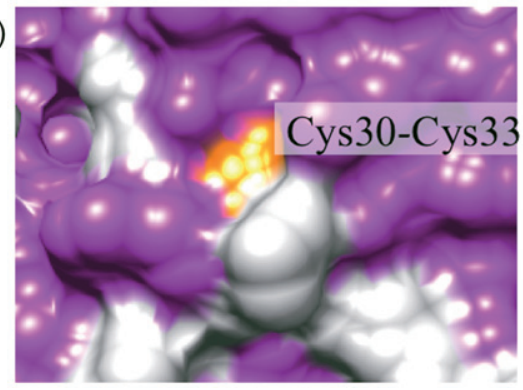

Figure 3. Molecular surfaces of thiol enzymes in reduced and oxidized states revealing hydrophobic patches. The proteins surfaces are colorized in light gray and hydrophobic amino acids in purple. E. coli Trx in reduced (A, PDB code: 1CL0) and oxidized state (B, PDB code: $1 \mathrm{XOA}$ ); Grx from $E$. coli in reduced (C, PDB code: 1EGR) and oxidized state (D, PDB code: 1EGO) and Dsba from E. coli in reduced (E, PDB code: $1 \mathrm{~A} 2 \mathrm{~L})$ and oxidized state (F, PDB code: 1A2M). The figures were generated using the Chimera software (http:// www.cgl.ucsf.edu/chimera/). 
features among Cys-based proteins is large enough to prevent a clear correlation between these parameters. We suspect that this kind of analysis should be performed within more homogenous set of proteins. Anyway, the more labile and unstable the disulfide, more oxidizing are the oxidoreductases such as DsbA [50].

\section{Catalysis of thiol-disulfide exchange reaction}

In spite of some limitations, the Brønsted relationship describes relatively well thiol-disulfide exchange reactions for aliphatic low molecular weight thiols. However, little is known on the applicability of the Brønsted relationship to proteins. Part of the difficulties to expand this knowledge to proteins is related to the fact that two sequential thiol-disulfide exchange reactions are required to reduce a disulfide by an oxidoreductase, as it will be further discussed below.

In an attempt to gain insights in this direction, reactions of peptides mimicking bovine pancreatic trypsin inhibitor (BPTI) and two oxidoreductases (DsbA and $\operatorname{Trx}$ ) in the reduced state with low molecular weight disulfides were performed. As aliphatic thiols, peptide thiols also reacted slowly with disulfide reagents (GSSG, HED, cysteine, and cystamine), displaying $k_{\text {obs }}$ in the $0.1-$ $10 \mathrm{M}^{-1} \mathrm{~s}^{-1}$ range [39]. Remarkably, rates for the same peptide vary depending on the disulfide reagent employed: GSSG (a negatively charged disulfide) displaying slowest rates, whereas cystamine (a positively charged disulfide) displaying fastest rates [39].

In some proteins, rates of thiol-disulfide exchange can attain higher values, such as the GSSG reaction with two of the six cysteine residues (Cys ${ }^{14}$ and $\mathrm{Cys}^{38}$ ) of BPTI. This phenomenon was attributed to positive charges nearby residues $\mathrm{Cys}^{14}$ and $\mathrm{Cys}^{38}$ of BPTI and other local structural factors related to the BPTI folding process [51]. Similarly, GSSG at micromolar concentrations can induce formation of inter-molecular disulfide in Thimet oligopeptidase, a thiol-rich metallopeptidase, containing 15 Cys residues [52]. Indeed, GSSG can catalyze disulfide bonds isomerization in proteins, until the configuration that stabilizes a given protein in its most stable conformation is achieved [53]. Anyway, in all these cases, rates of thiol-disulfide exchange reactions involved in disulfide shuffling are very slow in the 0.1$10 \mathrm{M}^{-1} \mathrm{~s}^{-1}$ range. In contrast, oxidoreductases within the Trx superfamily (which are the most studied thioldisulfide exchange catalyst so far) can attain rates of thiol-disulfide exchange reaction in the $10^{6}-10^{7} \mathrm{M}^{-1} \mathrm{~s}^{-1}$ range.

Below is the description of the best studied oxidoreductases and some of the factors that underlie their capacity to achieve extraordinary rates in thiol-disulfide exchange reactions.

\section{Trx system}

As mentioned before, thiol-disulfide exchange reactions are slow for aliphatic, low molecular thiols, but in living cells these reactions can be accelerated million times by oxidoreductases. Thioredoxin ( $\operatorname{Tr} x$ ) was the first enzyme described as a catalyst for thiol-disulfide exchange reactions. This oxidoreductase was initially discovered in Escherichia coli as a hydrogen donor for ribonucleotide reductase [30]. One of the first descriptions of the thiol-disulfide exchange catalysis by Trx was the demonstration that this oxidoreductase accelerates insulin reduction by DTT or by dihydrolipoamide by a factor of 10,000 times [54].

Thioredoxin is a low molecular weight protein (12-13 $\mathrm{kDa})$, whose redox activity is endowed by a $\mathrm{C}-\mathrm{X}-\mathrm{X}-\mathrm{C}$ motif. All Trxs have very conserved three-dimensional structures that are compact, with $90 \%$ of its residues in $\alpha$-helices, $\beta$-strands, or reverse turns [55]. The so-called Trx fold is also present in other oxidoreductases such as Grx, PDI, and DsbA and comprises a central four or five stranded $\beta$-sheet surrounded by $\alpha$-helices, with part of the dithiols/disulfide motif protruding from the protein surface (Figure 4A). The most $\mathrm{N}$-terminal Cys $\left(\mathrm{Cys}^{32}\right.$ in EcTrx1) is more exposed to the solvent, whereas the second Cys is buried into the polypeptide chain (reviewed in Ref. [56]) (Figure 4B). Another important feature of the Trx fold is a cis-Pro loop that approaches a Pro residue $\left(\mathrm{Pro}^{76}\right.$ in EcTrx 1 ) to the $\mathrm{C}-\mathrm{X}-\mathrm{X}-\mathrm{C}$ motif (Figure 4B), which is important for substrate recognition [57].

Remarkably, this folding has been highly conserved for 4 billion years or close to the origin of life [58]. Trxs present a conserved catalytic site (-Trp-Cys-Gly-Pro-CysLys-) that undergoes reversible oxidation to the cystine disulfide $\left(T r x-S_{2}\right)$ through the transfer of reducing equivalents from the two catalytic Cys residues to a disulfide substrate. Besides these residues, other amino acids play a role in the catalytic activity of Trx, but their precise role is not clearly established. A Pro and an Asp (Pro $^{76}$ and $\mathrm{Asp}^{26}$ in EcTrx1) are frequently implied in catalysis and are located in the proximity of the two catalytic Cys (Figure 4B). The oxidized Trx is reduced back to the Cys form $\left[\operatorname{Trx}-(\mathrm{SH})_{2}\right]$ by thioredoxin reductase, which is a NADPH-dependent flavoprotein (Figure 5).

In principle, the properties that govern the rates of thiol-disulfide exchange reactions for low molecular weight compounds [Equation (1)] should also apply to the reduction of protein disulfides by Trx. However, it is 

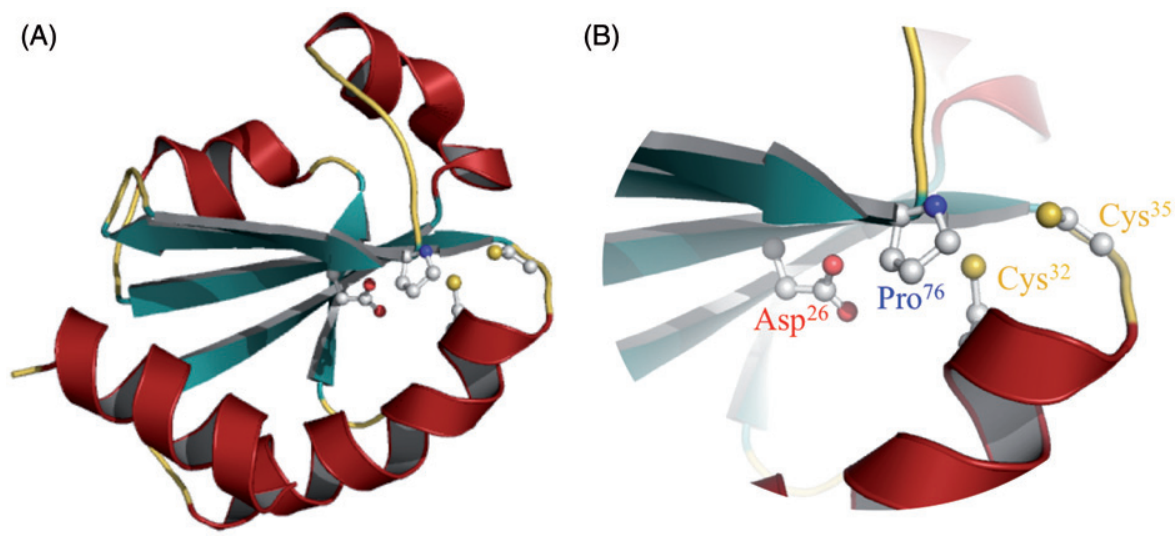

Figure 4. Thioredoxin structure and active site amino acids. (A) Crystallographic structure of thioredoxin from $E$. coli (PDB ID = 1XOB) showing the thioredoxin fold. Light green is the central five-stranded $\beta$ sheet, which is surrounded by four $\alpha$ helices (dark red). Catalytic Cys residues and amino acids involved in catalysis are depicted as ball and sticks. (B) Closer view of the active site. The two catalytic Cys residues (Cys ${ }^{32}=$ nucleophilic; $\mathrm{Cys}^{35}=$ resolving) are depicted in orange; conserved Pro ${ }^{76}$ and Asp $^{26}$ residues are represented in green in blue, respectively. (See color version of this figure in the online version.)

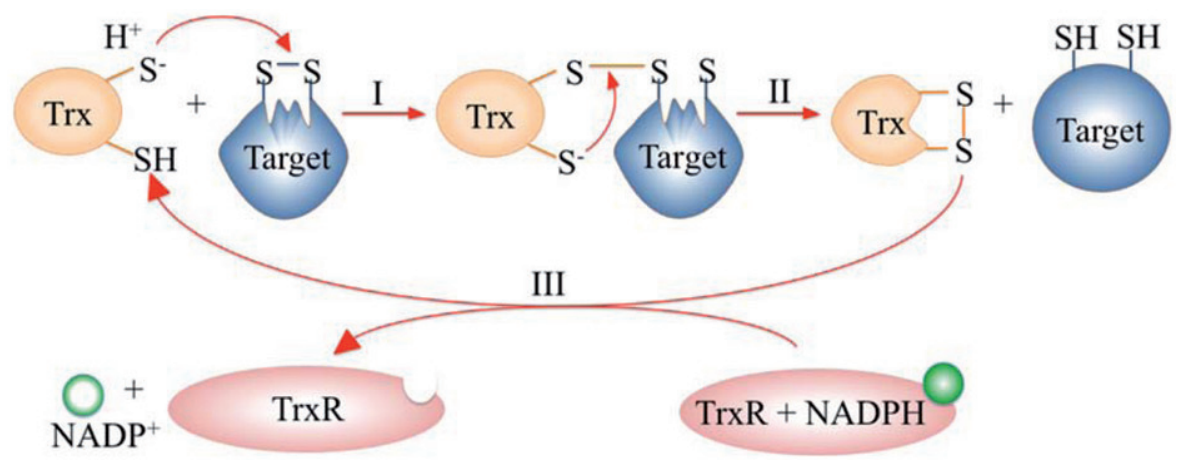

Figure 5. Catalytic cycle of thioredoxins. Initially, the reactive cysteine attacks the target disulfide, resulting in a transient mixed disulfide between Trx and the biological target which is resolved by the second Trx cysteine residue (I) resulting in the formation of an intramolecular disulfide bond in Trx (II), which is reduced by the TrxR using reducing equivalents from NADPH (III).

clear that electrostatic (section "Electrostatic effects") and steric factors (section "Steric effects") among other features should confer specificity for the reduction of target disulfides by Trx. On the other hand, analysis of the EcTrx1 X-ray crystal structure found no evidence of strained dihedral or bond angles at the disulfide [55], which is in agreement with our analysis shown in Table I. Therefore, additional mechanisms may be considered. Possibly, conformational changes during substrate binding that can generate geometries and structural features such as hydrophobic and complementary polar patches that may contribute to the catalysis of thiol-disulfide exchange reactions (reviewed in Ref. [56]) (Figure 6).

To reduce a disulfide bond in a client protein, dithiolic Trx enzymes have to undertake two sequential thioldisulfide exchange reactions (Figure 5). In the first one, the reactive Cys (the more $\mathrm{N}$-terminal $\mathrm{Cys}$ and equivalent to $\mathrm{Cys}^{32}$ of EcTrx1) attacks the disulfide, generating a mixed disulfide between $\operatorname{Trx}$ and the target protein
(Figure 5, reaction I). Then, in the second thiol-disulfide exchange reaction, the second Cys (more $\mathrm{C}$-terminal and equivalent to $\mathrm{Cys}^{35}$ of EcTrx1) reduces the mixed disulfide, generating oxidized Trx, and dithiolic target protein (Figure 5, reaction II). A factor that may favor this second thiol-disulfide exchange reaction is that $\mathrm{Cys}^{35}$ from EcTrx 1 is in a hydrophobic environment. As will be further discussed below Asp ${ }^{26}$ in EcTrx1 appears to be a key residue for the activation of $\mathrm{Cys}^{35}$ as a nucleophile for the mixed disulfide (Figure 3B), in the second thioldisulfide exchange reaction. During these two reactions, conformational movements take place and appear to be important in nucleophilic activation of the C-terminal Cys. Therefore, besides the properties accounted by the Brønsted correlation, other structural factors should also be taken into account when analyzing enzymes (reviewed in Ref. [56]).

As described previously, factors that affect ionization of attacking sulfur are critical for the generation of 
(A)

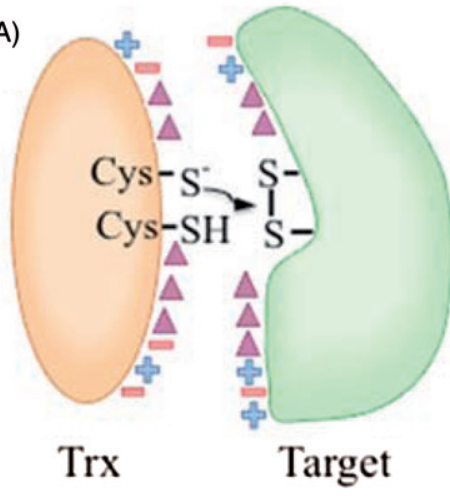

Hydrophobic
(B)

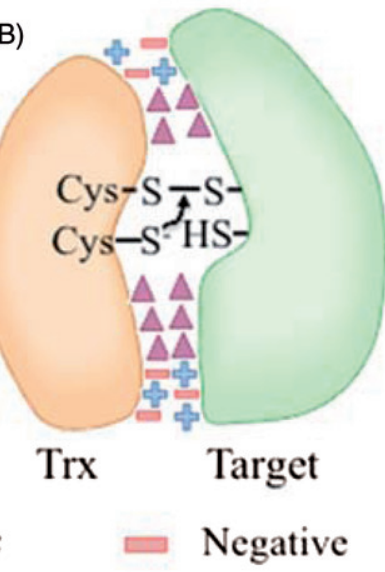

(C)

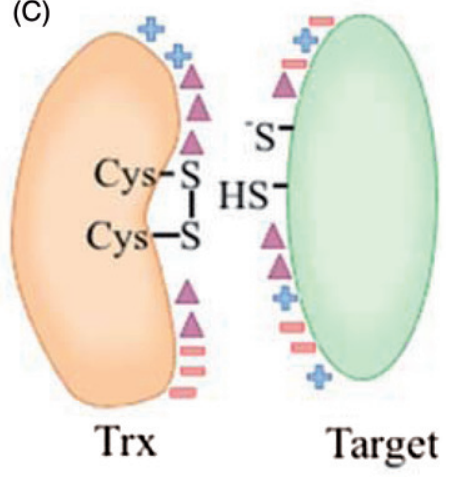

Positive

Figure 6. Factors underlying the efficiency and specificity in the reduction of biological targets by Trx. Trx recognize disulfide targets in proteins by a combination of factors such as polar (represented by " + " and "-" signals) and hydrophobic (represented by triangles) interactions, which allow (A) right orientation for the nucleophilic attack of the reactive Cys (Cys $\mathrm{S}^{-}$) over the target disulfide. (B) Formation of mixed disulfide Trx-S-S-Target and the nucleophilic attack over the mixed disulfide by the second Trx Cys residue. (C) Release of oxidized Trx (S-S) and the reduced biological target. During the thiol-disulfide exchange reactions, also topological changes occur between Trx and target proteins.

nucleophilic thiolate. Therefore, several attempts were performed to determine the $\mathrm{p} K_{\mathrm{a}}$ values of the two catalytic Cys, using methodologies, such as redox changes in fluorescence [59], UV absorption at $240 \mathrm{~nm}$ [9,60,61], Raman spectroscopy [62,63], NMR [64-66], and measurements of the $\mathrm{pH}$ dependence of the rate of alkylation [24]. For EcTrx1, p $K_{\mathrm{a}}$ values for the thiolate of $\mathrm{Cys}^{32}$ varies from 6.3 to 10.0 , whereas for the thiolate of $\mathrm{Cys}^{35}$ the range of the values are even higher (between 7 and 14), probably reflecting the fact that the second thiol group is buried into the polypeptide chain. Cheng and colleagues [56] performed a comprehensive analysis of all these data and observed that in spite of all the variation the majority of the determinations of the $\mathrm{p} K_{\mathrm{a}}$ of $\mathrm{Cys}^{32}$-SH are below the value for free cysteine (8.5-9.0). The positive dipole charge of the $\mathrm{N}$-terminal extremity of helix $\alpha 2$ (where $\mathrm{Cys}^{32}$ is located) is one of the factors that favor the deprotonation of this thiol group. Anyway, the variation of the determined $\mathrm{p} K_{\mathrm{a}}$ values is high and probably this is, at least, partially related to shortcomings of the distinct methods used to measure the $\mathrm{p} K_{\mathrm{a}}$ values $[67,68]$.

Noteworthy, most measurements were performed in the absence of protein ligands, in a condition where the protein is static. Static measurements may not be informative about how dynamic processes affect the relevant $\mathrm{p} K_{\mathrm{a}}$ values during the docking of a target protein into Trx active site [69]. Conformational changes occur in Trx through molecular interactions during substrate recognition and binding, and these can generate a local hydrophobic environment and a juxtaposition of titratable groups that affect the ionization of the Trx thiols $[70,71]$. Indeed, thiol proteins react with
Trxs orders of magnitude faster than with low molecular weight thiols, possibly due to conformational changes and reorientation of reactive groups during proteinprotein interactions that generate optimal geometry for $\mathrm{S}_{N} 2$ type of reaction $[9,64,68,72-76]$. Indeed, ${ }^{13} \mathrm{C}$ NMR experiments indicated that hydrogen bond rearrangements are involved in micro-millisecond range, compatible with Trx turnover rates [77]. Therefore, to account for the contribution of these dynamic structural factors, a correction factor $(\mathrm{Fc})$ has been introduced into the Brønsted relation for a thiol-disulfide exchange reaction. Accordingly, to best describe reactions of $\operatorname{Trx}(\mathrm{SH})_{2}$ with proteins, Equations (1) and (2) were taken and Fc was added to yield Equation (4) $[61,78]$.

$$
\begin{aligned}
k_{\mathrm{obs}}= & \left(c+\beta_{\mathrm{nuc}} \mathrm{p} K_{\mathrm{a}(\mathrm{nuc})}+\beta_{\mathrm{c}} \mathrm{p} K_{\mathrm{a}(\mathrm{c})}+\beta_{\mathrm{lg}} \mathrm{p} K_{\mathrm{a}(\mathrm{gg})}\right) \\
& -\log \left(1+10^{\left(\mathrm{p} K_{\mathrm{a}}(\mathrm{nuc})-\mathrm{pH}\right)}\right)+\mathrm{Fc}
\end{aligned}
$$

Acid/base catalysis is a central feature in the mechanism of thiol/disulfide oxidoreductases as expected for a reaction that depends on the ionization of sulfhydryl groups. The factors that influence the ionization of the two catalytic Cys are controversial and this issue has been also comprehensively reviewed by Cheng and coworkers [56]. As mentioned above, for the $\mathrm{N}$-terminal Cys (Cys ${ }^{32}$ in EcTrx), the positive charge of the N-terminal extremity of helix $\alpha 2$ appears to favor the deprotonation of its thiol group. Assuming the $p K_{\mathrm{a}}$ value for the most exposed residue as 7.0, probably the dipole effect of the helix $\alpha 2$ would be enough to reduce the $\mathrm{p} K_{\mathrm{a}}$ below the level of the free Cys $(\sim 8.5)$. This is because it was estimated that the interaction between the thiolate anion at the $\mathrm{N}$-terminus of the $\alpha$-helix in a model 
peptide provoked a decrease in the thiol $\mathrm{p} K_{\mathrm{a}}$ value by up to $1.6 \mathrm{pH}$ units when compared to an ordinary thiol $\mathrm{p} K_{\mathrm{a}}$ value [79]. However, theoretical studies indicated that other features should also be taken into account (reviewed in Ref. [80]).

More controversial than the macrodipole effect of helix $\alpha 2$ is the action of specific residues in acid-base catalysis. Several studies were performed to identify residues involved in the ionization of reactive Cys, but there are still uncertainties, which are probably related to differences among distinct Trxs. More challenging is the identification of the factors that affect the ionization of the thiol in the second Cys (Cys ${ }^{35}$ in EcTrx 1 ), which is buried in the polypeptide chain. Other complicating factor is that the mixed disulfide is formed only transiently $[69,81]$. In the specific case of GS-SG reduction, the $\mathrm{p} K_{\mathrm{a}}$ of GS-S-Trx-SH intermediate may not be very relevant because the rate of mixed disulfide intermediate formation is slow relative to the rate of its resolution [82]. It should be kept in mind that the rate constants for reduction of low molecular weight disulfides by Trx are several orders of magnitude lower than the reduction of protein disulfides (reviewed in Ref. [56]).

An Asp residue ( $\mathrm{Asp}^{26}$ in EcTrx) is frequently considered as one important residue for ionization of the second Cys (Cys ${ }^{35}$ in EcTrx1), residues through a hydrogen bond network mediated by a water molecule since these two residues are $5.6 \AA$ distant apart $[23,83,84]$ (Figure 4B). However, biochemical and theoretical studies indicated that the reduction of the mixed disulfide between Staphylococcus aureus arsenate reductase and SaTrx is not affected by $\mathrm{Asp}^{23}$ (Asp ${ }^{26}$ in EcTrx). In contrast, for EcTrx1, considerable experimental data have been accumulated to support a role of $\mathrm{Asp}^{26}$ in acid/base catalysis $[23,67,83,85,86]$. Indeed: (i) Asp $^{26}$ affects the microscopic $\mathrm{p} K_{\mathrm{a}}$ values of the active thiols [23] and (ii) the catalytic efficiency $\left(k_{\mathrm{cat}} / K_{\mathrm{M}}\right)$ for the EcTrx $1^{\mathrm{D} 26 \mathrm{~A}}$ mutant was only about $10 \%$ of the wild-type [67]. Remarkably, the effects of $\mathrm{Asp}^{26}$ in catalysis are greatly decreased at high pHs [77,83,85-87], further indicating that this residue play a role in the deprotonation of $\mathrm{Cys}^{35}$ sulfhydryl in EcTrx1. Differences in the mechanisms among distinct Trxs may help to explain these conflicting results related to the conserved Asp residue (reviewed in Ref. [56]).

Although less efficient than the wild-type protein, EcTrx $1^{\text {D26A }}$ mutant is still quite reactive towards thioredoxin reductase and ribonucleotide reductase [67], displaying $\left(k_{\mathrm{cat}} / K_{\mathrm{M}}\right)$ that are several orders of magnitude faster than thiol-disulfide exchange reactions between low molecular weight compounds. Therefore, other residues and structural factors should play a role in catalysis by Trx. Indeed, for Chlamydomonas reinhardtii thioredoxin $\mathrm{h}$ (CrTrxh), besides Asp ${ }^{30}$ (Asp $^{26}$ in EcTrx) and the dithiol-disulfide residues $\left(\mathrm{Cys}^{36}-\mathrm{Cys}^{39}\right), \operatorname{Trp}^{35}$, and Asp $^{65}$ were also proposed to participate in the catalytic mechanism [66]. Accordingly, EcTrx $1^{\text {W31A }}$ mutant (Trp ${ }^{31}$ is equivalent to $\operatorname{Trp}^{35}$ in CrTrxh) decreased the rate of insulin reduction [88].

Lys $^{57}$ appears also to play some role in acid/base catalysis as L57M mutation of EcTrx1 provoked significant increase of thiols $\mathrm{p} K_{\mathrm{a}}{ }^{\prime} \mathrm{s}$ (similar to the effect of D26A mutation). However, Lys ${ }^{57}$ of EcTrx1 had a minor role in the reduction of insulin or in the oxidation of thioredoxin reductase in comparison with the D26A replacement [67]. It would be interesting to study replacements of Lys $^{57}$ and $\mathrm{Asp}^{26}$ by other residues than Met and Ala. In yeast, it was proposed that $\mathrm{Asp}^{24}\left(\mathrm{Asp}^{26}\right.$ in EcTrx1) and Lys $^{54}$ (Lys $^{57}$ in EcTrx 1 ) act in a same mechanism involved in the dynamics of the water cavity in the activity site pocket. This water cavity is surrounded by $\mathrm{Cys}^{33}$, Lys ${ }^{54}$, and the buried $\mathrm{Asp}^{24}$ and appears to play relevant roles in the protein dynamics that occurs during transitions back and for between reduced and oxidized states [89]. Probably this water cavity in Trx mediates proton transfer and recognition of the target protein [90].

Finally, Pro $^{76}$ (Figure 4B) is another residue that may play relevant roles in catalysis, besides its involvement in the folding process of EcTrx1 [91,92]. As mentioned above, this residue is located in the cis-Pro loop, conserved in the Trx fold that is relevant for substrate recognition [57,93]. Indeed, $\mathrm{Pro}^{76}$ is even closer to the C$\mathrm{X}-\mathrm{X}-\mathrm{C}$ motive than $\mathrm{Asp}^{26}$ so it is possible that this residue also has roles in the catalysis of thiol-disulfide exchange reaction [56]. Indeed, P76A mutant of EcTrx1 possessed diminished activity than the wild type oxidoreductase [91]. Possibly, Pro $^{76}$ could be involved in a proton shuttle mechanism between the two catalytic Cys [56]. Probably multiple factors play a role in the acidity of the thiol groups in the $\mathrm{C}-\mathrm{X}-\mathrm{X}-\mathrm{C}$ motif of Trx enzymes. Therefore, Trx enzymes share several common residues and motifs that are involved in catalysis of thiol-disulfide exchange reactions. Moreover, Trx enzymes possess a common overall tertiary structure. In spite of these similarities, the distribution of surface charges varies considerably among distinct Trx enzymes [94-98], which affects their specificity to interact with their targets (reviewed in Ref. [56]).

This is well illustrated for CFBPase [99,100], an enzyme involved in gluconeogenesis and Calvin cycle. The redoxactive cysteines of CFBPase that are responsible for its activation are located in a solvent-exposed loop (170's loop) that is highly negatively charged [101,102]. Therefore, Trx enzymes that undergo thiol-disulfide exchange with CFBPase are expected to have a 
corresponding positively charged patch. Indeed, positively charged residues of Trx-f ( $a \operatorname{Trx}$ belonging to the ferredoxin-Trx system) and of Trx-m favor their capacities to activate CFBPase $[99,103]$. Apparently, these electrostatic interactions contribute to the formation of a non-covalent Trx-CBPase complex, in which the hydrophobic patch that comprise the $\mathrm{C}-\mathrm{X}-\mathrm{X}-\mathrm{C}$ motif would allow optimal orientation for thiol-disulfide exchange reactions between Trx and CBPase [95,104-106]. Indeed, as it will become evident throughout this review, electrostatic factors are main factors conferring specificity for enzymatic thiol-disulfide exchange reactions.

Initially, it was considered that chloroplasts rely in a unique redox system, in which Trxs are reduced by a ferredoxin-dependent Trx reductase, which in turn is dependent on ferredoxin reduced by the photosynthetic electron transport chain and, thus on light. One of the substrates of this ferredoxin-Trx system is CFPBase as described above. However, later on, the thiol-based system NADPH-Thioredoxin Reductase C (NRTC) was described in chloroplasts. NTRC is a multi-domain protein, containing in a single polypeptide two portions corresponding to the $\operatorname{Trx}$ (C-terminal) and thioredoxin reductase ( $\mathrm{N}$-terminal). Remarkably, the targets for the two thiol based systems are distinct, indicating the importance of features such as electrostatic interactions described above to guarantee specificity. One of the main targets for NTRC is 2-Cys Peroxiredoxins group (reviewed in Ref. [107]).

Similarly to plants, bacteria also contain in a single polypeptide (called AhpF), portions of both Trx (Nterminal), and thioredoxin reductase (C-terminal). Frequently, the AhpF gene is neighbor of the AhpC gene (encoding a 2-Cys Peroxiredoxin) [108]. This is consistent to the integrated function of AhpF and AhpC to reduce hydroperoxides at the expense of NADH or NADPH (reviewed in Ref. [108]). Bacteria have other thiol based systems and again their specificities are distinct, although there are some overlaps (reviewed in Ref. [109]). For instance, for another group of Prxs, such as $\mathrm{BCP} / \mathrm{PrxQ}$ from the plant pathogen Xylella fastidiosa, the electron donor is XfTsnC (a Trx similar to EcTrx1) and not XfAhpF [110].

In Saccharomyces cerevisiae, electrostatic factors were also identified as important elements underlying the species-specificity in yeast Trxs-ScTrxR1 interactions. Remarkably, ScTrxR1 is highly specific in the reduction of yeast Trxs but not Trx from bacteria or mammals [96]. While ScTrx1R can reduce yeast Trxs with extraordinary rates (second-order rate constants in the $10^{7} \mathrm{M}^{-1} \mathrm{~s}^{-1}$ range), no reduction of bacterial and mammalian Trx was observed [96]. Several factors underlie this specificity including the complementary electrostatic surfaces between ScTrxR1 and Trx enzymes loops (Figure 7). Previously, NMR analysis of ScTrx1 and ScTrx2 structures revealed that these oxidoreductases contain three highly flexible loops, which were implicated in Trx-substrate interactions [111,112]. In fact, single amino acids substitutions are found between the ScTrx1 and ScTrx2 loops (ScTrx1, 27-Y-ATWCGPCK-35; ScTrx2, 27-F-ATWCGPCK-35 and ScTrx1, 68-AEVS-A-MP-74; ScTrx2, 69-AEVS-S-MP-75), which appear to be related to differences with their reduction by ScTrxR1, since reciprocal amino acids substitutions provoked the inversion of reduction rates by ScTrxR1, and probably is related with the species specificity of Trx-TrxR reduction [96]. As a matter of fact, interactions with TrxR appear to have shapped the Trx enzymes (reviewed in Ref. [56]). There are five distinct groups of TrxR with $\mathrm{N}$ - and C-terminal extensions to a common catalytic core composed of a NADPH and a FAD binding domains [96]. Clearly, the evolution processes of Trx and TrxR enzymes evolution are connected. A challenge in the field is the elucidation of more structures of TrxR-Trx complexes, to reveal novel molecular aspects of protein-protein interactions. As a matter of fact, there is only one single complex between type 1 TrxR-Trx available in PDB database [73].

Very recently, again the concept that electrostatic factors are central aspects in the specificity of oxidoreductases was demonstrated by employing phosphoadenylylsulfate (PAPS) reductase from Escherichia coli [113]. Complementary electrostatic surfaces and not reduction potentials (also called redox potentials) determined specificity and efficiency of the oxidoreductases from distinct organisms as reductants for PAPS reductase. As mentioned above, electrostatic interactions contribute to the formation of non-covalent Trx-target protein complexes, in which the hydrophobic patches around the $\mathrm{C}-\mathrm{X}-\mathrm{X}-\mathrm{C}$ motif would allow optimal orientation for thiol-disulfide exchange reactions between Trx and target proteins [95,104-106]. Indeed, the hydrophobicity along the $\mathrm{C}-\mathrm{X}-\mathrm{X}-\mathrm{C}$ motif appears to be important for interaction with redox partners (Figure 3). Accordingly, mutation of Gly ${ }^{33}$ (first $X$ in the C-X-X-C motif in Trx) to either positively (Lys) or negatively (Asp) charged residues impaired the redox activity of EcTrx1 in both enzymatic and in cellular systems $[114,115]$. Indeed, structural analysis surrounding $\mathrm{C}-\mathrm{X}-\mathrm{X}-\mathrm{C}$ motif of thiol-disulfide oxidoreductases indicated that their environment is hydrophobic (Figure 3).

Employing single molecule force spectroscopy and molecular dynamics simulations in eight Trx enzymes from distinct organisms comprising all three domains of life, further evidence was given that a hydrophobic binding groove is important for specificity in the binding 

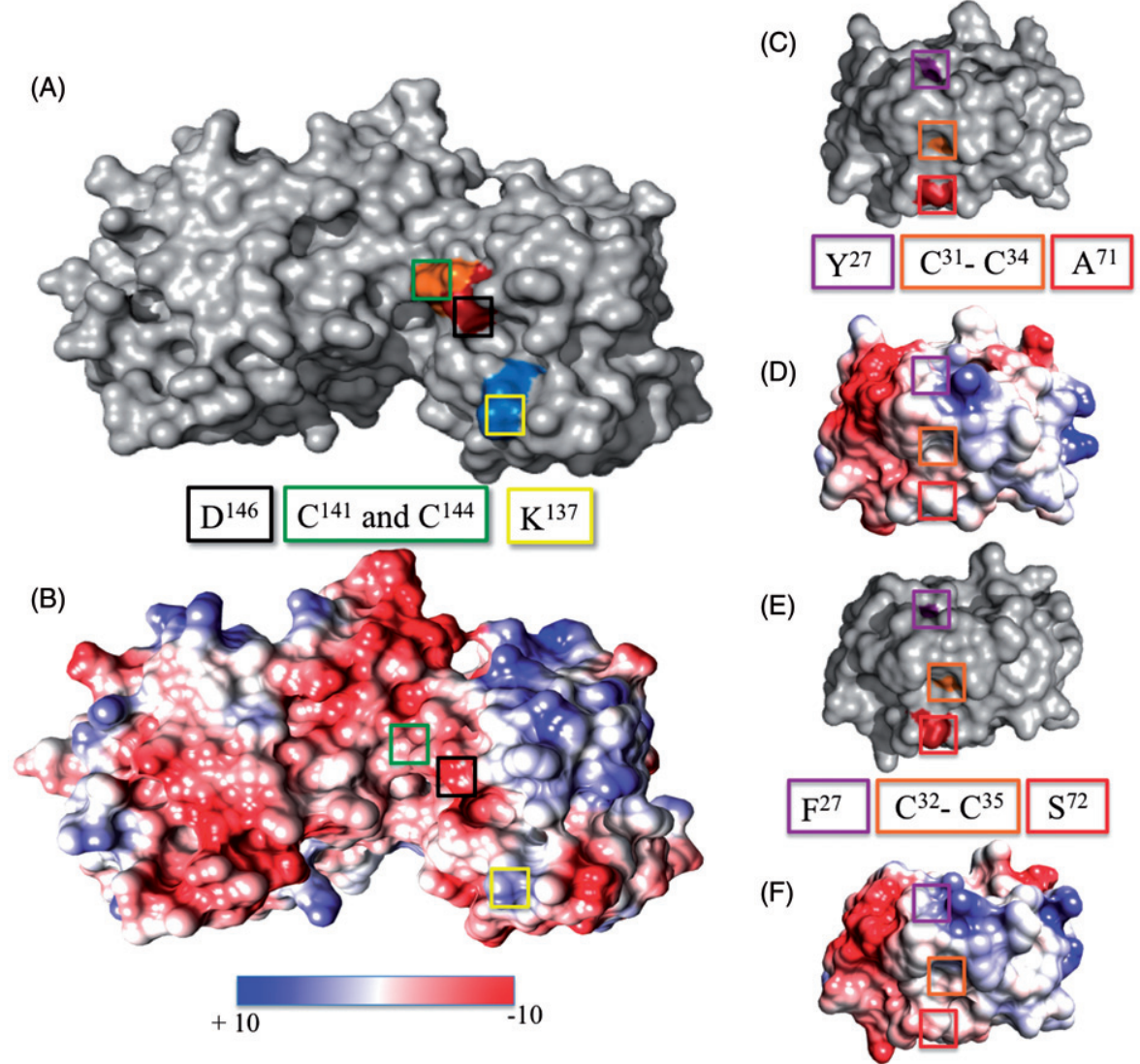

Figure 7. Molecular surfaces and complementary electrostatic interactions between ScTrxR1 and ScTrx1/ScTrx2. (A, C, E): Molecular surfaces of ScTrxR1, ScTrx1, and ScTrx2, respectively. (B, D, F): Electrostatic distribution on the surfaces of ScTrxR1, ScTrx1, and ScTrx2, respectively; positive and negative charges are represented by blue and red colors, respectively. (A) Specific residues involved in the interaction with ScTrx1/2 are colored as: Cys ${ }^{142}$ and Cys ${ }^{145}=$ orange; Lys ${ }^{137}=$ blue; Asp ${ }^{146}=$ red. The yellow, black, and green squares in (A) and (B) highlight the position of the $\mathrm{Lys}^{137}, \mathrm{Asp}^{146}$ and $\mathrm{Cys}^{142} / \mathrm{Cys}^{145}$, respectively. Once again, the squares highlight the position of the residues $\operatorname{Tyr}^{27}$ (ScTrx1) or $\mathrm{Phe}^{27}$ (ScTrx1) (purple), Ala ${ }^{71}$ (ScTrx1) or Ser ${ }^{72}$ (ScTrx2) (red), and cysteine disulfides (orange) (green) that are involved in the interaction with ScTrxR1 (more details on the effects of mutations on Ref. [96]). (See color version of this figure in the online version.)

to the substrate [116]. Noteworthy, the cis-Pro loop, a conserved feature of the Trx fold, is a constituent of this groove. According to this proposal of a hydrophobic binding groove, isothermal titration calorimetry indicated a universal entropy mechanism for Trx enzymes. Interestingly, Trx recognizes the oxidized form of its target proteins with exquisite selectivity, compared with their reduced counterparts [117]. Noteworthy, a protuberance (containing residues $\mathrm{Glu}^{50}$; $\mathrm{Arg}^{146}$ and $\mathrm{Cys}^{170}$ of yeast Tsa1) present only in the oxidized form of 2-Cys Peroxiredoxin is involved in its recognition as a target by ScTrx1 [118]. Anyway, it is still difficult to predict what proteins might be a Trx target. Probably, a good model for recognition of target protein by Trx enzymes involves initially electrostatic interaction that direct target proteins to the hydrophobic environment surrounding the $\mathrm{C}-\mathrm{X}-\mathrm{X}-\mathrm{C}$ motif (Figure 6).

It is also important to mention here that some Trx enzymes contain additional Cys residues besides those that take part in the $\mathrm{C}-\mathrm{X}-\mathrm{X}-\mathrm{C}$ motif that may affect substrate recognition. HsTrx 1 contains five $C y s$ residues: $\mathrm{Cys}^{32}$ and $\mathrm{Cys}^{35}$ are the two residues that belong to the CGPC motif, whereas $\mathrm{Cys}^{62}$, $\mathrm{Cys}^{69}$, and $\mathrm{Cys}^{73}$ are three non-conserved residues. Cys ${ }^{62}$ and $\mathrm{Cys}^{69}$ work together as an additional dithiol-disulfide center. When a disulfide is formed between $\mathrm{Cys}^{62}$ and $\mathrm{Cys}^{69}$, the ability of HsTrx1 to bind a target is impaired [119]. Remarkably, this $\mathrm{Cys}^{62}-\mathrm{Cys}^{69}$ non-active site disulfide is not a substrate for thioredoxin reductase, it is reducible by GSH/Grx1 system, whereas the $\mathrm{Cys}^{62}-\mathrm{Cys}^{69}$ dithiol can be oxidized by Prx1 [120]. Furthermore, $\mathrm{Cys}^{73}$ is also subjected to redox modifications, such as glutathionylation [121], and oxidation into an intermolecular disulfide bond [122,123]. Recently, a mixed disulfide between HsTrx1 and tissue factor involving $\mathrm{Cys}^{73}$ was reported and could be important in substrate recognition [124]. Possibly, these multiple oxidative states of HsTrx1 involving its five Cys residues play a role in the fine 
(A)

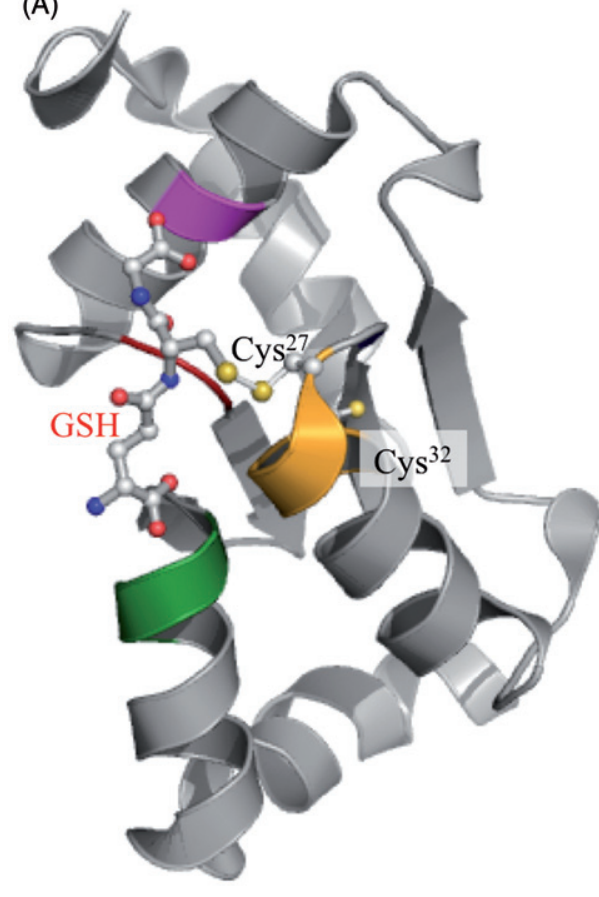

(B)

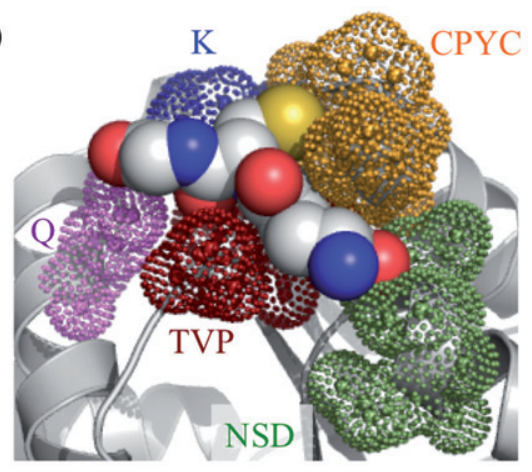

(C)

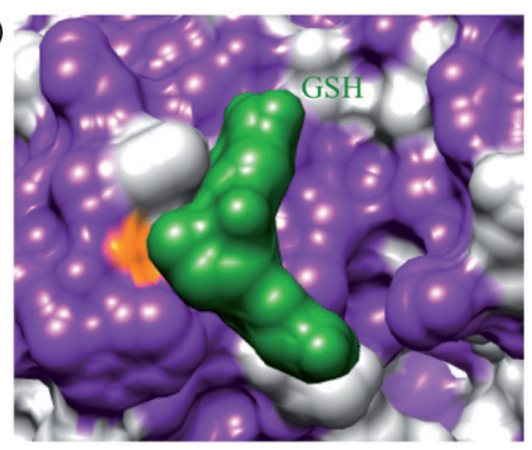

Figure 8. ScGrx2 structure and GSH binding site. (A) Overall structure of the ScGrx2-SG mixed disulfide (PDB code: 3D5J) represented in cartoon and colorized in gray. The glutathione and Cys residues are represented in balls and sticks and colorized by CPK ( $C=$ gray, $\mathrm{N}=$ blue, $\mathrm{O}=$ red, and $\mathrm{S}=$ orange). GSH binding site residues are depicted in the cartoon: K24, blue; Q 63, purple; 32-CPYC-35, orange; 74-TVP-76; dark red; 88-NSD-90, dark green. (B) Detail of the ScGrx2 glutathione binding site residues and motifs represented by spherical dots, with the same colors presented before and the GSH molecule represented in spheres and colorized by CPK. (C) ScGrx2 molecular surface of the active site region containing a GSH molecule bound to $\mathrm{Cys}^{27}$. The hydrophobic residues are colored in purple, the $\mathrm{Cys}^{27}$ in orange and all the others amino acids residues in white gray. The glutathione molecule is represented in green. The figures were generated using the Pymol software (www.pymol.org). (See color version of this figure in the online version.)

tune of the redox regulation of targets such as Ask1 (kinases), PTEN (phosphatases), and Ref-1 (transcription factor) (reviewed in Refs. [109,125]).

\section{Grx system}

Glutaredoxin (Grx) like Trx enzymes are heat stable thioldisulfide oxidoreductases with the thioredoxin structural fold (Figure $8 \mathrm{~A}$ ) that rely on $\mathrm{C}-\mathrm{X}-\mathrm{X}-\mathrm{C}$ motif (typically $\mathrm{C}$ $\mathrm{P}-\mathrm{Y}-\mathrm{C}$, but highly variable) to reduce disulfide bonds in the client proteins. Since Trx and Grx share a common structural fold, they probably also share the same ancestry $[126,127]$. "Glutaredoxin" (Grx) has a synonymous "Thioltransferase" name, reflecting the fact that these enzymes were independently discovered by two distinct groups. In one case, Grx was identified as the factor that still supports the reduction of ribonucleotide reductase (and thereby DNA replication) in strains of E. coli lacking thioredoxin [128]. This oxidoreductase was named thioltransferase by the authors that identified this enzyme by its ability to catalyze thiol-disulfide exchange reaction in rat liver, using $\left[{ }^{35} \mathrm{~S}\right] \mathrm{GSH}$ [129].
Grx denomination became more popular and will be used throughout this review.

In spite the similarities with Trx proteins, Grx enzymes possess very distinct amino acid sequences, displaying a specific binding site for GSH (Figure 8) that enables them to efficiently participate in glutathionylation/deglutathionylation reactions (reviewed in Refs. [130,131]). As a matter of fact, this GSH binding site is relevant to understand the distinct mechanistic features between Trx and Grx enzymes. NMR and X-ray crystallographic structures of several Grxs in mixed disulfides with GSH $[15,132-136]$ revealed conserved features of the GSH binding site (Figure $8 \mathrm{~B}$ and $\mathrm{C}$ ). This binding site comprises: (1) the active site itself, especially the $\mathrm{N}$-terminal active site cysteine (colored in yellow in Figure 8); (2) the residues colored in green in Figure 8; and (3) the TVP motif colored in red (Figure 8). The Pro residue of this motif is the amino acid present in the cis-Pro loop characteristic of the Trx fold (reviewed in Ref. [131]).

Like Trx, the most $\mathrm{N}$-terminal Cys residue of the $\mathrm{C}-\mathrm{X}-\mathrm{X}-\mathrm{C}$ motif in $\mathrm{Grx}$ is solvent exposed and it is 
(A)

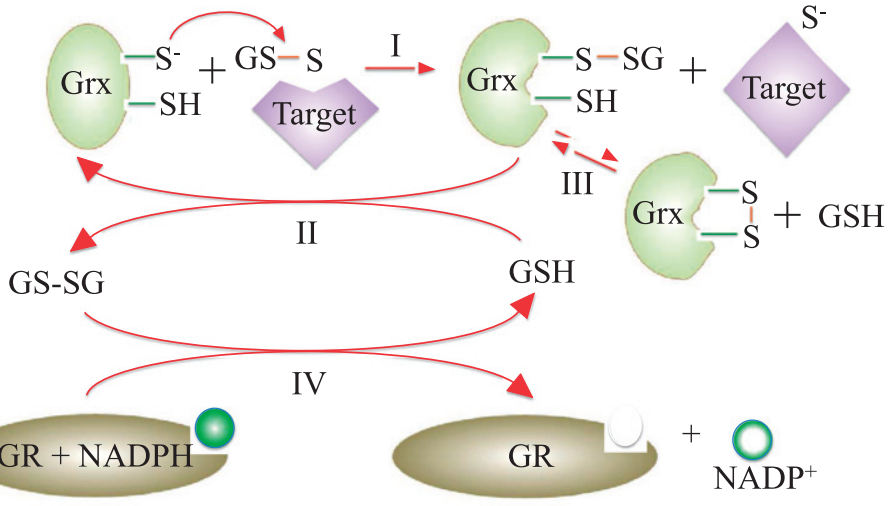

(B)

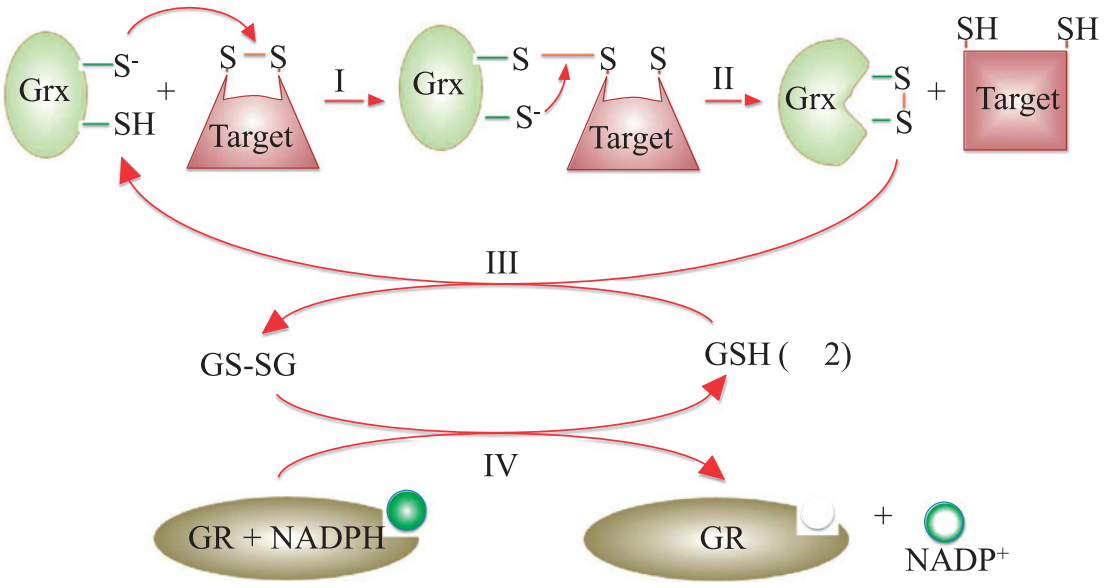

Figure 9. Mechanisms of disulfide bond reduction by the Grxs. (A) Monothiol mechanism. Reactive cysteine attacks the Target-SG disulfide, resulting in glutathionylated Grx (I), which is then reduced by GSH, generating GSSG (II) that is reduced by NADPH in a reaction catalyzed by the glutathione reductase (GR) (IV). Alternatively, an intramolecular disulfide bond in Grx can be generated by the nucleophilic attack of the second Cys residue to the mixed disulfide in glutathionylated Grx, releasing reducing GSH (III). (B) Dithiol mechanism. Reactive cysteine attacks the target protein disulfide, resulting in a mixed disulfide between Grx and the biological target, which is then resolved by the second Grx cysteine (I) resulting in the formation of an intramolecular disulfide bond in Grx (II), which is then reduced by GSH, resulting in reduced Grx and GSSG, which is in turn reduced back by the glutathione reductase enzyme (GR) using reducing equivalents from NADPH (IV).

responsible for the nucleophilic attack on the target disulfide. The most C-terminal Cys in the $\mathrm{C}-\mathrm{X}-\mathrm{X}-\mathrm{C}$ motif is solvent inaccessible (also similarly with $T r x$ ). In contrast to the majority of Trx enzymes, this buried Cys for most Grx enzymes is not required for some catalysis of thioldisulfide exchange reactions (reviewed in Ref. [137]), as this will be further discussed below.

The description of enzymes belonging to the Grx family is increasing, with novel variants being described. It appears that the Grx family of enzyme is more heterogeneous than the Trx counterpart. For instance, besides the classical Grx enzymes that contain the $\mathrm{C}-\mathrm{X}$ $\mathrm{X}-\mathrm{C}$ motif (called "dithiol Grx"), monothiol Grx that contain a C-X-X-S motif were also described, in which the C-terminal Cys is replaced by a Ser. In some cases, Grx is a domain of multi-domain protein (reviewed in Ref. [130]). The variability among Grx types is very high, in terms of their ability to bind iron-sulfur clusters, oligomerization state, and enzymatic activities. For some Grx, it was not possible to observe catalysis of thiol-disulfide exchange reaction (reviewed in Refs. $[130,137])$. Noteworthy, the Trx family also displays heterogeneity with proteins containing extra domains, such as EcTrx2 that contain a zinc finger motif at the $\mathrm{N}$-terminal extremity [138].

Glutaredoxin (Grx) enzymes can catalyze the reduction of disulfide bond by two mechanisms, depending on the number of Cys residues involved in catalysis: one (monothiol) or two (dithiol). The dithiol mechanism is essentially identical to the oxidative half-reaction described for Trx (Figure 9B, steps I and II). It is composed of two sequential thiol-disulfide exchange reactions. In the first one, the most exposed Cys residue of Grx attacks the disulfide in the target protein, generating a mixed Grx-protein disulfide (Figure 9B, step I). Then the most buried Cys residue attacks the 
mixed disulfide, generating oxidized Grx and dithiolic target protein (Figure 9B, step II). The reductive halfreaction then differs from $T r x$ enzymes, in which two GSH molecules (through two thiol/disulfide exchange reactions) reduce disulfide in Grx, generating reduced Grx and GSSG that is then reduced by glutathione reductase/NADPH (reviewed in Refs. [130,131]).

The dithiol mechanism is rarely investigated for Grxs, possibly because there is no handy assay available. However, because ribonucleotide reductase from $E$. coli can be readily obtained by conventional expression and purification methods, the dithiol mechanism could be investigated in bacterial Grx [134]. Probably the same applies to PAPS reductase and OxyR (a bacterial redox regulated transcription factor), which are also reduced by bacterial Grxs via the dithiol mechanism (reviewed in Ref. [131]). The reduction of ribonucleotide reductase by bacterial Grx resembles in several features the catalysis by Trx enzymes: (1) mutation of the second Cys in the $C$ $\mathrm{X}-\mathrm{X}-\mathrm{C}$ motif provokes abolishment of the disulfide reductase activity $[134,139]$, implying a dithiol mechanism; (2) electrostatic interaction appear to be responsible for specificity in enzyme-substrate interactions [140]; and (3) conformational changes are associated with ribonucleotide reductase binding to EcGrx1 [140].

The physiological significance of dithiol mechanism among Grx enzymes is not very well studied but recent studies with DrGrx2 (oxidoreductase from zebrafish and orthologous to mammalian Grx2) indicated that this enzyme is central to the homeostasis of the central nervous system. Indeed, silencing DrGrx2 expression resulted in loss of virtually all types of neurons by apoptotic cell death [141]. In both zebrafish and human cellular models for neuronal differentiation, Grx2 effects on vertebrate embryonic development are mediated by thiol-disulfide exchange reactions with collapsin, a central component of the semaphorin pathway [141]. Among eight Cys residues of collapsin, only two appear to be sensitive to hydrogen peroxide oxidation and this specific disulfide is target for DrGrx2 reductase activity through the dithiol mechanism [142].

Compared to the dithiol mechanism, the monothiol mechanism is more studied and many more targets were identified. It is generally related to the deglutathionylation of substrates and involves a Grx-glutathione mixed disulfide intermediate $[130,131,137]$. In the first step, the most exposed Cys residue attacks the mixed disulfide between the substrate and glutathione, generating reduced substrate, and glutathionylated Grx (Figure 9A, step I). Then, a second GSH molecule reduces the mixed disulfide between Grx and glutathione, regenerating the reduced form of Grx (Figure 9A, step II). This is the rate limiting step of the overall catalytic cycle (reviewed in
Ref. [130]). Noteworthy, in the monothiol mechanism, no mixed disulfide between $\mathrm{Grx}$ and target protein is formed. This might have consequences for the specificity in substrate binding, which remains to be elucidated. It is possible that other non-covalent factors (such electrostatic and hydrophobic interactions as described for Trx) between Grx and target proteins may provide specificity for enzyme-substrate interactions. Of note, mutation of the buried cysteine residue by serine in dithiol Grxs does not abolish the overall activity $[135,139,143-145]$, thus validating the monothiol mechanism. This is one of the features that distinguish Grx and Trx dithiol enzymes.

The monothiol mechanism can be analyzed through a bi-substrate (GSH and glutathionylated target protein), steady-state kinetic approach, following NADPH oxidation in a NADPH-glutathione reductase coupled assay. For most substrates, parallel lines are obtained in Lineweaver-Burk plots, when the concentration of the second substrate is varied in between each line, which is characteristic of a ping-pong mechanism, i.e. with no ternary complex formation. The exception is the HEDS assay and this will deserve special attention below. Probably most Grx enzymes operate through an "encounter type mechanism", taking into account: (i) that the obtained $K_{\mathrm{M}}$ and $V_{\max }$ values by bi-substrate, steady state analyses are infinite (secondary reciprocal plots intercept at zero); and (ii) the lack of potent and specific inhibitors for these oxidoreductases, meaning that substrate and enzyme react without any binding (reviewed in Ref. [130]). The possible absence of enzyme-substrate complex is consistent with the fact that no mixed disulfide between Grx and target protein is formed in the monothiol mechanism. HsGrx2 may be an exception, since there are some evidences that this oxidoreductase can bind GSH tightly [146,147], which might be related with the fact that this protein can form $\mathrm{Fe} / \mathrm{S}$ clusters. Moreover, DrGrx2 can catalyze reversible $S$ glutathionylation of the $\mathrm{NAD}^{+}$-dependent protein deacetylase sirtuin 1, which regulates vascular development in zebrafish [148]. Remarkably, DrGrx2 can reduce substrates by the monothiol (sirtuin 1) or dithiol (collapsin) mechanism [141,148]. Recently, DrGrx2 was also implied in heart development [149].

Specifically in regard to the first step (Figure 9B, step I) of the monothiol mechanism, this reaction is quite fast relative to the second step and it is highly selective for the glutathionyl moiety of the mixed disulfide $[143,150]$. For instance, reduction of disulfides that do not contain glutathione are not catalyzed by HsGrx1 [150] or by HsGrx2 [143]. The exclusive product of this reaction is the glutathionylated Grx species (no mixed disulfide between Grx and the target protein is detected) as well 
documented by means of mass spectrometry, among other approaches (reviewed in Ref. [130]). As a matter of fact, mutants of HsGrx1 and EcTrx1 that contain only the solvent exposed Cys residue revealed a remarkable difference: EcTrx1 (but not HsGrx1) gave rise to both glutathionyl-Grx and also to the mixed disulfide between this oxidoreductase and the target protein [135]. This is probably related to the existence of a GSH binding site in Grx.

As emphasized above, no mixed disulfide is formed between Grx and the target protein in the monothiol mechanism and as a consequence Grx enzymes can display low requirements for specific protein interactions. Accordingly, at least for some substrates (such as acyl coenzyme $A$ binding protein), the $p K_{a}$ values and accessibility of their cysteine residues are the two factors that dictate substrate discrimination by HsGrx1 [151]. Accordingly, for other proteins differences in $K_{\mathrm{M}}$ and $V_{\max }$ values were attributed to steric factors [150].

Reduction of glutathionylated-Grx by a second GSH molecule (Figure 9A, step II) allows turnover of Grx and is considered the rate limiting step. Not only GSH, but also other thiols can reduce Grx-glutathione mixed disulfide. Remarkably, the corresponding $\mathrm{pH}$ profiles of the reaction rates match the deprotonation of the corresponding low molecular weight sulfhydryl [143,152]. These findings are consistent with the fact that the step II is the rate limiting step of the monothiol mechanism (reviewed in Ref. [130]). The rates enhancements by $\mathrm{Grx}$ in relation to the non-catalyzed reactions are in the one thousand range and obey the Brønstead relationship [Equation (2)], except for GSH where an additional enhancement effect was observed [143,152]. The very low $\mathrm{p} K_{\mathrm{a}}$ of the active site Grx cysteine may help in the catalysis, since thiolate is a good leaving group in the second step of the monothiol mechanism (Figure 9A, step II). This may be another distinguishing feature between Trx and Grx enzymes. Accordingly, the $\mathrm{p} K_{\mathrm{a}}$ values of the corresponding Cys residue in Trx are four orders of magnitude higher $(\sim 7.0)$ and these oxidoreductases are not endowed with monothiol activity.

One of the reasons why the monothiol mechanism is well studied for Grx enzymes is the availability of a simple and inexpensive assay. The HEDS assay is based on the reduction of HEDS (the disulfide of 2-mercaptoethanol) by GSH (reviewed in Ref. [137]). The formation of GSSG (a product of this reaction) is then monitored spectrophotometrically in a coupled assay with glutathione reductase through the oxidation of NADPH. Puzzling, whereas reductions of most glutathionylated substrates occur through a ping-pong mechanism, the kinetic pattern observed in the HEDS assay is the sequential. Although the HEDS assay is a simple procedure, the interpretation of the results requires caution. The HEDS assay is composed of two sequential thiol-disulfide exchange reactions as described below:

$$
\begin{aligned}
& \mathrm{OH}-\mathrm{CH}_{2}-\mathrm{CH}_{2}-\mathrm{S}-\mathrm{S}-\mathrm{CH}_{2}-\mathrm{CH}_{2}-\mathrm{OH}(\mathrm{HEDS}) \\
& +\mathrm{GSH} \rightarrow \mathrm{OH}-\mathrm{CH}_{2}-\mathrm{CH}_{2}-\mathrm{S}-\mathrm{SG}+\mathrm{OH}-\mathrm{CH}_{2} \\
& -\mathrm{CH}_{2}-\mathrm{SH} \\
& \quad \text { (Reaction 4) } \\
& \mathrm{OH}-\mathrm{CH}_{2}-\mathrm{CH}_{2}-\mathrm{S}-\mathrm{SG}+\mathrm{GSH} \rightarrow \mathrm{OH}-\mathrm{CH}_{2}-\mathrm{CH}_{2} \\
& -\mathrm{SH}+\mathrm{GSSG}^{2}
\end{aligned}
$$

(Reaction 5)

$$
\begin{gathered}
\mathrm{OH}-\mathrm{CH}_{2}-\mathrm{CH}_{2}-\mathrm{S}-\mathrm{S}-\mathrm{CH}_{2}-\mathrm{CH}_{2}-\mathrm{OH}(\text { HEDS }) \\
+2 \mathrm{GSH} \rightarrow 2 \mathrm{OH}-\mathrm{CH}_{2}-\mathrm{CH}_{2}-\mathrm{SH}+\mathrm{GSSG}
\end{gathered}
$$

(Reaction 6)

In a standard HEDS assay, all the reagents, less Grx, are incubated for a couple of minutes for the formation of the mixed disulfide between GSH and HEDS. The reaction is then started by the addition of Grx [153]. It is classically assumed that reaction 4 is not catalyzed by Grx (Figure 10) since this oxidoreductase prefers glutathionylated disulfide substrates. To clarify controversies on the reaction mechanism in the HEDS assay, the mixed disulfide GSSEtOH was synthesized and purified and subsequently analyzed in an analogous glutathione reductase - NADPH coupled photometric assay [154]. As expected for other glutathionylated substrates, the results were consistent with a pingpong mechanism. In the HEDS assay, probably Grx can also catalyze the formation of the mixed disulfide between GSH and 2-mercaptoethanol (Figure 10, reaction I), even though the HEDS disulfide does not contain a glutathionyl moiety [154]. It is possible that GSH binds to a high affinity site in Grx, which might provide better orientation and geometry for reduction of a nonglutathionylated disulfide, such as HEDS.

In spite of these controversies, the HEDS assay has been widely used to characterize Grx oxidoreductases. Most of the conventional dithiol Grx are active in the HEDS assay. Moreover, mutational analyses of the second cysteine in the $\mathrm{C}-\mathrm{X}-\mathrm{X}-\mathrm{C}$ motif do not abolish this enzymatic activity (reviewed in Refs. $[130,137]$ ). ScGrx8 is an exception, since its ability to catalyze the reduction of HEDS at the expense of GSH is lost when the second cysteine residue of the $\mathrm{C}-\mathrm{X}-\mathrm{X}-\mathrm{C}$ motif is mutated by serine [155]. Intriguingly, native monothiol Grxs (such as ScGrx3-5, which have a C-X-X-S motif) are usually inactive in the HEDS assay. Possible explanations for the lack of enzymatic activity of these monothiol Grxs 


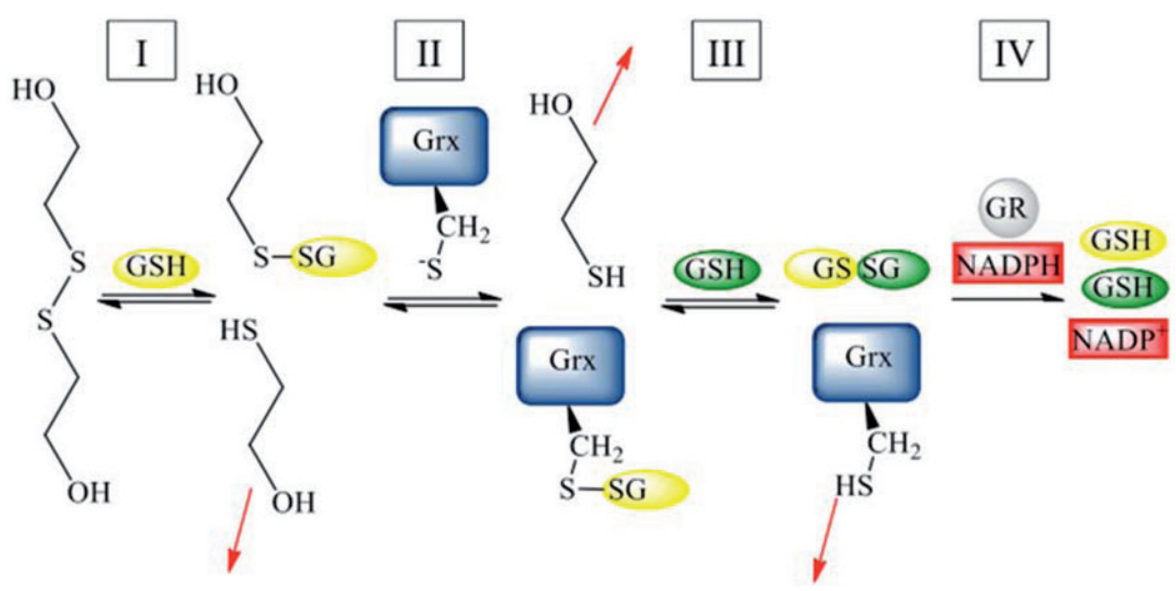

Figure 10. Schematic representation of the HEDS assay. (I) Thiol-disulfide exchange reaction between HEDS and GSH, producing a mixed disulfide between 2-mercaptoethanol and GSH with the release of 2-mercaptoethanol. (II) Reduction of mixed disulfide between 2-mercaptoethanol and Grx, releasing 2-mercaptoethanol and S-glutathionylated Grx. (III) Then, GSH reduces the Sglutathionylated Grx, (IV) resulting in reduced Grx and GSSG, which is reduced by NADPH in a reaction catalyzed by glutathione reductase (GR) (Adapted from Ref. [154]).

might be related with the lack of activation of the second GSH molecule as a nucleophile; and poor leaving group properties of the $\mathrm{N}$-terminal cysteine in the $\mathrm{C}-\mathrm{X}-\mathrm{X}-\mathrm{C}$ motif among other possibilities (reviewed in Ref. [137]).

For dithiol Grxs, the glutathionylated Grx intermediate can have two outcomes: (1) reduction by a second GSH molecule, regenerating reduced Grx (Figure 9A, step II); or (2) intramolecular disulfide formation due to the attack of the buried Cys residue (Figure 9A, step III). Reaction in step II allows turnover of Grx. Therefore, in principle, reaction in step III detracts Grx-SSG from turnover, slowing down the overall reaction. Therefore, to the extent that this reaction occurs, it is inhibitory. Indeed, mutation of the C-terminal active-site Cys by Ser in $\mathrm{HsGrx} 1$ and $\mathrm{HsGrx2}$ resulted in a two fold increase in specific activity $[135,143,156]$, since this mutation makes the reaction in step III (Figure 9A) impossible to occur. However, for other dithiol Grxs (such as EcGrx1 and ScGrx2) mutation of the second Cys residue provoked the opposite effect, i.e. decrease in the HEDS reduction activity $[15,139]$. Therefore, there should be biochemical and/or structural differences among dithiol Grxs.

ScGrx1 and ScGrx2 are dithiol oxidoreductases, possessing the typical conserved Cys-Pro-Tyr-Cys motif. Although these enzymes are $85 \%$ similar in terms of their amino acid sequence, ScGrx2 is 50 times more efficient than ScGrx1 in the HEDS assay [15]. Crystal structures of ScGrx2 in the oxidized form (intramolecular disulfide) and as glutathionyl mixed disulfide were elucidated [15] and compared with similar ones for ScGrx1 [133]. As expected, all the four structures overlapped quite well. However, distinct side-chain conformations of $\mathrm{Ser}^{30}$ (Cys ${ }^{30}$ in corresponding wild-type proteins) were observed in the glutathionylated structures of the C30S mutants of ScGrx1 and ScGrx2, which are related with the fact that the distances between $\mathrm{Ser}^{30}$ and the reactive $\mathrm{Cys}^{27}$ are markedly distinct (3.47 $\AA$ in $\mathrm{ScGrx} 1^{\mathrm{C} 30 \mathrm{~S}}$ and $5.14 \AA$ in ScGrx2 ${ }^{\mathrm{C} 30 \mathrm{~S}}$ ). Probably, anything that increases the distance between the two sulfur atoms of the $\mathrm{C}-\mathrm{X}-\mathrm{X}-\mathrm{C}$ motif might slow down the reaction in step III (Figure 9A) and thereby favor the overall monothiol mechanism [157]. Accordingly, sitedirected mutagenesis experiments are consistent with this hypothesis [15].

Equivalent to the ScGrx1/ScGrx2 pair, similar features are present in the EcGrx1/EcGrx3 pair. Into EcGrx3 glutathionylated structure [134], Ser ${ }^{14}$ (which replaces the C-terminal active-site cysteine in this structure) presents a more buried conformation similar to that of ScGrx $2{ }^{\mathrm{C} 30 \mathrm{~S}} \mathrm{GS}$. In all other Grx structures reported in the glutathionylated form (all obtained with mutations of the C-terminal active site cysteine to serine), including the EcGrx1 [132] the conformation of this Ser is similar to that found in ScGrx1GS. The more buried conformation of $\mathrm{Ser}^{30}$ in the ScGrx2GS structure appears to be related to the interaction with other residues, including a Glu residue [15]. In the wild-type ScGrx2 protein, this configuration would make $\mathrm{Cys}^{30}$ less prone to disulfide formation [15]. Remarkably, like ScGrx2, EcGrx3 possesses similar conformation in the active site and higher monothiolic activity than EcGrx1, although to a much lower extent (2-fold) than the ScGrx1/ScGrx2 pair [134].

Besides this structural factor, other features are associated with the catalytic activity of Grx enzymes. Since reaction in step $I I$ is the rate-limiting step in the monothiol mechanism $[130,158]$, the very low $p K_{a}$ values (3.0-4.0) of the N-terminal Cys residue (that functions as 

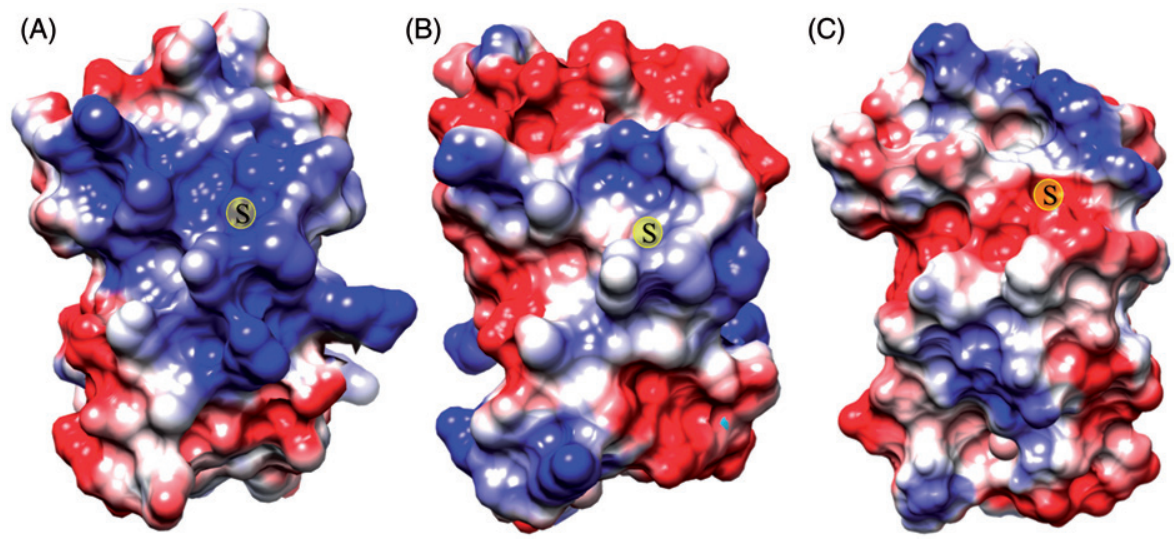

Figure 11. Charge distribution on the molecular surfaces charge of Grx enzymes in reduced form. Surface representation of the $H$. sapiens Grx1 (A) (PDB code: 1JHB), S. cerevisiae Grx2 (B) (3CTG) and E. coli Grx1 (C) (1EGO). The position of sulfur atom (S $\gamma$ ) of the reactive Cys is assigned by the " $\mathrm{S}$ " character in the yellow circle. The surfaces are represented in charge gradient and colorized as follow: blue $=$ positive, white $=$ neutral and red $=$ negative. The coulombic surface color range from +5 (blue) to -5 (red) $\left(\mathrm{kcal}^{\mathrm{mol}}{ }^{-1}\right.$ ). (See color version of this figure in the online version.)

the leaving group in this reaction) might favor the catalysis. This is consistent with the physicochemical principles described above (in the "Physico-chemical factors affecting thiol-disulfide exchange reaction for low molecular weight compounds" section) for thioldisulfide exchange reactions for aliphatic, low molecular weight thiols that follow the Brønsted relationship [Equation (2)] $[29,40]$. Therefore, for HsGrx1, the rate constant enhancement of the catalyzed reaction (in which the $\mathrm{p} K_{\mathrm{a}}$ value of the leaving group is 3.5) over the uncatalyzed reaction (taking into account the $\mathrm{p} K_{\mathrm{a}}$ value of an ordinary Cys residue, such as BSA-SH equal to 8.5), it is predicted to be $4^{\Delta \mathrm{p} K a}$, i.e. $4^{5}$ ( $\sim 1000$-fold) [151]. For HsGrx2, the predicted rate enhancement is $4^{4}$, which is again consistent with the $4^{\Delta \mathrm{pKa}}$ model, since the $\mathrm{p} K_{\mathrm{a}}$ value of its catalytic cysteine is 4.6 [143]. In contrast, Trx enzymes (with the $\mathrm{N}$-terminal catalytic Cys with $\mathrm{p} K_{\mathrm{a}}$ values around 7.0) exhibit very low deglutathionylating activity and no monothiol mechanism (reviewed in Ref. $[130,137])$.

Anyway, the extremely low $\mathrm{p} K_{\mathrm{a}}$ of the Grx catalytic cysteine does not fully account for the observed rate enhancement in the catalyzed reactions [130]. That is, the difference in catalytic cysteine $\mathrm{p} K_{\mathrm{a}}$ (around $1 \mathrm{pH}$ unit) accounts for only about half of the 10-fold lower specific activity of HsGrx2 compared with HsGrx1 [130]. Accordingly, dithiol yeast Grxs (ScGrx1 and ScGrx2) possess about the same $\mathrm{p} K_{\mathrm{a}}$ values for the reactive Cys, but display distinct activities (50-fold difference) in the HEDS assay [15].

Although it is intriguing to observe the extraordinary low $\mathrm{p} K_{\mathrm{a}}$ values for the nucleophilic Cys in Grx, the chemical basis for this phenomenon are still not completely understood. Similar to Trx enzymes, the location of the solvent exposed Cys residue at the positive pole ( $\mathrm{N}$-extremity) of helix $\alpha 2$, only partially explains the high acidity of this thiolate. Indeed, studies with helical synthetic peptides, in which the thiolate anion is located at the N-terminus (positive pole) of $\alpha$-helices resulted in only 1.6 units decreases in comparison with corresponding thiol $\mathrm{p} K_{\mathrm{a}}$ measured in an unfolded control peptide [79]. Since $\mathrm{p} K_{\mathrm{a}}$ values for thiols in the reactive Cys residues in Grxs ( 3.5) are five units below the $\mathrm{p} K_{\mathrm{a}}$ value of free Cys $(\sim 8.5)$, it is evident that other factors should operate. One possibility is that $\mathrm{H}$ bonding and ion pair of $\mathrm{N}$-terminal Cys thiolate with other residuescan be responsible to decrease $\mathrm{p} K_{\mathrm{a}}$ of reactive Cys residues in Grxs by $5 \mathrm{pH}$ units [159].

Computational approaches for HsGrx1 predicted that $\mathrm{Cys}^{22}-\mathrm{S}^{-} \ldots{ }^{+} \mathrm{H}_{3} \mathrm{~N}$-Lys ${ }^{19}$ the ion par might be relevant for the extraordinary low $\mathrm{p} K_{\mathrm{a}}$, due to the proximity of the opposite charges. However, site directed mutagenesis provoked only slight changes in $\mathrm{p} K_{\mathrm{a}}$ values (less than 1 $\mathrm{pH}$ unit) [159]. Apart from the already mentioned dipole effect of helix $\alpha 2$, hydrogen bonds with the $\mathrm{Thr}^{21}$ hydroxyl group may also contribute to the thiolated stabilization [159], although this is also controversial [80].

Through the analysis of the HsGrx1 reduced structure, it was shown that the extraordinary low $\mathrm{pK}_{\mathrm{a}}$ of the Cys ${ }^{22}$ thiolate was likely due to stabilization by a local region of substantial positive potential resulting from the composite local environment rather than from a single interaction [160]. For HsGrx1, the overall dipole moment of the whole polypeptide extends directly through the active site pocket [160] (Figure 11A). We performed similar analyses in the electrostatic surfaces of ScGrx2 (Figure 11B) and EcGrx1 (Figure 11C), but in these cases no such dipole was observed. Since ScGrx2 and EcGrx1 


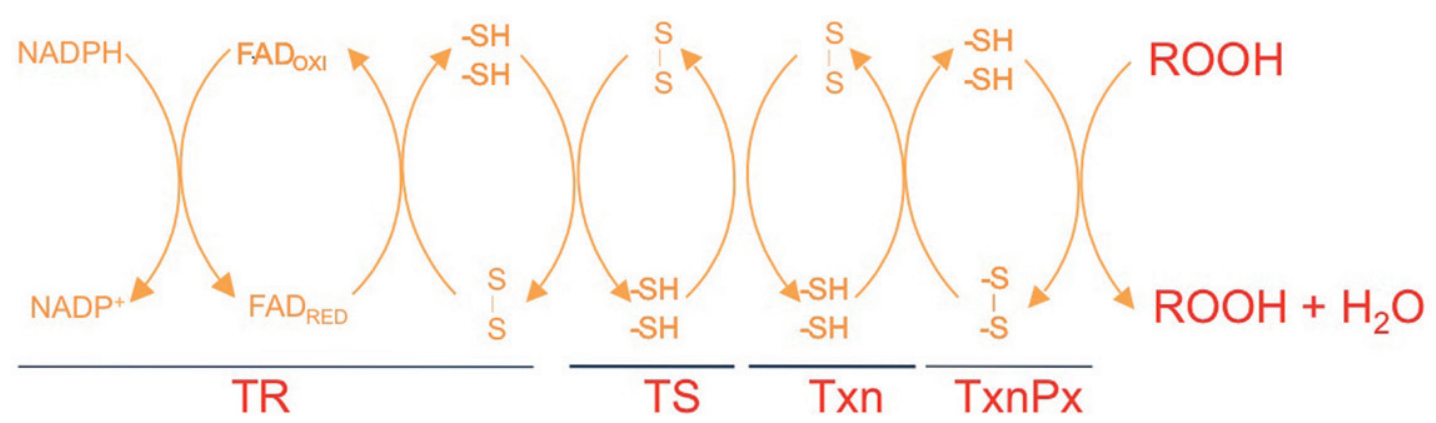

Figure 12. The hydroperoxide decomposition by the system composed by TxnPx, Txn, $\mathrm{T}\left(\mathrm{SH}_{2}\right)$, and TR. The hydroperoxide decomposition is carried out by the Tryparedoxin peroxidase ( $\mathrm{TxnPx}$ ) releasing an alcohol and a water molecule. The disulfide oxidized cysteines from TxnPx are reduced by the enzyme tryparedoxin ( $\mathrm{Txn}$ ) using reducing equivalents from trypanothione $\mathrm{T}\left(\mathrm{SH}_{2}\right)$ which is oxidized to TS2 which is reduced by the Trypanothione reductase (TR) a flavoprotein that use reducing equivalents from NADPH.

also have extraordinary low $\mathrm{p} K_{\mathrm{a}}$ values, other still elusive factors should be involved in stabilizing the nucleophilic Cys in the thiolate form.

Anyway, taking into account the Brønsted linear free energy relationship [Equation (2)], it was evident that the extraordinary low $\mathrm{p} K_{\mathrm{a}}$ of the Grx catalytic Cys does not fully account for the observed rate enhancement in the presence of GSH (reviewed in Ref. [130]). Indeed, when GSH is used as the second substrate, second-order rate constants are further increased for HsGrx1 [151] and HsGrx2 [143] over rates with other thiol substrates. Therefore, it is a challenge to reveal the Grx mechanisms that underlie the enhancement of GSH nucleophilicity as a second substrate for attack and turnover of the Grx-SSG intermediate (the rate limiting step of the overall monothiol pathway), especially considering the lack of kinetically relevant substrate-binding modes (see earlier). Possible mechanisms for this enhanced nucleophilicity are acid/base catalysis of proton abstraction from the attacking GSH by Grx residues or by the glutathionyl moiety of the Grx-SSG mixed disulfide. Other hypothesis is the stabilization of the incipient thiolate of the second GSH substrate by positively charged basic groups on the enzyme. Indeed, mutation of the Lys (K19Q or $\mathrm{K} 19 \mathrm{~L})$ close to the catalytic cysteine of HsGrx1, caused little change in the $p K_{a}$ of the catalytic cysteine but resulted in substantially lower specific activity [159], suggesting that Lys ${ }^{19}$ might enhance the nucleophilicity of GSH [130]. NMR characterization of the GrxSSG mixed disulfide indicated that the Lys $^{19}$ residue is also relevant in the stabilization of the adducted glutathionyl moiety [135]. Structure-activity relations in which distinct residues are mutated may yield important information about their roles in catalysis [130].

The physiological meanings of the ability of Grx to catalyze reversible S-glutathionylation has been extensively discussed elsewhere [161-163] and will not be further reviewed here. The amount of information in this subject is huge, reflecting the fact that more than 200 mammalian proteins are post-translationally modified with the glutathionyl moiety (reviewed in Ref. [131]). Also, very relevant are the new findings on the complexes between Grx enzymes and Fe-S clusters that were reviewed recently [164] and impact biology and medicine.

Therefore, Grxs mediate a myriad of processes such as DNA synthesis; regulation of gene expression; energy production; protein folding; protection against apoptosis; sulfate assimilation, cytoskeleton arrangement. The mechanisms underlying these processes include deglutathionylation (through the monothiol mechanism) or the disulfide reduction (through the dithiol mechanism) or binding to Fe-S clusters, which involve hydrophobic and electrostatic interactions in the recognition of protein substrates.

\section{Txn-T(SH) 2 system}

Another important example of specificity in thiol-disulfide exchange reactions comes from organisms belonging to the Kinetoplastea order that includes Trypanosome and Leishmania genera. These protozoa (many of them parasites) present an unique thioldisulfide network that include trypanothione $\left[\mathrm{T}(\mathrm{SH})_{2}\right]$ an abundant low molecular weight thiol (reviewed in Refs. $[165,166]) . T(\mathrm{SH})_{2}$ is formed by the conjugation of two glutathione molecules with spermidine [N1,N8-(bis)-glutathionylspermidine], generating a dithiol [167]. The positively charged amino group in the spermidine bridge confers to the thiol groups of $\mathrm{T}(\mathrm{SH})_{2}$ a $\mathrm{pK}$ value of 7.4 that coincides with the physiological $\mathrm{pH}$ and, therefore, is more acidic than the corresponding value of GSH [166]. As expected, formation of an intramolecular disulfide is kinetically favored for $\mathrm{T}(\mathrm{SH})_{2}$, when 


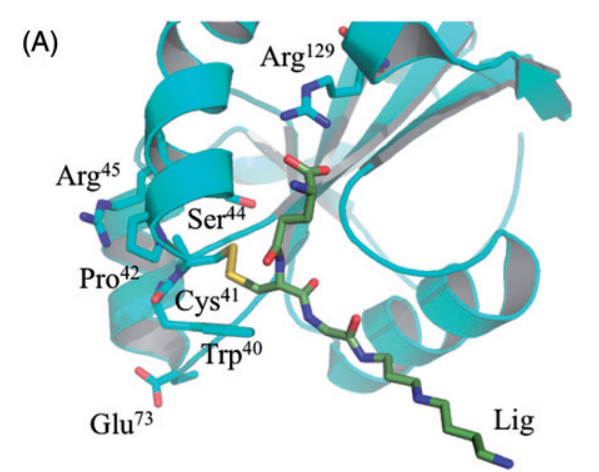

(C)
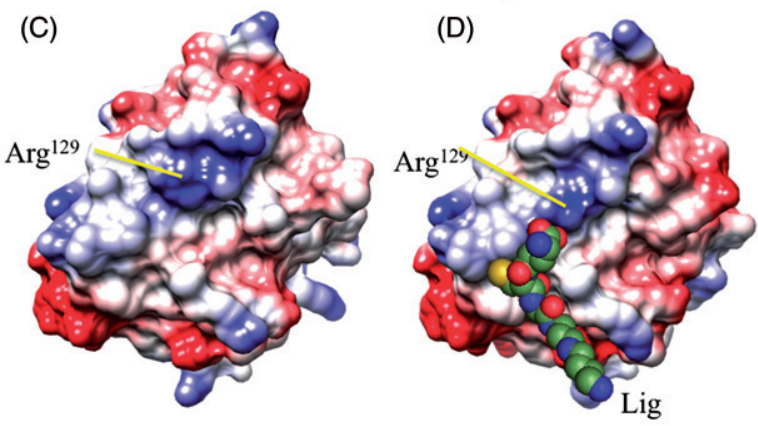
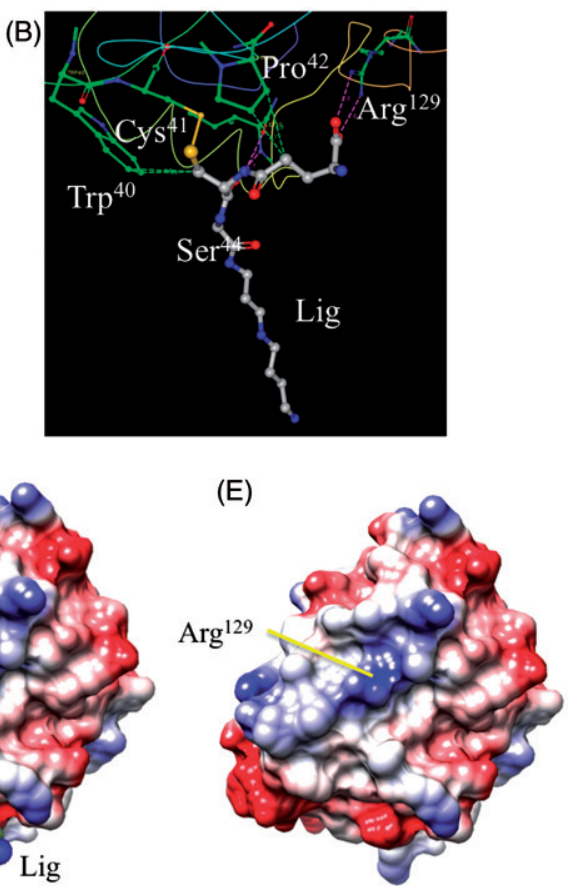

Figure 13. Crystallographic structure $C$. fascicula Txn2 bound to glutathionyl-spermidine. (A) Cartoon representation of the CsTxn2 ${ }^{\text {C44S }}$ mutant (colorized in light blue) containing a glutathionyl-spermidine molecule making a disulfide bond with Cys ${ }^{41}$ (PDB code: $115 G$ ). The side chains of the residues related to substrate binding or catalysis as also the glutathionyl-spermidine are represented by sticks with carbon atoms colorized in light blue (CsTxn2) or dark green (glutathionyl-spermidine). Colors of other atoms follow: $\mathrm{N}=$ blue, $\mathrm{O}=$ red and $\mathrm{P}=$ dark orange. (B) Molecular interactions between CsTxn2 ${ }^{\mathrm{C} 44 \mathrm{~S}}$ and the ligand. The enzyme is represented in ribbon and the amino acids involved in substrate binding are represented by ball and stick. Hydrophobic interactions are represented by the green dashed lines and polar ones by pink dashed lines. The interactions and representations were performed using the RCSB PDB ligand explorer 4.2 .0 (http://www.rcsb.org/). (C) CsTxn2 with the cysteines oxidized to disulfide; (D) CsTxn2 bounded to T(SH); (E) The same as in D but with the ligand omitted to facilitate the observation of the binding site. The CsTxn2 ${ }^{\text {C44S }}$ surface was colorized as follow: blue = positive, white $=$ neutral and red = negative. The glutathionyl-spermidine is represented by spheres and the atoms colorized as follow: $\mathrm{C}=$ dark green, $\mathrm{N}=$ blue, $\mathrm{O}=$ red, and $\mathrm{P}=$ dark orange. The coulombic surface color range from +10 (blue) to -10 (red) $\left(\mathrm{kcal} \mathrm{mol}^{-1}\right)$. (See color version of this figure in the online version.)

compared with the intermolecular oxidation of two molecules of GSH $[29,168]$.

$\mathrm{T}(\mathrm{SH})_{2}$ is the direct reductant of tryparedoxin (Txn), a disulfide reductase with homology to Trx but displaying a characteristic C-X-X-C (residues 40-45) and higher molecular weight $(\sim 16 \mathrm{kDa})$, among other distinct features [169]. $\mathrm{T}(\mathrm{SH})_{2}$ and Txn play central roles in the metabolism of trypanosomatids such as the synthesis of DNA precursors and hydroperoxide reduction $[165,166]$. Regarding, hydroperoxide metabolism, several thioldisulfide exchange reactions take place and they confer specificity towards the overall system (Figure 12).

Txn is the predominant oxidoreductase in trypanosomatids [166]. Txn is reduced by $\mathrm{T}(\mathrm{SH})_{2}$ and oxidized by TxnPx and both of these thiol-disulfide exchange reactions display high selectivity that are mediated by electrostatic factors, as will be described below. Txn enzymes are endowed with a WCPPCR active site motif and form a distinct molecular clade within the superfamily of thioredoxin-type proteins [170].
Regarding the reduction of Txn by $\mathrm{T}(\mathrm{SH})_{2}$, an unique mechanism was observed, in which electrostatic forces induce an unusual $\mathrm{T}(\mathrm{SH})_{2}$ conformation $[169,171]$. Structure of Txn2 ${ }^{\mathrm{C} 44 \mathrm{~S}}$ in complex with mono-glutathionyl-spermidine $[\mathrm{T}(\mathrm{SH})]$ (that probably mimicks several features of the real substrate $\left.\mathrm{T}(\mathrm{SH})_{2}\right)$, displays Txn $\operatorname{Arg}^{129}$ interacting to the carboxyl group of $\mathrm{T}(\mathrm{SH})$ and a negative charge in Txn attracting the basic amine of spermidine (Figure 13A), whereas $\operatorname{Trp}^{40}$ and Pro $^{43}$ perform hydrophobic interactions with $\mathrm{T}(\mathrm{SH})$ (Figure 13B). Furthermore, a positive patch containing the $\mathrm{Arg}^{129}$ is probably stabilizing the structure of the mixed disulfide between Tnx2 and $\mathrm{T}(\mathrm{SH})$ (Figure 13C-E).

Besides, modelling studies were also carried out and suggested that $\mathrm{Arg}^{45(44)}, \mathrm{Glu}^{73(72)}, \mathrm{lle}^{110(109)}$, cis-Pro ${ }^{111}$ (110)-bond and $\mathrm{Arg}^{129}$ (128) residues are involved in the binding of CfTxn2 (CfTxn1) to T(SH) 2 , the two Arg residue would interact with the glutathionyl carboxyl groups of the dithiol [169]. In addition, the substitution of the Pro ${ }^{43}$ by Tyr may interfere with the $\operatorname{Arg}^{129}$ orientation [172]. 

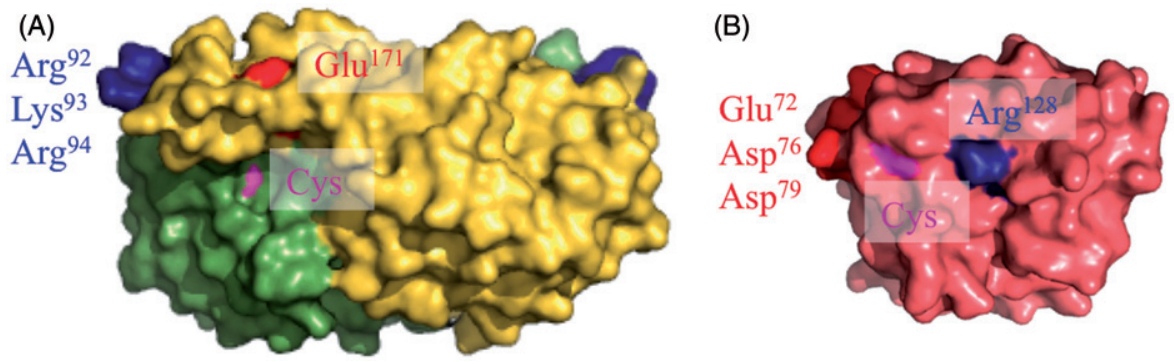

Figure 14. Complementary charge residues on the surfaces of TbTxnPx and TbTxn. (A) Surface model of TxnPx with each monomer of the homodimer colorized in green and yellow. The positive cluster represented by $\mathrm{Arg}^{92}$, $\mathrm{Lys}^{93}$, and $\mathrm{Arg}^{94}$ is represented in blue and the $\mathrm{Glu}^{171}$ in red. (B) Molecular surface of monomers of TbTxn colorized in rose with the acidic cluster (Glu ${ }^{72}$, Asp $^{76}$, and Asp ${ }^{79}$ ) represented in red and the $\mathrm{Arg}^{128}$ in blue. Cys residues in both enzymes are in magenta. (See color version of this figure in the online version.)

Mutations in Txn were performed in an attempt to make its active site more similar to Trx or Grx, but they did not result in thioredoxin or glutaredoxin-like activities [172]. Probably, specificity in the Txn-T(SH)2 is achieved by complementary electrostatic interactions that are far away from the active site $[169,171]$.

Following the same trend described before, Tryparedoxin peroxidase ( $\mathrm{TxnPx}$ ) enzymes are specifically reduced by $\mathrm{TbTxn}$, less efficiently by $\operatorname{Trx}$, and not reduced at all by $\mathrm{GSH}$ or $\mathrm{T}(\mathrm{SH})_{2}$ [173]. Therefore, the molecular aspects underlying the specificity of the reduction of TbTxnPx by TbTxn were evaluated by sitedirected mutagenesis and by structural biology, including electron microscopy. Negatively charged residues $\mathrm{Glu}^{72}, \mathrm{Asp}^{76}, \mathrm{Asp}^{79}$, and $\mathrm{Arg}^{128}$ from TbTxn could establish saline bonds with the $\mathrm{Arg}^{92}, \mathrm{Lys}^{93}, \mathrm{Arg}^{94}$, and $\mathrm{Glu}^{171}$ from TbTxnPx (Figure 14).

The structure of TxnPx from Trypanosoma cruzi is decameric [174], similarly to the structure of other 2-Cys Prx (Figure 15A-C). Considering this structure and electron microscopy images, a complex of decameric TcTxnPx with 10 molecules of TcTxn, one in each TcTxnPx active site [173] was modelled (Figure 15D).

Due to the specificities of the thiol-disulfide exchange reaction, enzymes involved in the hydroperoxide metabolism dependent on $\mathrm{T}(\mathrm{SH}) 2$ and $\mathrm{Txn}$ can be good candidates for the design of inhibitors with the potential to the development of drugs.

\section{Other thiol-disulfide oxidoreductases}

In this item, some general aspects for disulfide bond formation protein $\mathrm{A}$ (DsbA) and protein disulfide isomerase (PDI) will be described. DsbA and PDI act mainly as oxidants, in contrast to Grx and Trx, which react as reductants towards client proteins. The number of thiol disulfide oxidoreductases is extensive and specific reviews are available for each one. At the end of this topic, the use of lipoamide in thiol-disulfide exchange is also briefly discussed as an example of another oxidizing thiol (distinct than Cys residues discussed so far). According to the above sections, the mechanisms by which DsbA, PDI, Grx and Trx enzymes increase rates of thiol-disulfide exchange reactions are distinct, although they share the same structural fold and the $\mathrm{C}-\mathrm{X}-\mathrm{X}-\mathrm{C}$ motif. [175].

Protein disulfide isomerase (PDI) in mammalian organisms and DsbA in bacteria are two oxidoreductases that catalyze reversible thiol-disulfide exchange reactions and are involved in disulfide formation in target proteins. It is important to realize that in spite of their biological role, oxidoreductases can catalyze reactions in both directions. This is particularly relevant for thioldisulfide exchange reactions that are highly reversible [35]. Therefore, as any enzyme, DsbA and PDI accelerate thiol-disulfide exchange reactions in both directions and, as a consequence, the equilibrium is achieved at shorter times $[35,130]$. Anyway, as described for other thiol-disulfide oxidoreductases, electrostatic factors and acid/base catalysis also underlie the catalytic mechanism of PDI [176].

Protein disulfide isomerase (PDI) and DsbA also possess the Trx fold (Figure 16), but they present structural differences (reviewed in Ref. [57]). DsbA are single domain proteins ( $E$. coli DsbA presenting a molecular weight of $23 \mathrm{kDa}$ ) with the characteristic C-P$\mathrm{H}-\mathrm{C}$ motif (Figure 16A) [177]; whereas PDI enzymes contain four Trx domains named a, $a^{\prime}, b$, and $b^{\prime}$ arranged in a U-shape form (Figure 16B) [178]. Domains $b$ and $b^{\prime}$ form a rigid base in the U-shaped tetradomain molecule with respect to the more flexible a and $a^{\prime}$ domains [57]. Only domains a and $a^{\prime}$ contain the typical C-G-H-C motif (containing the $\mathrm{Cys}^{53}$ and $\mathrm{Cys}^{56}$; $\mathrm{Cys}^{397}$ and $\mathrm{Cys}^{400}$, respectively - the numbering referring to the human isoform) found in PDI enzymes (Figure 16B). In turn, the domains $b$ and $b^{\prime}$ are related 


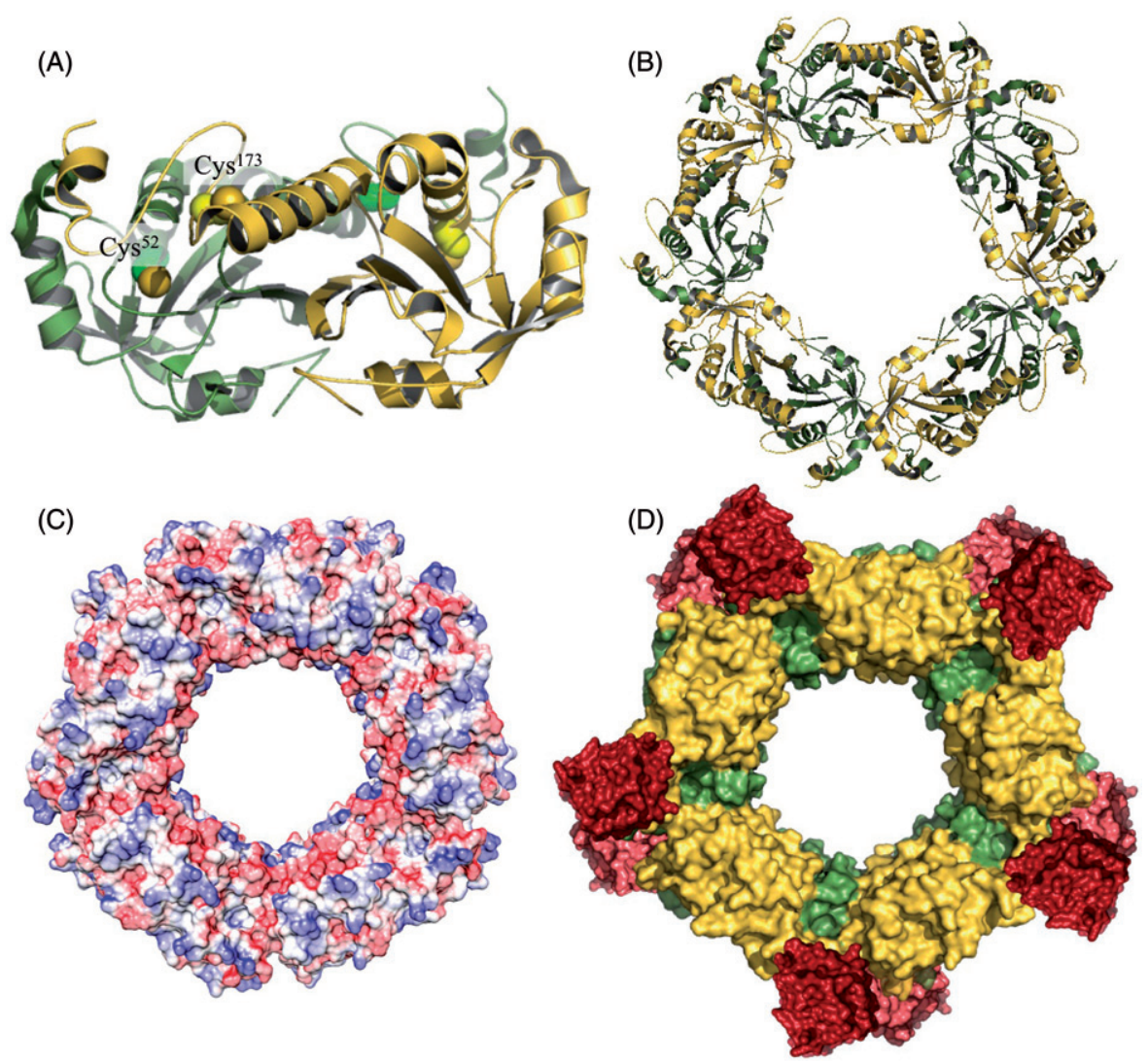

Figure 15. Crystallographic structure T. cruzi TcTxnPx and model of TcTxbP-Txn complex. Cartoon representation of the TxnPx from Typanossoma cruzi (TcTxnPx) homodimer (A) and decamer (B) (PDB code: 4LLR). In both representations, one monomer is colorized in yellow and the other in green. The Cys residues are represented by spheres and the carbon atoms in a color tone similar to the cartoon monomer. The sulfur atoms are in orange. (C) TcTxnPx surface colorized by charge (red = negative, blue = positive, and white = neutral). (D) Model of the Txn-TxnPx complex. The homo dimers of the decameric structure TcTxnPx are colorized in green and yellow. Monomers of TcTxn are colorized in red or rose. (See color version of this figure in the online version.)

to the substrate specificity of the PDI enzymes (reviewed in Refs. [178,179]).

The reduction potentials of DsbA and PDI enzymes are more oxidizing (as example, $\mathrm{EcDsbA}$ has $\mathrm{E}^{\circ \prime}=-0.09$ to $-0.11 \mathrm{~V} ;[10,11]$ ) than Trx and Grx enzymes (as an example EcTrx 1 has $E^{\circ \prime}=-0.27 \mathrm{~V}$ [61]), which are in line with their roles in thiol-disulfide redox status (reviewed in Refs. $[35,56]$ ). Reduction potentials (also called redox potentials) refer to equilibrium conditions and it means by definition that electrons will tend to flow from the conjugated redox pair of lower reduction potential to the pair of higher reduction potential. Therefore, the more negative redox potential, the greater will be the trend to donate electrons.

Reduction potentials are thermodynamic parameters that are correlated with $K_{\text {ox }}$ (for oxidation constant), which are particular redox equilibrium constants $\left(K_{\text {eq }}\right)$ for redox reactions as is the case of thiol-disulfide exchange reactions (For more details see Refs. [35,36]). The variations in the reduction potential described above ( 0.15V) represent huge thermodynamics changes in these structurally related thiol-disulfide oxidoreductases, since they correspond to variation of $K_{\text {ox }}$ in the $10^{5}$ range [35].

One of the factors determining this immense variation in the reduction potentials among thioldisulfide oxidoreductases is the composition of the two amino acids in between the two Cys residues of a $\mathrm{C}-\mathrm{X}-\mathrm{X}-\mathrm{C}$ motif. Remarkably, replacement of the two amino acids in between the two Cys of a reducing enzyme with those from a more oxidizing one causes the redox potential of the enzyme to become more oxidizing, and vice versa $[10,24,64,88,180,181]$. Indeed, in the case of $E$. coli DsbA (EcDsbA), whose active site motif is $\mathrm{C}-\mathrm{P}-\mathrm{H}-\mathrm{C}$, mutations of the Pro and His residues provoked changes in the equilibrium constant higher than 1000 thousand fold [10], which was correlated with the $\mathrm{p} K_{\mathrm{a}}$ of the thiolate in its reactive Cys [182]. Then the $\mathrm{C}-\mathrm{X}-\mathrm{X}-\mathrm{C}$ active-site motif of thioldisulfide oxidoreductases was proposed to act as a 


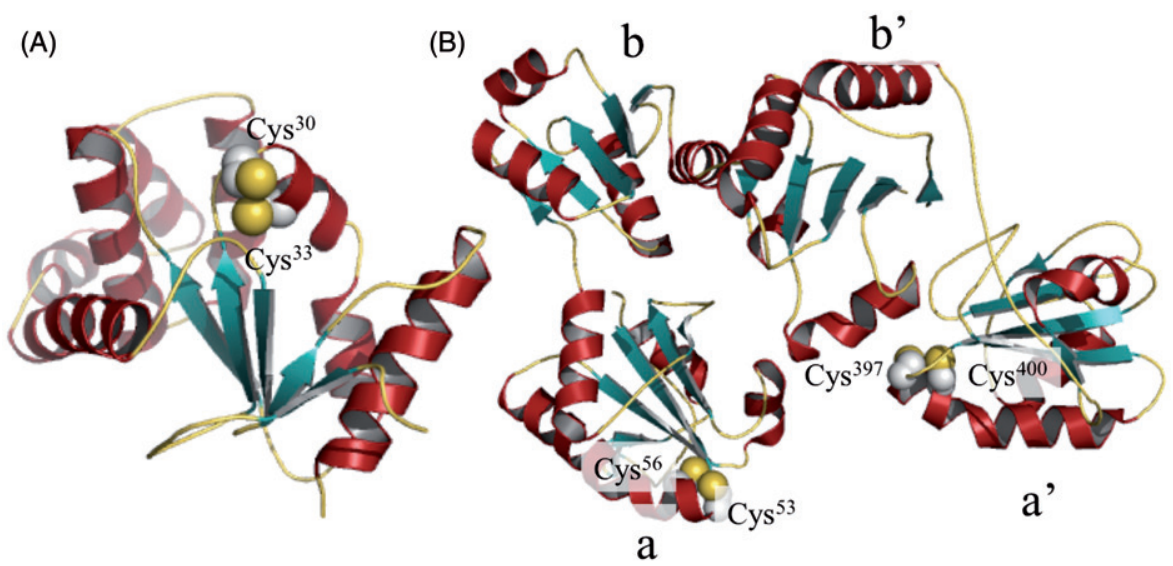

Figure 16. Overall structures of the DsabA and PDI. (A) Overall crystallographic structure of the one - domain EcDsbA with Cys in reduced form ( $\mathrm{Cys}^{30}$ and $\mathrm{Cys}^{33}$ ) (PDB code: $1 \mathrm{~A} 2 \mathrm{~L}$ ). (B) Structure of the reduced HsPDI (PDB code: 3ELI) revealing the $U$ shape conferred by the spatial organization of the four domains $\left(a, a^{\prime}, b\right.$ and $\left.b^{\prime}\right)$, all of them off with the Trx fold. $\beta$ sheets are represented in light green, the $\alpha$ helices in dark red, and the turns/random coils in yellow orange. Catalytic Cys residues are depicted as spheres and colorized as follow: $\mathrm{C}=$ white, $\mathrm{N}=$ blue, $\mathrm{O}=$ red, and $\mathrm{S}=$ orange. (See color version of this figure in the online version.)

redox rheostat, the sequence of which determines its reduction potential properties [182].

Although the two $\mathrm{X}-\mathrm{X}$ residues in the $\mathrm{C}-\mathrm{X}-\mathrm{X}-\mathrm{C}$ are important for the reduction potential, other factors appear to affect this thermodynamic parameter. Indeed, as mentioned before, proteins with the thioredoxin fold possess a loop containing a cis-proline, which closely approaches the $\mathrm{C}-\mathrm{X}-\mathrm{X}-\mathrm{C}$ motif [183]. The residue that precedes the cis-proline can take part in hydrogen bond with the catalytic Cys residues and thereby affect reduction potentials [183]. Mutational studies indicated that the cis-proline loop is also involved in stabilization of EcDsbA mixed disulfide intermediates with substrates in vivo [184], metal binding by the active site Cys residues [185]; and binding and positioning of the disulfide present in the substrate $[93,186]$. Studies with archeal Trxs are in an apparent contrast with the rheostat model [187], reinforcing the idea that there are multiple factors governing the reduction potentials of thiol-disulfide oxidoreductases, besides the composition of the amino acids in the $\mathrm{C}-\mathrm{X}-\mathrm{X}-\mathrm{C}$ motif.

In any case, the reduction potentials are not necessarily determinants of the function of these proteins as oxidants or reductants. In general, kinetics predominates over thermodynamics in controlling reactions pathways in living organisms [188]. For instance, mutations at position 33 (first $\mathrm{X}$ in the $\mathrm{C}-\mathrm{X}-\mathrm{X}-\mathrm{C}$ motif of $\mathrm{Trx}$ ) do not affect significantly their redox potential but do affect their activities in vitro and in vivo [114,115]. Moreover, EcGrx1 catalyzes protein disulfide formation 30-fold faster than rat PDI, although thermodynamically rat $\mathrm{PDI}$ is a 600 -fold better oxidizing agent than EcGrx1 [172]. Also, EcTrx1 can also act as an oxidant in vivo under certain condition, promoting disulfide bond formation in the cytoplasm $[189,190]$.

The most important factor to determine if an oxidoreductase will favor disulfide reduction or formation is the redox environment where the protein is located (reviewed in Ref. [191]). The redox environment of a cellular compartment is influenced by various redox couples that interact with each other in a dynamic way, under the influence of metabolic and anabolic processes. Since glutathione is by far the most abundant low molecular thiol in cells, the couple GSH/GSSG should be frequently considered in order to analyze the function of a thiol-disulfide oxidoreductase, taking into account that in cells kinetics rather than thermodynamics prevail (reviewed in Ref. [188]).

Therefore, disulfide bond formation in proteins takes place at the appropriate cell compartments, where the concentrations of GSSG are higher. In the case of eukaryotic organisms, PDI is located within the endoplasmic reticulum (reviewed in Ref. [192]), whereas in the case of bacteria, DsbA is located within the periplasm of Gram-negative (reviewed in Ref. [193]). These are oxidizing environments that favor oxidation of dithiols into disulfides before protein secretion.

Studies using ribonuclease $A$ as a model gave support to the postulate that, at least for small globular proteins, the native structure is determined only by the protein's amino acid sequence [194]. However, PDI and DsbA can accelerate this process, since disulfide bond formation is often the rate-limiting step in the overall folding process [195]. After introducing a disulfide into a client protein, PDI is reduced. To turnover, PDI needs to be re-oxidized (Figure 17A and $\mathrm{B}$ ). The classical pathway involves the 
(A)

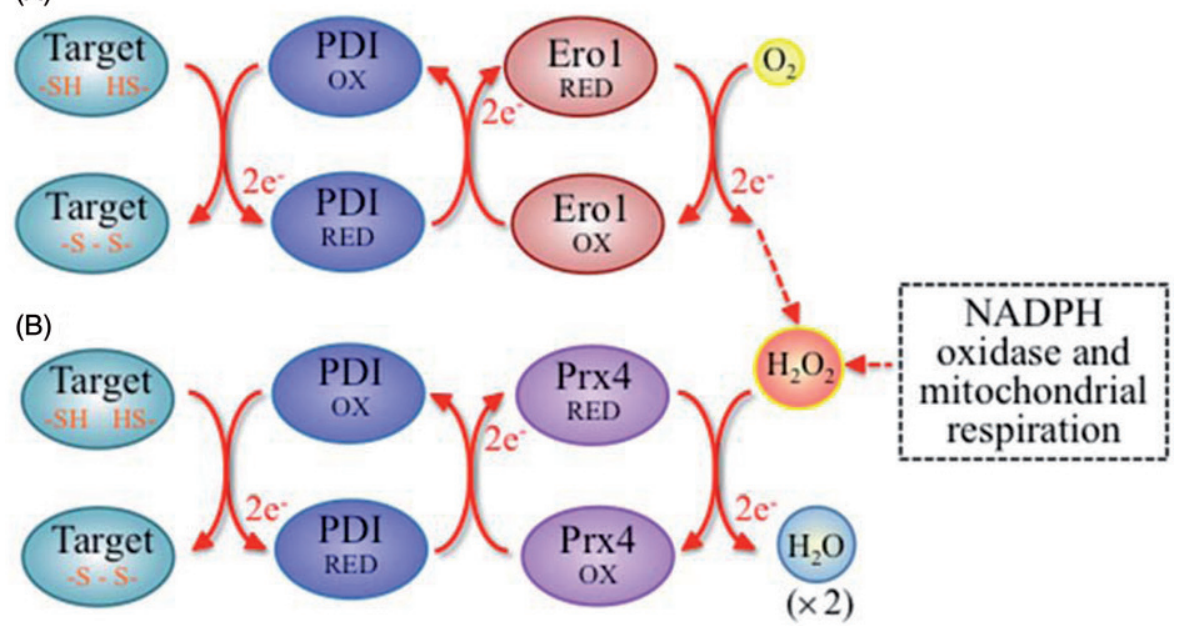

(C)

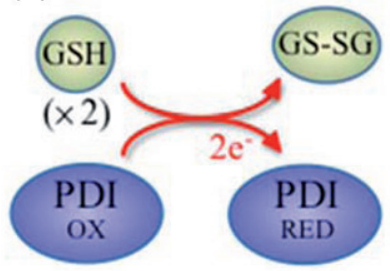

(D)

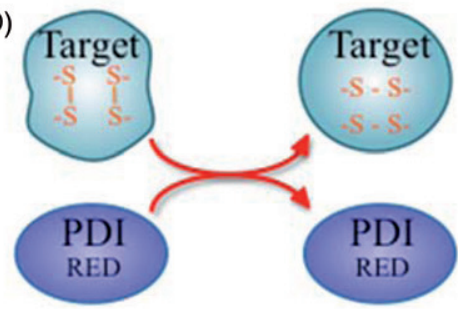

Figure 17. Redox pathways involved in the disulfide bond formation and disulfide bond isomerization activities of PDI. (A) Disulfide bond formation results in reduced PDI, which is re-oxidized by Ero1, which in turn is re-oxidized by molecular oxygen $\left(\mathrm{O}_{2}\right)$, releasing hydrogen peroxide. (B) Disulfide bond formation results in reduced PDI, which is re-oxidized by Prx4, which is then oxidized by hydrogen peroxide. (C) Disulfide oxidized PDI can be reduced by GSH, required for disulfide isomerase activity. (D) Disulfide isomerase activity of PDI. Several thiol-disulfide exchange reaction take place (not represented in this scheme), with no change in the oxidation state of the reactants and products; only the disulfide configuration of the target protein is altered.

flavin-thiol/disulfide containing protein named Ero1 (Figure 17A). After oxidizing PDI, ERO1 gets reduced and also needs to be re-oxidized to turnover. This happens through a sequence of reaction, whose final electron acceptor is molecular oxygen, giving rise to hydrogen peroxide (Figure 17A). Therefore, formation of disulfide bond in the ER has a potential oxidative threat to the cells. Mammalian Prx4 was recently discovered to have two roles in the ER: (i) as hydrogen peroxide removing enzyme and (ii) as PDI oxidizing (Figure 17B) $[196,197]$. In less complex eukaryotes such yeast, there is only one gene for ERO1 and no Prx to oxidize PDI, whereas in mammals there are two ERO1 (ERO1 $\alpha$ and ERO1 $\beta$ ) and Prx4. ERO1 $\alpha$ is widespread in diferent cell types, whereas ERO1 $\beta$ is more restricted to the pancreas [36].

Then, it was predicted that the triple mutant Ero1 $\alpha /$ ERO1 $\beta /$ Prx4 mice would present a very severe phenotype, since PDI re-oxidation would be severly affected [198]. Surprisingly, that was not the case. The triple mutant mice displayed only mild phenotype with scurvy-like features. In analogy with classical scurvy, it was hypothesized that the scurvy-like phenotype was associated with reduced ascorbate levels. Oxidation of ascorbate by sulfenic acids, as described by 1-Cys Prx [199] is one possible pathway to divert this vitamin from enzymes involved in the synthesis of collagen. According to their hypothesis, deletion of all three PDI oxidases lead to accumulation of sulfenates (Cys-SOH) and reduction in the steady-state levels of ascorbate. These data indicated that the redox pathway involving ascorbate and sulfenic acids may be widespread, being kinetic characterization required to validate this proposal. Anyway, several other redox reactions take place in the ER during oxidative protein folding, such as those mediated by Gpx7 and Gpx8, which may represent alternative ways to oxidize PDI (reviewed in Ref. [200]).

Protein disulfide isomerase (PDI) has a second activity that is rearrangement of disulfide bonds in proteins, which is called disulfide isomerization (Figure 17D), which is driven by energy minimization during the folding process of the client protein [57]. Disulfide isomerization activity requires PDI in the reduced state to start a sequence of thiol-disulfide exchange reactions that will lead to disulfide shuffling (Figure 13D). Two thiol disulfide exchanges (each one involving two 

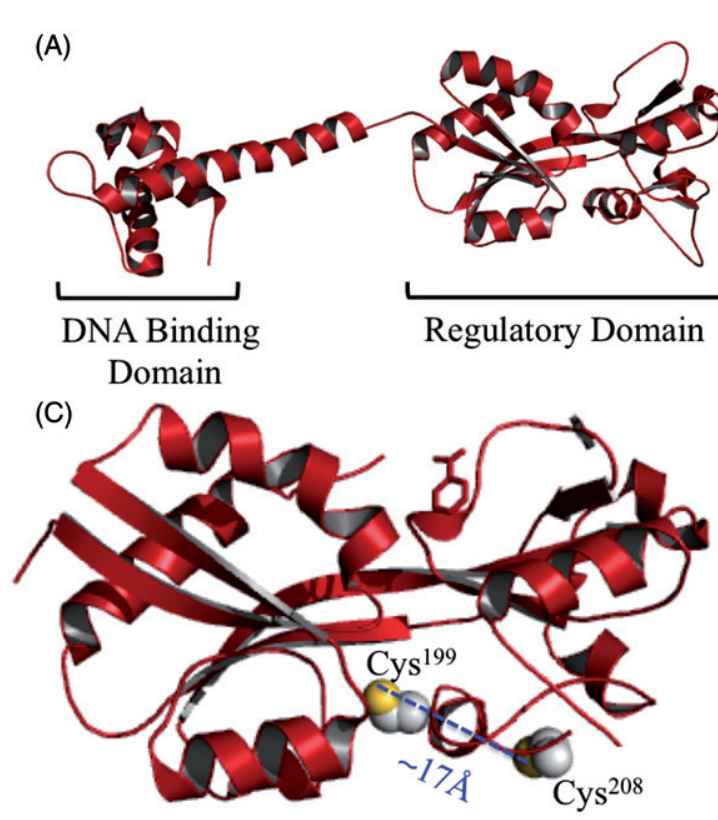
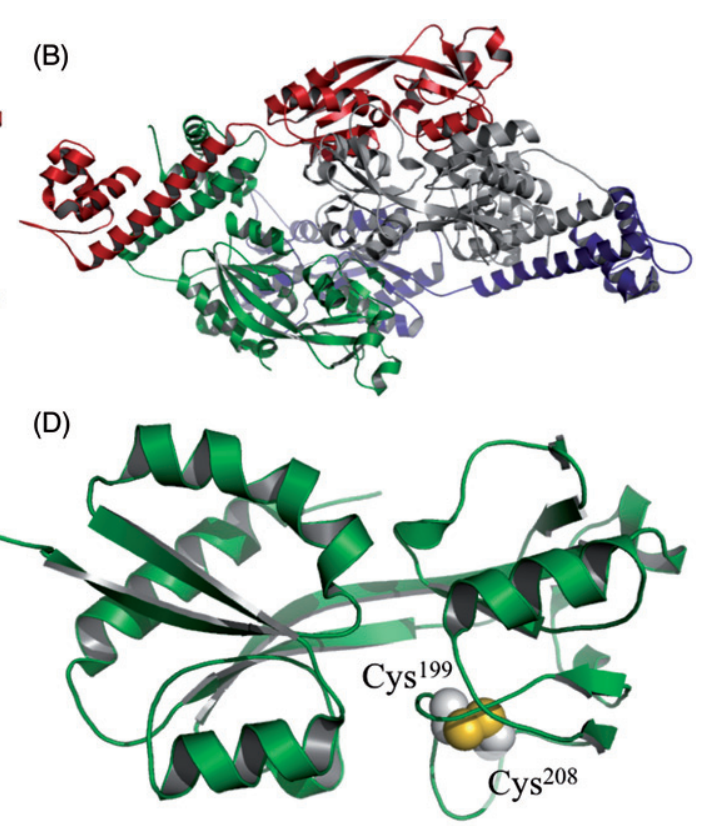

Figure 18. Structural changes of OxyR transcriptional activator. (A) Cartoon representation of the crystallographic structure of $P$. aeruginosa OxyR transcriptional regulator depicting the DNA binding domain ( $\mathrm{N}$-terminal) and redox regulatory domain (C-terminal) (PDB code: 4X6G). (B) OxyR tetramer with the monomers represented by different colors (red, green, blue, and gray). (C) Structure of the redox domain on inactive state of E. coli OxyR (PDB code: 1169). The regulatory redox active cysteines (Cys ${ }^{199}$ and Cys ${ }^{208}$ ) are reduced and $17 \AA$ two away from each other. (D) Structure of the oxidized E. coli OxyR redox domain (PDB code: 116A). As a consequence of oxidation of the nucleophilic Cys ${ }^{199}$, a short $\alpha$ helix unwinds (residues 200-204), allowing the Cys $s^{199}-C_{y s}{ }^{208}$ disulfide formation and the activation of the transcription factor. Cys residues are represented by spheres and colorized by $\mathrm{CPK}(\mathrm{C}=\mathrm{green}$, $\mathrm{N}=$ blue, $\mathrm{O}=$ red, and $\mathrm{S}=$ orange). (See color version of this figure in the online version.)

thiol-disulfide exchange reactions) take place in this process. As a result, the net of overall disulfide isomerization reaction, the oxidation states of reactants and the products are the same, only the configuration of the disulfides among the Cys residues change (Figure 17D). GSH is probably utilized to keep part of the PDI pool in the reduced state (Figure 17C).

In contrast, in the disulfide formation activity, PDI start the process in its oxidized form (disulfide) that acts as an electron acceptor to form disulfide bonds in sulfhydrylcontaining substrate proteins (Figure 17A). Interestingly, isolated $a$ and $a^{\prime}$ domains can reduce disulfides and oxidize dithiols in target proteins, but they cannot shuffle disulfides [201].

In contrast to eukayotes, there is a specialization between disulfide bond formation (carried out by DsbA) and disulfide bond isomerization (carried out by $\mathrm{DsbC}$ ) in bacteria. DsbC is a dimer of two-domain subunits, whose quartenary structure resembles the tertiary structure of PDI [57]. Probably, the U-shape is a required feature for proteins with disulfide isomerase activity. Accordingly, Mia40 is a thiol-disulfide oxidoreductase in the intermembrane space of mitochondria that displays good oxidase activity, but poor disulfide isomerase activity. Furthermore, Mia40 is a monomeric, single domain thiol-disulfide oxidoreductase [202]. Disulfide formation/ isomerization is a vast field that we do not intend to cover here. The reader is referred to reviews such as $[57,192,193]$.

Noteworthy, oxidoreductases not only rely on Cys residues as described so far. Instead, some enzymes utilize lipoamide to carry out thiol/disulfide exchange reactions. In cells, lipoamide (6,8-dithiooctanoic amide) is majority found with the carboxyl group attached to protein by an amide linkage. In this way, the lipoyl group participates as a cofactor in the multienzyme complexes that catalyze the oxidative decarboxylation of $\alpha$-keto acids in oxidative pathways [203]. Lipoamide disulfides are five membered cyclic disulfides which are well known to exhibit $\sim 600$-fold enhanced reactivity due to the ring strain effects related to the dihedral angle (Figure 1). Therefore, these disulfides are more unstable and in principle more prone to oxidize substrates [48].

Traditionally, lipoylated proteins are associated as electron acceptors in oxidative pathways, but they can also act in reductive processes [204]. Indeed, Cys-based peroxidases of the $\mathrm{Ohr} / \mathrm{OsmC}$ family were specifically reduced by lipoylated proteins from bacteria [205], although recently it was shown that in some cases, Trx (but not mycoredoxin system) can also reduce these 

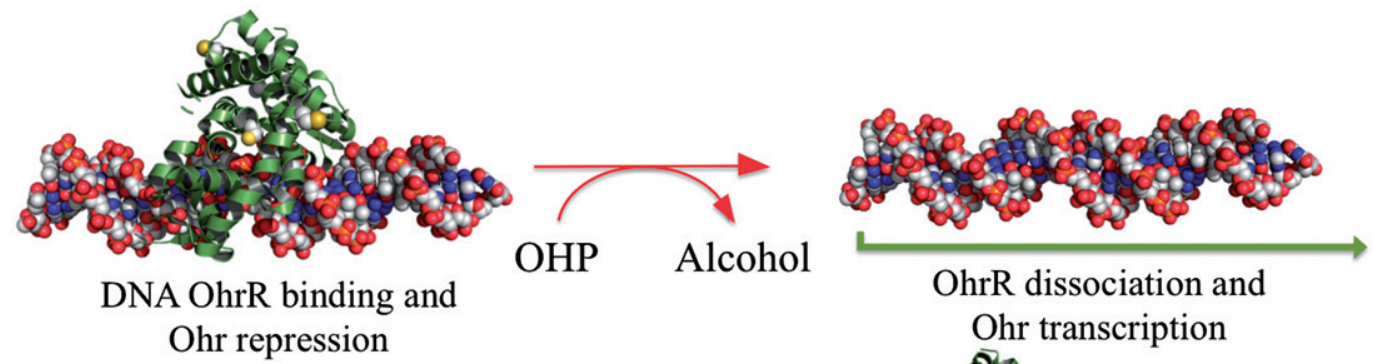

OhrR dissociation and

Ohr transcription
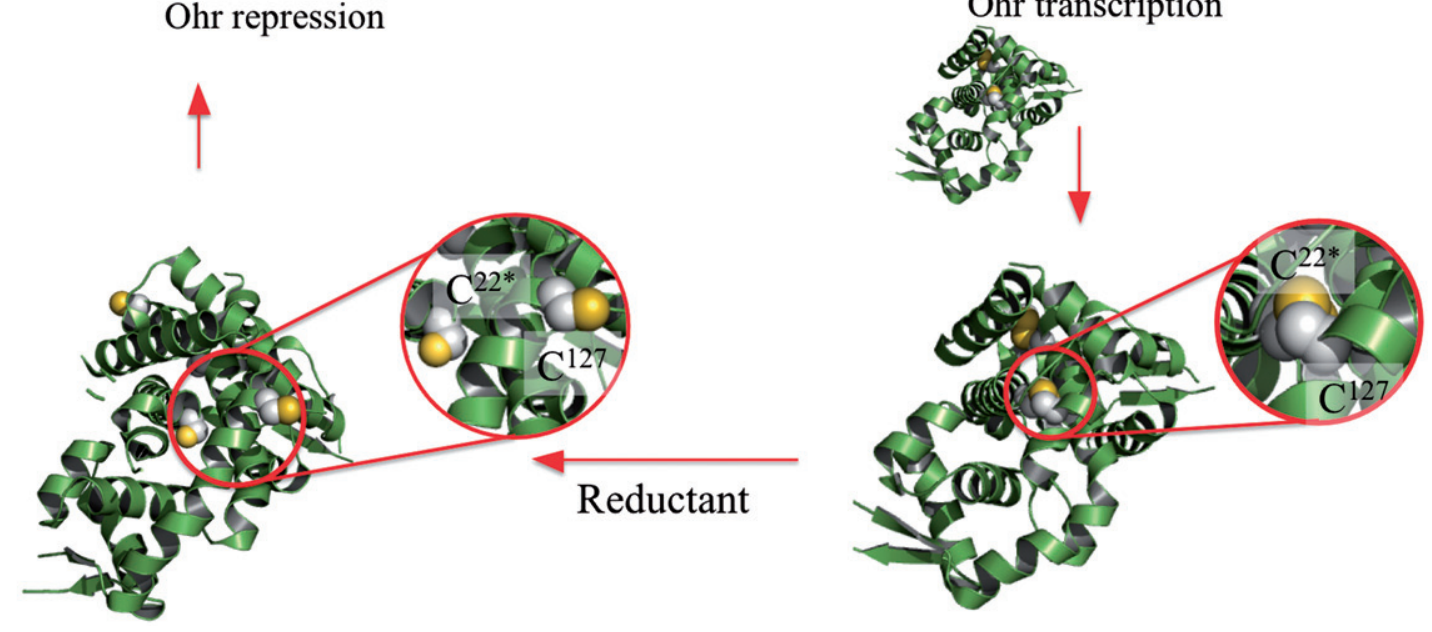

Figure 19. Transcription regulation by OhrR. The $X$. campestris OhrR is a homodimeric transcriptional regulator (repressor), containing two cysteine residues in each polypeptide chain $\left(\mathrm{Cys}^{22}\right.$ and $\mathrm{Cys}^{127}$ ). When Cys residues are reduced, OhrR binds to Ohr promoter, preventing the transcription. Oxidation of $\mathrm{Cys}^{22}$ by organic hydroperoxide (OHP) results in an inter-molecular disulfide formation with $\mathrm{Cys}^{127}$ of the adjacent monomer, triggering conformational modifications, and release of OhrR from Ohr promoter. With the decrease of OHP levels, the OhrR disulfide is reduced back to thiols by a biological reductant (Trx in Chromobacterium violaceum [239]). The OhrR is represented in cartoon and colorized in dark green. The side chains of Cys residues are represented by spheres $(C=$ white and $\mathrm{S}=$ orange). DNA molecules are represent by spheres and colorized as follow: $\mathrm{C}=$ white, $\mathrm{N}=$ blue, $\mathrm{O}=$ red, and $\mathrm{P}=$ dark orange. The coordinates of OhrR crystallographic structures in reduced and oxidized states were obtained at PDB databank under the access codes 2PEX and 2PFB, respectively. (See color version of this figure in the online version.)

substrates [206]. Furthermore, lipoylated E2 from Mycobacterium tuberculosis reduces a thioredoxin-like protein (AhpD), thereby indirectly supporting the peroxidase activity of AhpC [207]. Besides, lipoylated enzymes can donate electrons to ribonucleotide reductase via Grx1 [208]. The factors responsible for the specificity of lipoylated proteins towards their targets are still poorly understood.

To better understand the roles of these thiol-disulfide oxidoreductases in vivo, some convenient tools that were recently developed are the genetically encoded fluorescent probes. The expression of fusions of oxidoreductases such as Grx with fluorescent proteins (as YFP) allowed the estimation of thiol-disulfide redox pairs without the need of cell lysis (reviewed in Ref. $[209,210])$. Through this experimental approach, the GSH/GSSG ratio determined in the cytosol is around 10,000 , i.e. about three orders of magnitude higher than previously thought [211]. Probably, lysosome (vacuole in yeast) contaminated the previous determinations, as this organelle contains high levels of GSSG [212]. Anyway, precautions should be taken since as any experimental methodology is also subject to artifacts (reviewed in Ref. [213]).

\section{Thiol-disulfide interchange reactions in transcriptional redox pathways}

Below are some examples of pathways in which much of the specificity is achieved by protein-protein interactions (including electrostatic interactions) during thiol-disulfide exchange reactions [109]. We focused here in pathways related to the regulation of gene expression (transcription), since this approach can give us an evolutionary perspective. Other redox signaling pathways affected by oxidoreductases are described in depth in other reviews $[74,125]$.

\section{Thiol-disulfide exchange in bacterial transcription factors}

In the environment or during pathogen-host interactions, bacterial cells are routinely exposed to various oxidants that can disturb the cellular redox balance 
I)

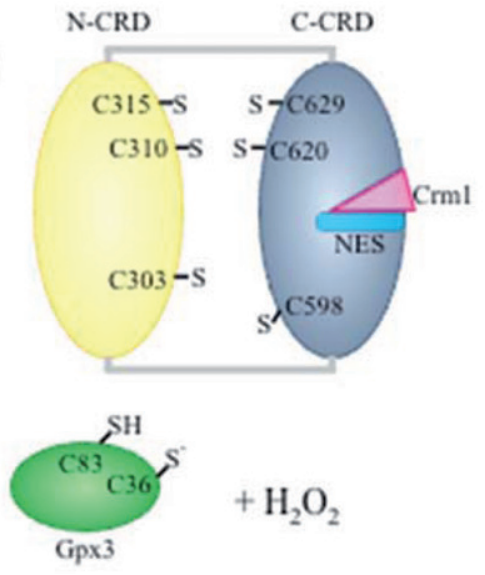

$\operatorname{Trx}$

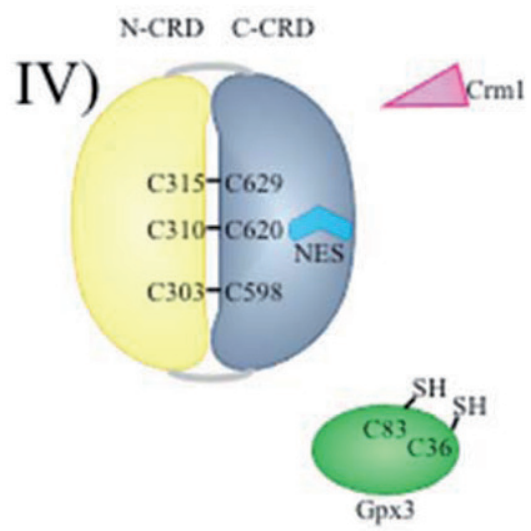

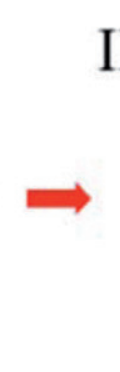

II)
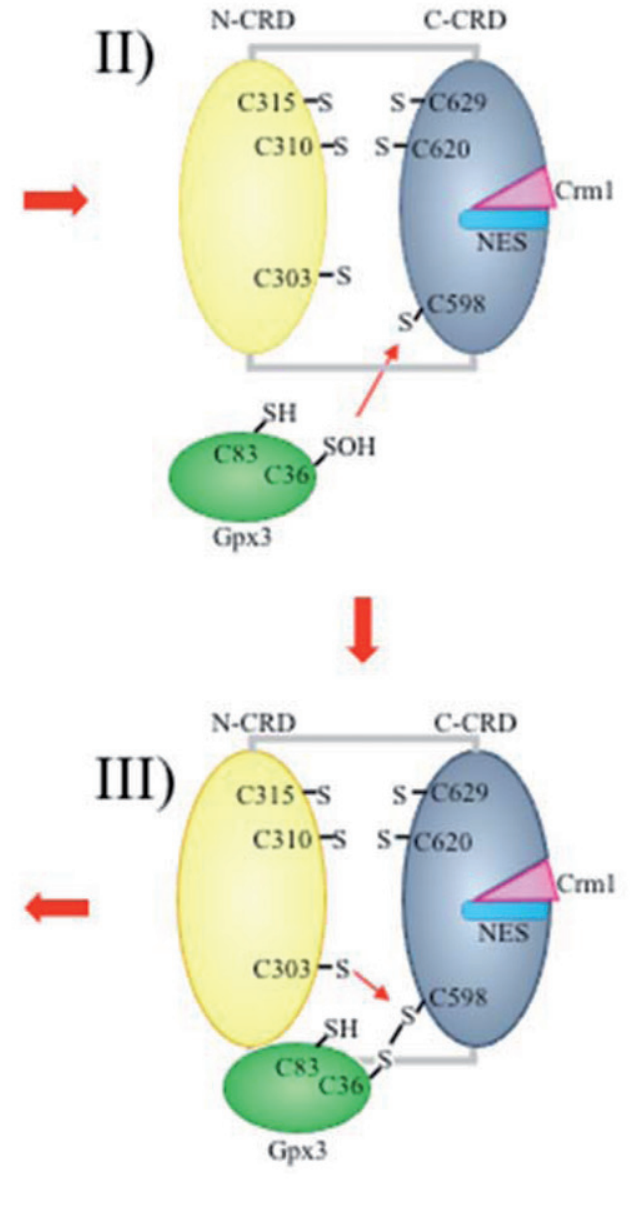

Figure 20. Yap1 activation by Gpx3. (I) Two domains of Yap1 containing regulatory cysteines are represented in yellow (N-terminal Cys Rich Domain = N-CRD) and blue (C-terminal Cys Rich Domain = C-CRD). In its reduced form, Yap1 is located in the cytosol as a consequence of the binding of nuclear exporter Crm1 (pink) in the Yap1 NES domain (light blue). (II) When Cys ${ }^{36}$ of Gpx3 (green) is oxidized to Cys-SOH by hydrogen peroxide and (III) a mixed disulfide is formed between $\mathrm{Cys}^{36}$ of $\mathrm{Gpx3}$ and the Cys ${ }^{598}$ from Yap1 CCRD. This mixed disulfide is resolved by the $\mathrm{Cys}^{303}$ from N-CRD, forming an intramolecular disulfide $\left(\mathrm{C}^{303}-\mathrm{C}^{598}\right)$, resulting in Yap1 topological alterations and the release of Crm1 from NES. Consequently, Yap1 is transported to the nucleus, allowing its physical interaction with promoters of target genes. (See color version of this figure in the online version.)

and damage many macromolecular components including DNA, proteins and lipids [214-216]. Consequently, bacteria have evolved redox-sensing transcription factors (TFs) that make use of redoxsensitive Cys residues or redox-active cofactors to sense specific oxidants and coordinate the transcription during adaptive responses [217-221]. These inducible responses to oxidative stress involve increased expression of antioxidant enzymes (catalases, peroxidases, and superoxide dismutases) that detoxify specific oxidants and other protective proteins that prevent and repair oxidative damage [214]. Elaborated regulatory networks comprise redox sensors and signaling pathways, which show high sensitivity and specificity. Bacterial TFs display high diversity of sensing mechanisms involving sensors based on thiols, heme and Fe-S cluster moieties [216-218].
Here, we describe four examples of thiol-based regulatory proteins that undergo reversible cysteine modification and for which there is experimental evidence about the mechanisms involved in both their oxidation and reduction: the hydrogen peroxide sensor OxyR, the organic hydroperoxide sensor OhrR, the disulfide stress sensor $\sigma$ R-RsrA and the photosynthetic activity sensor PedR. In all of these cases, redox signaling is achieved through selective oxidation of the reactive thiols that display distinct reactivities for different oxidants, followed by specific thiol-disulfide exchange reactions that control their DNA-binding activities.

The E. coli and Pseudomonas aeruginosa OxyR TF are prototypes of redox regulated proteins that are specifically activated by hydrogen peroxide, followed by disulfide bond formation. Recently, the crystallographic structure of the full-length $P$. aeruginosa OxyR was 

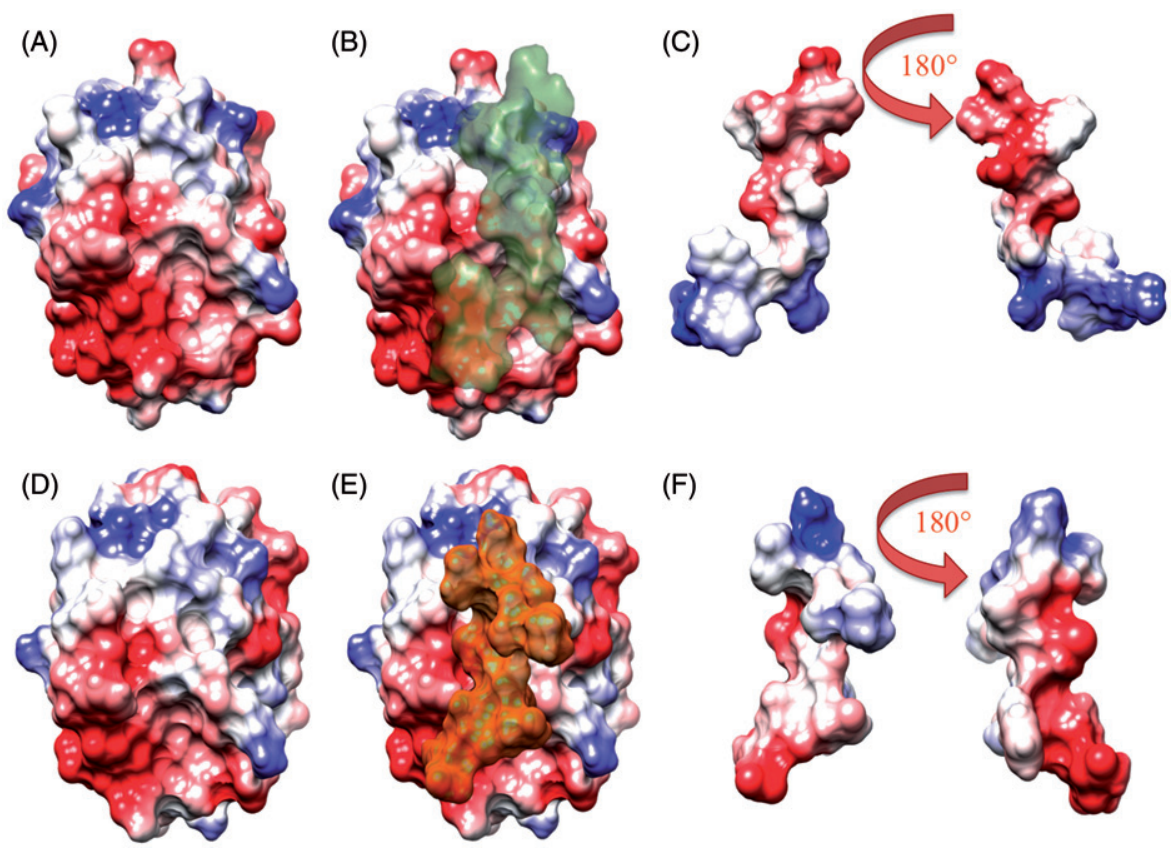

Figure 21. Molecular surfaces showing complimentary charged patches between Trx and TF peptides. (A and D) Charge distribution along HsTrx1 surface, (B) HsTrx1 in complex with a fragment (56-FRFRYVCEGPSHS-68) of the p50 subunit from Nf- $\kappa \beta$ TF (PDB code: $1 \mathrm{MDI})$, represented in dark green with the transparency adjusted to $50 \%$ to clarify the fragment position. (C) Charge distribution on the Nf- $\kappa \beta$ peptide surface at the solvent exposed surface and the HsTrx contact surface (rotated $180^{\circ}$ ), making evident the charges complementarity. (E) HsTrx1 in complex with Ref1 peptide (59 - PATLKICSWNVDG -71) with surface colorized in orange (transparency $=50 \%$ ). (F) Molecular surface of Ref1 fragment showing the solvent exposed surface and the HsTrx contact surface (rotated $180^{\circ}$ ). The surfaces were colorized as follow: blue $=$ positive, white $=$ neutral, and red $=$ negative. The coulombic surface color range from +10 (blue) to -10 (red) ( $\mathrm{kcal} \mathrm{mol}^{-1}$ ). (See color version of this figure in the online version.)

determined, revealing the enzyme possess two distinct globular domains, referred as the $\mathrm{N}$-terminal domain or the DNA binding domain and the C-terminal domain or regulatory domain (RD) [222] (Figure 18A). By crystallographic and gel filtration analysis, evidences were obtained that OxyR is a tetramer [222], which is stabilized by several polar and hydrophobic interactions (Figure 18B). The crystallographic structure of the EcOxyR regulatory domain in the inactive, reduced state was also determined, revealing that the two redox active Cys residues (Cys ${ }^{199}$ and $\mathrm{Cys}^{208}$ ) are separated by $\sim 17 \AA$ (Figure $18 \mathrm{C}$ ). Upon exposure to sub-micromolar levels of hydrogen peroxide, the highly reactive Cys ${ }^{199}$ residue of OxyR is oxidized to a sulfenic acid intermediate (Cys-SOH), which then forms an intramolecular disulfide bond with the $\mathrm{Cys}^{208}$ residue (Figure 18D) as a result of protein remodeling of vicinal regions close to the redox cysteines [222-224]. This $\mathrm{Cys}^{199}{ }^{19 y \mathrm{Cys}^{208}}$ disulfide bond formation in each subunit of OxyR tetramer triggers global structural changes in the protein, resulting in recruitment of the RNA polymerase and activation of the OxyR regulon [221,225], which comprises genes encoding products that minimize the damage caused by hydrogen peroxide (such as catalase, cys-based peroxidases and iron storage proteins) and enzymes involved in disulfide reduction (such as GR, Grx, and Trx) [221]. Oxidized OxyR is deactivated upon reduction of the disulfide bond by the glutaredoxin system [224]. In this thiol-based redox switch, the process of OxyR oxidation is faster than the OxyR re-reduction, allowing transient expression of the antioxidant systems $[223,224,226,227]$. Recently, it has been described that OxyR from $P$. aeruginosa is reduced by the TrxA/TrxB2 thioredoxin system, whose encoding genes are also members of the OxyR regulon [228]. OxyR was also proposed to be activated by other oxidants [229], such as S-nitrosothiols [230]. Curiously, in many Gram-positive bacteria PerR, a Fur family metal-responsive TF, substitutes OxyR as the sensor of hydrogen peroxide [231].

As mentioned before, OhrR is a redox-sensing TF of the MarR family that acts as a specific sensor of organic hydroperoxide through the repression of the ohr (organic hydroperoxide resistance) gene expression [218]. When oxidized by organic hydroperoxides (OHPs), OhrR de-represses the ohr gene, increasing the production of Ohr that catalyzes the reduction of OHPs to the corresponding alcohol [232]. OhrR proteins typically sense OHPs by one conserved Cys in Grampositive bacteria (as detailed in Bacillus subtilis 1-Cys 
OhrR) or two redox-active Cys in Gram-negative bacteria (as detailed in Xanthomonas campestris 2-Cys OhrR) $[218,233]$. In both cases, the initial step involves the oxidation of the $\mathrm{N}$-terminal cysteine to a sulfenic acid (Cys-SOH) intermediate. In the second step, the sulfenic acid undergo a condensation reaction with another thiol, leading formation of an intermolecular disulfide bond in the $X$. campestris 2-Cys OhrR [234] or mixed disulfides (Sthiolation with free cysteine or with bacillithiol) in the $B$. subtilis 1-Cys OhrR $[235,236]$. The disulfide bond formation in OhrR provokes its dissociation from the DNA promoter and transcription of the target ohr gene. Disulfide bond formation or mixed disulfide formation are reversible oxidation products of OhrR and thereby protect this TF from irreversible overoxidation to sulfinic $\left(\right.$ Cys $\left.-\mathrm{SO}_{2} \mathrm{H}^{-}\right)$or sulfonic acid $\left(\mathrm{Cys}-\mathrm{SO}_{3} \mathrm{H}^{-}\right)$. OhrR also appears oxidized as S-bacillithiolated OhrR in sodium hypochlorite $(\mathrm{NaOCl})$ treated cells [237].

OhrR disulfides can be regenerated back to the dithiol form capable to bind DNA, through the catalytic action of thiol disulfide reductases. In the case of $B$. subtilis, specialized thiol-disulfide oxidoreductases (bacilliredoxins $B r x A$ and $B r x B$ ) can reduce the mixed disulfide between S-bacillithiol and 1-Cys OhrR [238], whereas in Chromobacterium violaceum, the intermolecular disulfide in 2-Cys OhrR is specifically reduced by the thioredoxin system [239]. A challenge here is to demonstrate the ability of these thiol-disulfide oxidoreductases to reduce disulfides in OhrR in in vivo systems. A comprehensive view of the mechanism $X$. campestris 2-Cys OhrR redox DNA binding is presented in Figure 19.

The $\sigma$ R-RsrA (Sigma/antisigma) system is the third example of redox-based transcription mechanism that mediates response to thiol oxidation in bacteria. Sigma factors are subunits of RNA polimerases required for the initiation of transcription. These proteins enable specific binding of RNA polymerase to their target promoters. Each molecule of RNA polymerase holoenzyme binds to only one sigma factor and there are specific sigma factors for distinct responses. The specific sigma factor used to initiate transcription of a given gene will vary, depending on the gene and on the environmental signals needed to initiate transcription of that particular gene. Anti-sigma factors are regulatory proteins that bind sigma factors and thereby inhibit their transcriptional activities. RsrA from Streptomyces coelicolor is the best-characterized member of an anti-sigma factor (ZAS) family that senses disulfide stress through a $\mathrm{Zn}(\mathrm{II})$ thiolate group [240,241]. Under reducing conditions, RsrA sequesters $\sigma R$ (its cognate sigma factor) in a transcriptional inactive complex. Under exposure to diamide (a thiol-specific oxidant) RsrA forms a disulfide bond, which causes the release of zinc, structural change of RsrA, and the dissociation of the $\sigma \mathrm{R}$-RsrA complex, thereby allowing transcription of the $\sigma R$ regulon $[240,242,243]$. In $S$. coelicolor, $\sigma R$ controls a large regulon, including a core set of target genes conserved across several actinomycetes, such as those encoding Trx, TrxR, and enzymes for the synthesis of the lowmolecular-weight thiol mycothiol (MSH) [244]. Induction of these disulfide reducing systems creates a negative feedback homeostasis loop, because both Trx and MSH can reduce RsrA (at least in vitro), turning off $\sigma R$ $[240,245]$. Further experiments are needed to determine whether oxidized RsrA is directly reduced by thioredoxin and mycoredoxin in in vivo systems.

The fourth example of thiol-based system is centered on PedR that is a sensor of photosynthetic activity in cyanobacteria. Photosynthetic organisms undergo a drastic change in gene expression after the shift from low to high light conditions, a process known as photosynthetic acclimation response. In the cyanobacterium Synechocystis sp. PCC 6803, this acclimation process is mediated by PedR, a redox-responsive TF belonging to the small LuxR-type regulator subfamily [246]. PedR activation involves the activity of the photosynthetic electron transport chain and the light conditions. Under low light conditions, PedR is oxidized in a dimeric form, capable to bind DNA and thereby directly regulate expression of its target genes. Upon exposure to high light conditions, PedR is reduced by the thioredoxin system, causing its transient inactivation. The reducing equivalents that are transferred from Trx to PedR are supplied by the photosynthetic electron transport chain $[246,247]$. Orthologs of PedR containing a C-terminal extension with three conserved Cys residues are found exclusively in cyanobacterial species [246].

In conclusion, it is evident that specific thiol-based systems evolved in bacteria to mount the distinct responses to various oxidants through discrete thioldisulfide exchange pathways.

\section{Thiol-disulfide exchange in yeast redox-sensing transcription pathways}

Whereas some bacterial TFs such as OxyR and OhrR act as direct sensors and simultaneously as transducer of redox signals (i.e. regulation of transcription), in eukaryotic systems the functions of sensing and regulation are separated in distinct proteins, increasing the complexity of the pathways. In some cases, highly reactive proteins, like GPx- or Prx-type peroxidases, act as redox sensors of oxidants and specifically transmit these signals to downstream TFs through selective protein-protein interactions and thiol-disulfide exchange reactions. 
In yeast, the classical system supporting this model is the hydrogen peroxide signaling pathway controlled by the TF Yap1 from S. cerevisiae [248-250]. Yap1 is a basic leucine zipper (bZIP) TF that responds to hydrogen peroxide by activating the expression of genes for antioxidant enzymes and components of thiol homeostasis $[251,258]$. The activation mechanism of Yap1 in response to hydrogen peroxide is complex, involving redox-mediated subcellular localization of Yap1 and its interaction with glutathione peroxidase 3 (Gpx3), the sensor of the peroxide in this pathway $[252,253]$. The Yap1 protein contains two Cys-rich domains (CRDs) that are important for signaling, an $\mathrm{N}$-terminal domain $(\mathrm{N}$ CRD) with three Cys residues $\left(\mathrm{Cys}^{303}, \mathrm{Cys}^{310}\right.$, and $\mathrm{Cys}^{315}$ ) and an C-terminal domain (C-CRD) containing other three Cys residues $\left(\mathrm{Cys}^{598}, \mathrm{Cys}^{620}\right.$, and $\mathrm{Cys}^{629}$ ) and a nuclear export sequence (NES). Under non-stress conditions, Yap 1 is mainly in the cytoplasm due to the action of the nuclear exporter $\mathrm{Crm} 1$ that recognizes NES in Yap1 [254] (Figure 20, step I). Hydrogen peroxide oxidizes $\mathrm{Gpx} 3$ into a $\mathrm{Cys}^{36}$ sulfenic acid (Cys-SOH; Figure 20, step II), which condenses with Yap1 $\mathrm{Cys}^{598}$, giving rise to a Yap1-Gpx3 mixed disulfide intermediate (Figure 20, step III). This transient mixed disulfide is then resolved into the Yap1 intra-molecular Cys ${ }^{303}-\mathrm{Cys}^{598}$ disulfide [253], followed by formation of other intramolecular disulfide bonds [255] (Figure 20, step IV). These disulfide bonds between the C-CRD and N-CRD domains cause structural changes in Yap1, masking the NES present in the C-CRD domain [256]. Consequently, the Yap1-Crm1 complex is disrupted and Yap1 accumulates in the nucleus, leading to the activation of target genes (reviewed in Ref. [248]). Both Gpx3 and Yap1 are specifically reduced by the thioredoxin system upon removal of the stress, restoring the localization of Yap1 in the cytoplasm [249,253]. A third protein involved in this pathway is Ybp1 that physically interacts with Yap1 and thereby stimulates nuclear accumulation of this TF induced by hydrogen peroxide [257]. In addition to hydrogen peroxide, Yap1 responds to other chemicals such as diamide, being activated by other thiol-based mechanism [258].

Therefore, Cys-based peroxidases (including Gpx3) are the major sensors of hydrogen peroxide in yeast, whereas in E. coli the TF OxyR plays this role. Indeed, a yeast strain deleted for the five Prx genes and three Gpx genes is still viable, but lost its capacity to transcriptionally respond to hydrogen peroxide stimuli [259]. This difference in the responses to hydrogen peroxide between prokaryotes and eukaryotes might be related with the cellular compartmentalization that allows regulation through transport of TFs into distinct cellular compartments.
As mentioned before, besides Cys-based peroxidases, Trxs are also capable to activate TFs and other proteins involved in signal transduction in a redox regulated manner. Noteworthy, in many cases, only the reduced or the oxidized Trx binds to a target protein (more details below in mammalian systems). However, Trx reacts only slowly with oxidants such as hydrogen peroxide, making this process unlikely on chemical grounds [260]. Since most Prxs are reduced by Trx, this oxidoreductase is concomitantly oxidized in the disulfide state. Possibly, Prx could mediate the transfer of oxidizing equivalents from hydrogen peroxide to Trx, affecting signal transduction pathways dependent on this disulfide reductase. We could name this mechanism as the "Prx-Trx model", which gained support with the finding that overoxidation of Prx from Schizosaccharomyces pombe does not result in Trx oxidation, allowing this oxidoreductase to reduce other targets such as ribonucleotide reductase and methionine sulfoxide reductase [261]. Still according to this model, it is expected a specific physical interaction between Prx and Trx if they are involved in signal transduction pathways. Indeed, structural features in yeast 2-CysPrx (Tsa1) that are also conserved in mammalian Prx appear to be responsible for its specific reduction by ScTrx1 or ScTrx2 [118]. Possibly, Trx but not other thiol-disulfide reductases can recognize structural features in 2-Cys Prx. Further evidences for this Trx-Prx model of redox regulation are described below in mammalian systems.

\section{Thiol-disulfide exchange in mammalian redox-sensing transcription pathways}

Following the trend of increasing complexity, in mammalian cells the redox regulated pathways contain more proteins and the corresponding mechanisms involve transport of TFs into distinct cellular compartments. This is an extensive subject that we do not intend to fully cover. Anyway, one of the most studied redox regulated TFs in mammalian cells is NF- $\kappa B[262,263]$ and it will described here in line with the previous sections. NF- $\kappa B$ transcriptional activity is critical for processes such as immunity and inflammation (reviewed in Ref. [264]). Active NF- $\kappa B$ with the ability to bind to specific elements in the promoter of target genes is a dimer, whose subunit composition may vary. The classical NF- $\kappa B$ is composed of the p50 and RelA (p65) subunits. All the NF- $\kappa B$ subunits share the Rel-homology domain (RHD), which is involved in the DNA binding, dimerization and complexation with $\mathrm{I}-\kappa \mathrm{B}$ subunits. $\mathrm{I}-\kappa \mathrm{B}$ subunits are inhibitory proteins that provide the first level of NF- $\kappa B$ regulation through the sequestration of this TF in the cytosol. Under appropriate stimuli, I-KB dissociates from 
$\mathrm{NF}-\mathrm{KB}$ allowing its translocation to the nucleus and activation of transcription (reviewed in Ref. [264]).

Thiol-based regulation of NF- $\mathrm{KB}$ was suggested by analysis of the DNA binding activity of this TF [262]. Sitedirected mutagenesis suggested that HsTrx1 stimulates DNA binding by reduction of a disulfide bond involving $\mathrm{Cys}^{62}$ of NF-KB [262]. Indeed, transient expression or exogenous application of HsTrx1 resulted in a dosedependent inhibition of NF- $\kappa \mathrm{B}$ activity, as demonstrated in gel shift and transactivation experiments [263]. Furthermore, as described throughout this review, the solution structure of HsTrx1 in a mixed disulfide with a 13-residue peptide containing $\mathrm{Cys}^{62}$ of p50 (Figure 21A and $B$ ) revealed that this complex is stabilized by numerous hydrogen-bonding, electrostatic, and hydrophobic interactions that confer substrate specificity [265]. Therefore, these features follow the trend described above for Trx recognition of their targets (in the "Trx system" section), including the complementarity of charges in the electronic surfaces of HsTrx1 and $\mathrm{NF}-\kappa \mathrm{B}$. Not only the DNA binding activity of NF- $\kappa B$ is redox modulated, but also its translocation from cytosol to the nucleus is also modulated by HsTrx1 (reviewed in Ref. [74]). The dissociation of the I- $\kappa B / N F-\kappa B$ complex is inhibited by reduced HsTrx1, leading to the accumulation of this TF in the cytosol [266].

In contrast to the effects on NF- $\kappa B$, HsTrx1 enhanced activator protein-1 (AP-1) transcriptional activity [263], by an indirect mechanism. AP-1 is a heterodimeric TF composed by the products of the c-fos and c-jun protooncogenes. Dimerization occurs through interaction between leucine zipper domains, which allows proper orientation of a region rich in basic amino acids that forms the DNA-binding domain (reviewed in Ref. [267]). As for NF-KB, the DNA binding activity of AP-1 is redox modulated through a single conserved $C y s$ residue in the DNA-binding domain of the heterodimer. Another level of redox regulation is achieved by a nuclear protein (named Ref-1 or APE1) that can reduce the redox active Cys residue and thereby stimulate DNA-binding activity of AP-1 in vitro [268]. Remarkably, Ref-1 is not only a Cysbased redox protein but it is also endowed with apurinic/apyrimidinic endonuclease activity [269], suggesting a cross-talk between redox regulation of gene expression and DNA repair.

Ref-1/APE1's duality in performing both endonuclease and Cys-based redox chemistry is unique to mammals and these activities are separated in distinct structural domains. For instance, APE1 in zebrafish lacks any redox function, yet it is fully active as an AP endonuclease [280]. Later it was shown that Ref-1/APE1 not only reduced AP-1, but also other TFs with redox active Cys residues such as NF- $\kappa B, \mathrm{p} 53$, and HIF- $1 \alpha$. Remarkably, the ability of Ref-1/APE1 to reduce Cys residues in TFs is related in multiple steps in carcinogenesis (reviewed in Ref. [271]).

Therefore, Ref-1/APE1 appears to be a thiol-disulfide oxidoreductase dedicated to the reduction of TFs, although the mechanism underlying this process is not fully elucidated. $\mathrm{Cys}^{65}$ is the nucleophilic thiol that attacks the disulfide bond (or sulfenic acid) in the TF, generating a mixed disulfide bond between the Ref-1/ APE1 and the TF. Then, the resolution step is very complex, which is related to the fact that human Ref-1/ APE1 contains seven Cys residues, all except $\mathrm{Cys}^{65}$ and $\mathrm{Cys}^{138}$ are conserved in zebrafish APE [272]. Moreover, the identification of the steps in resolution is a challenge, since no disulfide bonds are observed in the crystal structures of zebrafish APE1 or human Ref-1/ APE1; and no Cys residues are close to each other to form intramolecular disulfide bonds without structural rearrangements [270, reviewed in Ref. 271]. Initially, it was thought that Ref-1-TF mixed disulfide would be the resolved by $\mathrm{Cys}^{93}$, leading to the reduction of Cys residues in the TF and to an intra-molecular disulfide in Ref-1/APE1 between $\mathrm{Cys}^{65}$ and $\mathrm{Cys}^{93}$ [271], but the mechanism is more complex, involving disulfide shuffling among the seven Cys residues. Results with Cys mutants of Ref-1/APE1 are consistent with a role for $\mathrm{Cys}^{65}$ as the nucleophilic cysteine, while $\mathrm{Cys}^{93}$ and $\mathrm{Cys}^{99}$ playing roles at the final steps of a sequence of thioldisulfide exchange reactions among all seven Cys residues of Ref-1/APE1 [272]. This disulfide isomerase process in Ref-1/APE1 resembles in several aspects the sequence of thiol-disulfide exchange reactions that occurs in BPTI and Thimet oligopeptidase (see "Catalysis of thiol-disulfide exchange reaction" section), as well as the reactions catalyzed by PDI.

In spite of this complex mechanism, after reduction of a TF, Ref-1/APE1 requires to be reduced in order to turnover. HsTrx1 is specifically responsible for Ref-1/ APE1 reduction $[268,269]$. Therefore, the sequence of thiol-disulfide exchange reactions required to activate a TF involves at least three proteins.

$$
\text { HsTrx } 1 \rightarrow \text { Ref-1/APE1 } \rightarrow \text { TF (Example: AP-1 or NF- } \kappa \text { B) }
$$

This is in contrast to the bacterial (that requires only one protein, OxyR) and yeast (that requires two proteins, Gpx3 and Yap1) systems. Other mammalian proteins (such as Prx and TrxR) may operate upstream to HsTrx1, reducing or oxidizing this oxidoreductase and increasing the complexity of the pathways. In the pathways mediated by Ref-1/APE1, the stimuli that activate these TFs are still not identified [271].

Details of the molecular mechanism by which HsTrx1 recognizes Ref-1/APE1 as a substrate came from 
structural biology. The NMR solution structure of the HsTrx1 mixed disulfide with a peptide containing the redox active Cys of Ref-1/APE1 was obtained and compared with the similar HsTrx1-NF- $\kappa B$ structure [273]. As described in the "Trx system" section, HsTrx1 possesses a deep hydrophobic groove that participates in the recognition of Ref-1/APE1 as a substrate (Figure 21D-F), similar conformation as observed in the HsTrx1NF- $\kappa B$ structure (Figure 21A-C). However, the orientation of Ref-1 and NF- $\kappa$ B peptides in the hydrophobic groove is opposite in terms of their $\mathrm{N}$ - and C-extremities, and taking the reactive Cys residues as references [273]. Furthermore, in contrast to the HsTrx1-NF- $\kappa B$ structure, electrostatic factors appear to play minor roles in the stabilization of HsTrx1-Ref-1/APE1 complex [273]. In both solution structures, the complexes complexes were also stabilized by mixed disulfides, in addition to noncovalent interactions.

Although pathways that activate TFs in mammals comprise various proteins, a simpler pathway was recently described that presents similar features to the yeast Gpx3-Yap1 pathway. The activation of a TF (STAT3) by mammalian Prx (Prx2) displayed a similar mechanism of transmission of oxidizing equivalents [274]. As expected for a sensor, Prx2 is rapidly oxidized by peroxide, generating a sulfenic acid that condenses with a Cys residue of STAT3. The mixed disulfide between Prx2 and STAT3 is then reduced by a resolving Cys of STAT3 [274].

This model is consistent with chemical and biological aspects of redox signaling: (a) the sensor (Prx2 or Gpx3) is highly reactive towards hydroperoxides and (b) the TF (STAT3 or Yap1) that appear oxidized in biological systems. In line with these observations, Prx1 was also described as a sensor protein that transmitted oxidizing equivalents and thereby activate other messenger proteins not necessarily TFs [275-277]. As mentioned above, NF- $\kappa B$ and AP1 are two TFs that are also redox-regulated by HsTrx1. Since Trx enzymes can be reduced by TrxR and oxidized by Prx, these two enzymes may also affect signaling pathways.

In contrast, signaling proteins whose activities are dependent on Cys residues, such as PTP1B and PTEN are frequently reported to be oxidized in various biological systems. Frequently it is assumed that PTP1B and PTEN are directly oxidized by hydrogen peroxide, although this is not always supported by kinetics [250]. Indeed, PTP1B and PTEN react slowly with hydrogen peroxide (rate constant about $10 \mathrm{M}^{-1} \mathrm{~s}^{-1}$ ) and are not abundant proteins. Since Prx enzymes react one million times faster with hydrogen peroxide and are very abundant proteins, these peroxidases should outcompete PTP1B and PTEN for hydroperoxides. More extensive discussion on this subject can be found in [278] (accompanying review).

As mentioned in the "Thiol-disulfide exchange in yeast redox-sensing transcription pathways" section, another mechanism for hydrogen peroxide signaling is also plausible both in biological as well as in chemical grounds would involve not only Prx, but also Trx (that we referred to "Prx-Trx model"). Most Prxs are reduced by Trx, which consequently becomes oxidized, in an intra-molecular disulfide state. Possibly, Trx (or other oxidoreductases) could then transfer oxidizing equivalents to phosphatases or TFs (such as NF- $\mathrm{KB}$ ), among other proteins. Indeed, it is known for a long time that several signal transduction pathways are activated by the oxidized, but not by the reduced form of Trx. For instance, only reduced form of HsTrx1 binds Ask-1, thereby inhibiting its kinase activity. The oxidation of HsTrx1 leads to the physical dissociation of the complex and, consequently, to the activation of Ask-1, ensuring apoptosis [279]. In line with this observation, reduced HsTrx1 (but not oxidized form) activates the MKK4-NF$\kappa \mathrm{B}$ pathway leading to induction of $\mathrm{Mn}-\mathrm{SOD}$ expression [280].

Further evidence for the Prx-Trx model came from studies of HsTrx1 oxidation in the presence of HsPrx1 and hydrogen peroxide [120]. As described in the "Trx system" section, HsTrx1 has three non-canonical Cys residues, besides $\mathrm{Cys}^{32}$ and $\mathrm{Cys}^{35}$ that take part in the classical $\mathrm{C}-\mathrm{X}-\mathrm{X}-\mathrm{C}$ motif. The $\mathrm{Cys}^{62}$ and $\mathrm{Cys}^{69}$ can also form a disulfide that impairs the thiol-disulfide oxidoreductase, by disrupting interactions between Trx and its target protein [119]. The two-disulfide HsTrx1 was generated in A549 cells under oxidative stress, which was formed from oxidation of HsTrx 1 catalyzed by Prx 1 in the presence of hydrogen peroxide [120]. This accumulation of oxidized HsTrx 1 that received oxidized equivalents from hydrogen peroxide, mediated by Prx 1 could then signal redox sensitive pathways such the Ask1 mentioned above.

Remarkably, HsGrx1 but not the HsTrxR1 was capable to reduce the non-canonical disulfide between $\mathrm{Cys}^{62}$ and $\mathrm{Cys}^{69}$ in HsTrx1 through the monothiol mechanism [120], indicating a complex redox interaction among at least three specific and distinct partners. Redox signaling is a complex process and probably more features underlying this process are to be revealed.

\section{Conclusions and perspectives}

Thiol-disulfide exchange reactions are frequently overlooked in redox signaling, although they confer specificity through protein-protein interactions. Indeed, oxidoreductases such as Trx and Grx are highly efficient 
in reducing target disulfides and at the same time present high specificity towards their substrates, which is achieved by non-covalent interactions such as electrostatic and hydrophobic interactions and hydrogen bonds. In contrast, un-catalyzed thiol-disulfide exchange reactions between aliphatic low molecular weight compounds are very slow, being unlikely to occur in cells. Since reactants and products in thiol-disulfide reactions contain the same functional groups, it is a challenge to characterize kinetics of such highly reversible reactions. Therefore, tools to better characterize these reactions are required, besides the steady-state coupled systems based on the oxidation of $\mathrm{NAD}(\mathrm{P}) \mathrm{H}$ that are already available. Genetically encoded probes appear to be nice tools to study thiol/disulfide pools but care should be taken to avoid artifacts, such as pH effects [213]. Structural biology will probably continue to be a relevant methodology to reveal mechanistic aspects underlying redox processes as well as to raise new hypothesis necessary for the continuous development in the field. A challenge is the determination of the structures of protein complexes between thiol-disulfide oxidoreductases and their targets.

\section{Declaration of interest}

This work was supported by grant 13/07937-8 from the Fundação de Amparo à Pesquisa do Estado de São Paulo.

\section{References}

[1] Netto LE, Oliveira MA, Monteiro G, Demasi AP, Cussiol JR, Discola $\mathrm{KF}$, et al. Reactive cysteine in proteins: protein folding, antioxidant defense, redox signaling and more. Comp Biochem Physiol C Toxicol Pharmacol 2007; 146:180-193.

[2] Marino SM, Gladyshev VN. Proteomics: mapping reactive cysteines. Nat Chem Biol 2011;7:72-73.

[3] Winterbourn CC, Metodiewa D. Reactivity of biologically important thiol compounds with superoxide and hydrogen peroxide. Free Radic Biol Med 1999;27:322-328.

[4] Singh R, Whitesides GM. Thiol-disulfide interchange. In: Patai S, Rappoport Z, eds. Sulphur-containing functional groups. Chichester, UK: John Wiley \& Sons, Inc.; 1993:633-658.

[5] Aida M, Nagata, C. An ab initio MO study on the disulfide bond: properties concerning the characteristic SS dihedral angle. Theor Chim Acta 1986;70:73-80.

[6] Nelson KJ, Parsonage D, Hall A, Karplus PA, Poole LB. Cysteine $\mathrm{pK}_{\mathrm{a}}$ values for the bacterial peroxiredoxin AhpC. Biochemistry 2008;47:12860-12868.

[7] Parsonage D, Karplus PA, Poole LB. Substrate specificity and redox potential of $\mathrm{AhpC}$, a bacterial peroxiredoxin. Proc Natl Acad Sci USA 2008;105:8209-8214.

[8] Roberts BR, Wood ZA, Jönsson TJ, Poole LB, Karplus PA. Oxidized and synchrotron cleaved structures of the disulfide redox center in the $\mathrm{N}$-terminal domain of Salmonella typhimurium AhpF. Protein Sci 2005;14:2414-2420.

[9] Nelson JW, Creighton TE. Reactivity and ionization of the active site cysteine residues of DsbA, a protein required for disulfide bond formation in vivo. Biochemistry 1994;33:5974-5983.

[10] Grauschopf U, Winther, JR, Korber P, Zander T, Dallinger $\mathrm{P}$, Bardwell JCA. Why is DsbA such an oxidizing disulfide catalyst? Cell 1995;83:947-955.

[11] Wunderlich M, Glockshuber R. Redox properties of protein disulfide isomerase (DsbA) from Escherichia coli. Protein Sci 1993;2:717-726.

[12] Hirasawa $M$, Schürmann $P$, Jacquot JP, Manieri W, Jacquot $P$, Keryer $E$, et al. Oxidation-reduction properties of chloroplast thioredoxins, ferredoxin: thioredoxin reductase, and thioredoxin f-regulated enzymes. Biochemistry 1999;38:5200-5205.

[13] Foloppe N, Nilsson L. The glutaredoxin -C-P-Y-Cmotif: influence of peripheral residues. Structure 2004;12:289-300.

[14] Åslund F, Berndt KD, Holmgren A. Redox potentials of glutaredoxins and other thiol-disulfide oxidoreductases of the thioredoxin superfamily determined by direct protein-protein redox equilibria. J Biol Chem 1997;272:30780-30786.

[15] Discola KF, Oliveira MA, Cussiol JRR, Monteiro G, Bárcena $J A$, Porras $P$, et al. Structural aspects of the distinct biochemical properties of glutaredoxin 1 and glutaredoxin 2 from Saccharomyces cerevisiae. J Mol Biol 2009;385:889-901.

[16] Veine DM, Arscott LD, Williams CH Jr. Redox potentials for yeast, Escherichia coli and human glutathione reductase relative to the NAD+/NADH redox couple: enzyme forms active in catalysis. Biochemistry 1998;37:1557515582.

[17] Sahlman L, Williams CH Jr. Lipoamide dehydrogenase from Escherichia coli. Steady-state kinetics of the physiological reaction. J Biol Chem 1989;264:8039-8045.

[18] Schultz PG, Au KG, Walsh CT. Directed mutagenesis of the redox-active disulfide in the flavoenzyme mercuric ion reductase. Biochemistry 1985;24:6840-6848.

[19] Fox B, Walsh CT. Mercuric reductase. Purification and characterization of a transposon-encoded flavoprotein containing an oxidation-reduction-active disulfide. J Biol Chem 1982;257:2498-2503.

[20] Karala AR, Lappi AK, Ruddock LW. Modulation of an active-site cysteine $\mathrm{pK}_{\mathrm{a}}$ allows PDI to act as a catalyst of both disulfide bond formation and isomerization. J Mol Biol 2010;396:883-892.

[21] Chambers JE, Tavender TJ, Oka OB, Warwood S, Knight D, Bulleid NJ. The reduction potential of the active site disulfides of human protein disulfide isomerase limits oxidation of the enzyme by Ero1 $\alpha$. J Biol Chem 2010;285:29200-29207.

[22] Reutimann $H$, Straub B, Luisi PL, Holmgren A. A conformational study of thioredoxin and its tryptic fragments. J Biol Chem 1981;256:6796-6803.

[23] Chivers PT, Prehoda KE, Volkman BF, Kim BM, Markley JL, Raines RT. Microscopic $\mathrm{pK}_{\mathrm{a}}$ values of Escherichia coli thioredoxin. Biochemistry 1997;36:14985-14991.

[24] Mössner E, Huber-Wunderlich M, Rietsch A, Beckwith J, Glockshuber R, Åslund F. Importance of redox potential for the in vivo function of the cytoplasmic disulfide 
reductant thioredoxin from Escherichia coli. J Biol Chem 1999;274:25254-25259.

[25] Mason JT, Kim SK, Knaff DB, Wood MJ. Thermodynamic basis for redox regulation of the Yap1 signal transduction pathway. Biochemistry 2006;45: 13409-13417.

[26] O'Donnell ME, Williams $\mathrm{CH}$ Jr. Proton stoichiometry in the reduction of the FAD and disulfide of Escherichia coli thioredoxin reductase. Evidence for a base at the active site. J Biol Chem 1983;258:13795-13805.

[27] Williams $\mathrm{CH}$, Jr. Mechanism and structure of thioredoxin reductase from Escherichia coli. FASEB J 1995;13: 1267-1276.

[28] Reckenfelderbaumer N, Krauth-Siegel RL. Catalytic properties, thiol pK value, and redox potential of Trypanosoma brucei tryparedoxin. J Biol Chem 2002;277:17548-17555.

[29] Gilbert HF. Molecular and cellular aspects of thioldisulfide exchange. Adv Enzymol Relat Areas Mol Biol 1990;63:69-172.

[30] Laurent TC, Moore EC, Reichard P. Enzymatic synthesis of deoxyribonucleotides. IV. Isolation and characterization of thioredoxin the hydrogen donor from Escherichia coli. J Biol Chem 1964;239:3436-3444.

[31] Boschi-Muller S, Azza S, Sanglier-Cianferani S, Talfournier F, Van Dorsselear A, Branlant G. A sulfenic acid enzyme intermediate is involved in the catalytic mechanism of peptide methionine sulfoxide reductase from Escherichia coli. J Biol Chem 2000;275:35908-35913.

[32] Lowther WT, Brot N, Weissbach H, Honek HF, Matthews, B. Thiol-disulfide exchange is involved in the catalytic mechanism of peptide methionine sulfoxide reductase. Proc Natl Acad Sci USA 2000;97:6463-6468.

[33] Chae HZ, Chung SJ, Rhee SG. Thioredoxin-dependent peroxide reductase from yeast. J Biol Chem 1994;269:27670-27678.

[34] Hansen RE, Roth D, Winther JR. Quantifying the global cellular thiol-disulfide status. Proc Natl Acad Sci USA 2009; 106:422-427.

[35] Jensen KS, Hansen RE, Winther JR. Kinetic and thermodynamic aspects of cellular thiol-disulfide redox regulation. Antioxid Redox Signal 2009;11:1047-1058.

[36] Nagy P. Kinetics and mechanisms of thiol-disulfide exchange covering direct substitution and thiol oxidation-mediated pathways. Antioxid Redox Sign 2013;18:1623-1641.

[37] Ferrer-Sueta G, Manta B, Botti H, Radi R, Trujillo M, Denicola $A$. Factors affecting protein thiol reactivity and specificity in peroxide reduction. Chem Res Toxicol 2011;24:434-450.

[38] Trujillo M, Clippe A, Manta B, Ferrer-Sueta G, Smeets A, Declercq JP, et al. Pre-steady state kinetic characterization of human peroxiredoxin 5: taking advantage of Trp84 fluorescence increase upon oxidation. Arch Biochem Biophys 2007;467:95-106.

[39] Bulaj G, Kortemme T, Goldenberg DP. Ionization-reactivity relationships for cysteine thiols in polypeptides. Biochemistry 1998;37:8965-8972.

[40] Szajewski RP, Whitesides GM. Rate constants and equilibrium constants for thiol-disulfide interchange reactions involving oxidized glutathione. J Am Chem Soc 1980;102:2011-2026.
[41] Wilson JM, Bayer RJ, Hupe DJ. Structure-reactivity correlations for the thiol-disulfide interchange reaction. J Am Chem Soc 1977;99:7922-7926.

[42] DeCollo TV, Lees WJ. Effects of aromatic thiols on thioldisulfide interchange reactions that occur during protein folding. J Org Chem 2001;66:4244-4249.

[43] Fernandes PA, Ramos MJ. Theoretical insights into the mechanism for thiol/disulfide exchange. Chemistry 2004;10:257-266.

[44] Hansen RE, Østergaard H, Winther JR. Increasing the reactivity of an artificial dithiol-disulfide pair through modification of the electrostatic milieu. Biochemistry 2005;44:5899-5906.

[45] Hupe DJ, Wu D. Effect of charged substituents on rates of the thiol-disulfide interchange reaction. J Org Chem 1980;45:3100-3103.

[46] Snyder GH, Cennerazzo MJ, Karalis AJ, Field D. Electrostatic influence of local cysteine environments on disulfide exchange kinetics. Biochemistry 1981;20:6509-6519.

[47] Snyder GH. Free energy relationships for thiol-disulfide interchange reactions between charged molecules in 50\% methanol. J Biol Chem 1984;259:7468-7472.

[48] Singh R, Whitesides GM. Degenerate intermolecular thiolate-disulfide interchange involving cyclic five-membered disulfides is faster by $\sim 10^{3}$ than that involving sixor seven-membered disulfides. J Am Chem Soc 1990;112:6304-6309.

[49] Sideris DP, Petrakis N, Katrakili N, Mikropoulou D, Gallo A, Ciofi-Baffoni $S$, et al. A novel intermembrane spacetargeting signal docks cysteines onto Mia40 during mitochondrial oxidative folding. J Cell Biol 2009;187: 1007-1022.

[50] Wunderlich M, Glockshuber R. In vivo control of redox potential during protein folding catalyzed by bacterial protein disulfide-isomerase (DsbA). J Biol Chem 1993;268:24547-24550

[51] Dadlez M, Kim PS. Rapid formation of the native 14-38 disulfide bond in the early stages of BPTI folding. Biochemistry 1996;35:16153-16164.

[52] Demasi M, Piassa Filho GM, Castro LM, Ferreira JC, Rioli V, Ferro ES. Oligomerization of the cysteinyl-rich oligopeptidase EP24.15 is triggered by S-glutathionylation. Free Radic Biol Med 2008;44:1180-1190.

[53] Creighton TE. The two-disulphide intermediates and the folding pathway of reduced pancreatic trypsin inhibitor. J Mol Biol 1975;95:167-199.

[54] Holmgren A. Thioredoxin catalyzes the reduction of insulin disulfides by dithiothreitol and dihydrolipoamide. J Biol Chem 1979;254:9627-9632.

[55] Katti SK, LeMaster DM, Eklund H. Crystal structure of thioredoxin from Escherichia coli at $1.68 \AA$ resolution. J Mol Biol 1990;212:167-184.

[56] Cheng Z, Zhang J, Ballou DP, Williams CH, Jr. Reactivity of thioredoxin as a protein thiol-disulfide oxidoreductase. Chem Rev 2011;111:5768-5783.

[57] Gruber CW, Cemazar M, Heras B, Martin JL, Craik DJ. Protein disulfide isomerase: the structure of oxidative folding. Trends Biochem Sci 2006;31:455-464.

[58] Ingles-Prieto A, Ibarra-Molero B, Delgado-Delgado A, Perez-Jimenez R, Fernandez JM, Gaucher EA, et al. Conservation of protein structure over four billion years. Structure 2013;21:1690-1697. 
[59] Holmgren A. Tryptophan fluorescence study of conformational transitions of the oxidized and reduced form of thioredoxin. J Biol Chem 1972;247:1992-1998.

[60] Lee DY, Ahn BY, Kim KS. A thioredoxin from the hyperthermophilic archaeon Methanococcus jannaschii has a glutaredoxin-like fold but thioredoxin-like activities. Biochemistry 2000;39:6652-6659.

[61] Mössner $E$, Huber-Wunderlich $M$, Glockshuber $R$. Characterization of Escherichia coli thioredoxin variants mimicking the active-sites of other thiol/disulfide oxidoreductases. Protein Sci 1998;7:1233-1244.

[62] Li H, Hanson C, Fuchs JA, Woodward C, Thomas GJ Jr. Determination of the $\mathrm{pK}_{\mathrm{a}}$ values of active-center cysteines, cysteines-32 and -35, in Escherichia coli thioredoxin by Raman spectroscopy. Biochemistry 1993;32:5800-5808.

[63] Vohník S, Hanson C, Tuma R, Fuchs JA, Woodward C, Thomas GJ, Jr. Conformation, stability, and active-site cysteine titrations of Escherichia coli D26A thioredoxin probed by Raman spectroscopy. Protein Sci 1998;7: 193-200.

[64] Chivers PT, Laboissiere MC, Raines RT. The CXXC motif: imperatives for the formation of native disulfide bonds in the cell. EMBO J 1996;15:2659-2667.

[65] Forman-Kay JD, Clore GM, Gronenborn AM. Relationship between electrostatics and redox function in human thioredoxin: characterization of $\mathrm{pH}$ titration shifts using two-dimensional homo- and heteronuclear NMR. Biochemistry 1992;31:3442-3452.

[66] Krimm I, Lemaire S, Ruelland E, Miginiac-Maslow M, Jaquot JP, Hirasawa $M$, et al. The single mutation Trp35 $\rightarrow$ Ala in the 35-40 redox site of Chlamydomonas reinhardtii thioredoxin $\mathrm{h}$ affects its biochemical activity and the $\mathrm{pH}$ dependence of C36-C39 1H-13C NMR. Eur J Biochem 1998;255:185-195.

[67] Dyson HJ, Jeng MF, Tennant LL, Slaby I, Lindell M, Cui DS, et al. Effects of buried charged groups on cysteine thiol ionization and reactivity in Escherichia coli thioredoxin: structural and functional characterization of mutants of Asp 26 and Lys 57. Biochemistry 1997;36:2622-2636.

[68] Takahashi N, Creighton TE. On the reactivity and ionization of the active site cysteine residues of Escherichia coli thioredoxin. Biochemistry 1996;35:8342-8353.

[69] Roos G, Foloppe N, Van Laer K, Wyns L, Nilsson L, Geerlings $P$, Messens J. How thioredoxin dissociates its mixed disulfide. PLoS Comput Biol 2009;5:e1000461.

[70] Graminski GF, Kubo Y, Armstrong RN. Spectroscopic and kinetic evidence for the thiolate anion of glutathione at the active site of glutathione S-transferase. Biochemistry 1989;28:3562-3568.

[71] Moutevelis E, Warwicker J. Prediction of $\mathrm{pK}_{\mathrm{a}}$ and redox properties in the thioredoxin superfamily. Protein Sci 2004;13:2744-2752.

[72] Biterova El, Turanov AA, Gladyshev VN, Barycki JJ. Crystal structures of oxidized and reduced mitochondrial thioredoxin reductase provide molecular details of the reaction mechanism. Proc Natl Acad Sci USA 2005;102:15018-15023.

[73] Lennon BW, Williams CH Jr, Ludwig ML. Twists in catalysis: alternating conformations of Escherichia coli thioredoxin reductase. Science 2000;289:1190-1194.
[74] Lillig $\mathrm{CH}$, Holmgren A. Thioredoxin and related molecules - from biology to health and disease. Antioxid Redox Signaling 2007;9:25-47.

[75] Sandalova T, Zhong L, Lindqvist Y, Holmgren A, Schneider $G$. Three-dimensional structure of a mammalian thioredoxin reductase: implications for mechanism and evolution of a selenocysteine-dependent enzyme. Proc Natl Acad Sci USA 2001;98:9533-9538.

[76] Shaked Z, Szajewski RP, Whitesides GM. Rates of thioldisulfide interchange reactions involving proteins and kinetic measurements of thiol $\mathrm{pK}_{\mathrm{a}}$ values. Biochemistry 1980;19:4156-4166.

[77] LeMaster DM. Structural determinants of the catalytic reactivity of the buried cysteine of Escherichia coli thioredoxin. Biochemistry 1996;35: 14876-14881.

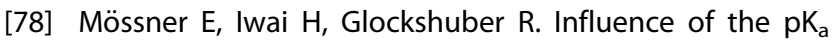
value of the buried, active-site cysteine on the redox properties of thioredoxin-like oxidoreductases. FEBS Lett 2000;477:21-26.

[79] Kortemme T, Creighton TE. Ionization of cysteine residues at the termini of model alpha-helical peptides. Relevance to unusual thiol $\mathrm{pK}_{\mathrm{a}}$ values in proteins of the thioredoxin family. J Mol Biol 1995;253:799-812.

[80] Roos G, Foloppe N, Messens J. Understanding the $\mathrm{pK}_{\mathrm{a}}$ of redox cysteines: the key role of hydrogen bonding. Antioxid Redox Signal 2013;18:94-127.

[81] Carvalho AT, Swart M, van Stralen JN, Fernandes PA, Ramos MJ, Bickelhaupt FM. Mechanism of thioredoxincatalyzed disulfide reduction. Activation of the buried thiol and role of the variable active-site residues. Phys Chem B 2008;112:2511-2523.

[82] Wynn R, Cocco MJ, Richards FM. Mixed disulfide intermediates during the reduction of disulfides by Escherichia coli thioredoxin. Biochemistry 1995;34: 11807-11813.

[83] Chivers PT, Raines RT. General acid/base catalysis in the active site of Escherichia coli thioredoxin. Biochemistry 1997;36:15810-15816.

[84] Menchise V, Corbier C, Didierjean C, Saviano M, Benedetti $E$, Jacquot JP, Aubry A. Crystal structure of the wild-type and D30A mutant thioredoxin $\mathrm{h}$ of Chlamydomonas reinhardtii and implications for the catalytic mechanism. Biochem J 2001;359:65-75.

[85] Dyson HJ, Tennant LL, Holmgren A. Proton-transfer effects in the active-site region of Escherichia coli thioredoxin using two-dimensional $1 \mathrm{H}$ NMR. Biochemistry 1991;30:4262-4268.

[86] Langsetmo K, Fuchs JA, Woodward C. The conserved, buried aspartic acid in oxidized Escherichia coli thioredoxin has a $\mathrm{pK}_{\mathrm{a}}$ of 7.5. Its titration produces a related shift in global stability. Biochemistry 1991;30:7603-7609.

[87] LeMaster DM, Springer PA, Unkefer CJ. The role of the buried aspartate of Escherichia coli thioredoxin in the activation of the mixed disulfide intermediate. J Biol Chem 1997;272:29998-30001.

[88] Krause G, Holmgren AA. Substitution of the conserved tryptophan 31 in Escherichia coli thioredoxin by sitedirected mutagenesis and structure-function analysis. J Biol Chem 1991;266:4056-4066. 
[89] Cruzeiro-Silva C, Gomes-Neto F, Machado LE, Miyamoto CA, Pinheiro AS, Correa-Pereira $\mathrm{N}$, et al. Hydration and conformational equilibrium in yeast thioredoxin 1: implication for $\mathrm{H}(+)$ exchange. Biochemistry 2014;53:2890-2902.

[90] Iqbal A, Gomes-Neto F, Myiamoto CA, Valente AP, Almeida FC. Dissection of the water cavity of yeast thioredoxin 1: the effect of a hydrophobic residue in the cavity. Biochemistry 2015;54:2429-2442.

[91] Kelley RF, Richards FM. Replacement of proline-76 with alanine eliminates the slowest kinetic phase in thioredoxin folding. Biochemistry 1987;26:6765-6774.

[92] Langsetmo K, Fuchs J, Woodward C. Escherichia coli thioredoxin folds into two compact forms of different stability to urea denaturation. Biochemistry 1989;28:3211-3220.

[93] Maeda K, Hägglund P, Finnie C, Svensson B, Henriksen A. Structural basis for target protein recognition by the protein disulfide reductase thioredoxin. Structure 2006;14:1701-1710.

[94] Martin JL. Thioredoxin - a fold for all reasons. Structure 1995;3:245-250.

[95] Mora-García S, Rodríguez-Suárez R, Wolosiuk RA. Role of electrostatic interactions on the affinity of thioredoxin for target proteins. Recognition of chloroplast fructose1, 6-bisphosphatase by mutant Escherichia coli thioredoxins. J Biol Chem 1998;273:16273-16280.

[96] Oliveira MA, Discola KF, Alves SV, Medrano FJ, Guimarães BG, Netto LE. Insights into the specificity of thioredoxin reductase-thioredoxin interactions. A structural and functional investigation of the yeast thioredoxin system. Biochemistry 2010;49:3317-3326.

[97] Schwarz O, Schürmann $P$, Strotmann H. Kinetics and thioredoxin specificity of thiol modulation of the chloroplast H+-ATPase. J Biol Chem 1997;272:16924-16927.

[98] Wahl MC, Irmler A, Hecker B, Schirmer RH, Becker K. Comparative structural analysis of oxidized and reduced thioredoxin from Drosophila melanogaster. J Mol Biol 2005;345:1119-1130.

[99] Geck MK, Larimer FW, Hartman FC. Identification of residues of spinach thioredoxin $f$ that influence interactions with target enzymes. J Biol Chem 1996;271: 24736-24740.

[100] Knaff DB. Oxidation-reduction properties of thioredoxins and thioredoxin-regulated enzymes. Physiol Plant 2000;110:309-313.

[101] Jacquot JP, Lopez-Jaramillo J, Chueca A, Cherfils J, Lemaire $S$, Chedozeau B, et al. High-level expression of recombinant pea chloroplast fructose-1,6-bisphosphatase and mutagenesis of its regulatory site. Eur J Biochem 1995;229:675-681.

[102] Villeret V, Huang S, Zhang Y, Xue Y, Lipscomb WN. Crystal structure of spinach chloroplast fructose-1,6bisphosphatase at $2.8 \AA$ resolution. Biochemistry 1995;34:4299-4306.

[103] López-Jaramillo J, Chueca A, Jacquot JP, Hermoso R, Lázaro JJ, Sahrawy M, López Gorgé J. High-yield expression of pea thioredoxin $\mathrm{m}$ and assessment of its efficiency in chloroplast fructose-1,6-bisphosphatase activation. Plant Physiol 1997;114:1169-1175.

[104] Balmer Y, Koller A, Val GD, Schürmann P, Buchanan BB. Proteomics uncovers proteins interacting electrostatically with thioredoxin in chloroplasts. Photosynth Res 2004;79:275-280.

[105] Braun H, Lichter A, Haberlein I. Kinetic evidence for protein complexes between thioredoxin and NADPmalate dehydrogenase and presence of a thioredoxin binding site at the $\mathrm{N}$-terminus of the enzyme. Eur J Biochem 1996;240:781-788.

[106] Haberlein I, Vogeler B. Completion of the thioredoxin reaction mechanism: kinetic evidence for protein complexes between thioredoxin and fructose 1,6-bisphosphatase. Biochim Biophys Acta 1995;1253:169-174.

[107] Cejudo FJ, Ferrández J, Cano B, Puerto-Galán L, Guinea $M$. The function of the NADPH thioredoxin reductase C-2-Cys peroxiredoxin system in plastid redox regulation and signalling. FEBS Lett 2012;586:2974-2980.

[108] Poole LB. Bacterial defenses against oxidants: mechanistic features of cysteine-based peroxidases and their flavoprotein reductases. Arch Biochem Biophys 2005;433:240-254.

[109] Meyer Y, Buchanan BB, Vignols F, Reichheld JP. Thioredoxins and glutaredoxins: unifying elements in redox biology. Annu Rev Genet 2009;43:335-367.

[110] Horta BB, Oliveira MA, Discola KF, Cussiol JR, Netto LES. Structural and biochemical characterization of peroxiredoxin $\mathrm{Q} \beta$ from Xylella fastidiosa: catalytic mechanism and high reactivity. J Biol Chem 2010;285:16051-16065.

[111] Amorim GC, Pinheiro AS, Netto LES, Valente AP, Almeida FC. NMR solution structure of the reduced form of thioredoxin 2 from Saccharomyces cerevisiae. J Biomol NMR 2007;38:99-104.

[112] Pinheiro AS, Amorim GC, Netto LES, Almeida FC, Valente AP. NMR solution structure of the reduced form of thioredoxin 1 from Saccharomyces cerevisiae. Proteins 2008;70:584-587.

[113] Berndt C, Schwenn JD, Lillig CH. The specificity of thioredoxins and glutaredoxins is determined by electrostatic and geometric complementarity. Chem Sci 2015;6:7049-7058.

[114] Lin TY. G33D mutant thioredoxin primarily affects the kinetics of reaction with thioredoxin reductase. Probing the structure of the mutant protein. Biochemistry 1999;38:15508-15513.

[115] Lin TY, Chen TS. A positive charge at position 33 of thioredoxin primarily affects its interaction with other proteins but not redox potential. Biochemistry 2004;43:945-952.

[116] Perez-Jimenez R, Li J, Kosuri P, Sanchez-Romero I, Wiita $A P$, Rodriguez-Larrea $D$, et al. Diversity of chemical mechanisms in thioredoxin catalysis revealed by singlemolecule force spectroscopy. Nat Struct Mol Biol 2009;16:890-896.

[117] Palde PB, Carroll KS. A universal entropy-driven mechanism for thioredoxin-target recognition. Proc Natl Acad Sci USA 2015;112:7960-7965.

[118] Tairum CA, Oliveira MA, Horta BB, Zara FJ, Netto LES. Disulfide biochemistry in 2-cys peroxiredoxin: requirement of Glu50 and Arg146 for the reduction of yeast Tsa1 by thioredoxin. J Mol Biol 2012;424:28-41.

[119] Watson WH, Pohl J, Montfort WR, Stuchlik O, Reed MS, Powis G, Jones DP. Redox potential of human thioredoxin 1 and identification of a second dithiol/disulfide motif. J Biol Chem 2003;278:33408-33415. 
[120] Du Y, Zhang H, Zhang X, Lu J, Holmgren A. Thioredoxin 1 is inactivated due to oxidation induced by peroxiredoxin under oxidative stress and reactivated by the glutaredoxin system. J Biol Chem 2013;288:3224132247.

[121] Casagrande S, Bonetto V, Fratelli M, Gianazza E, Eberini I, Massignan $\mathrm{T}$, et al. Glutathionylation of human thioredoxin: a possible crosstalk between the glutathione and thioredoxin systems. Proc Natl Acad Sci USA 2002;99:9745-9749.

[122] Andersen JF, Sanders DA, Gasdaska JR, Weichsel A, Powis G, Montfort WR. Human thioredoxin homodimers: regulation by $\mathrm{pH}$, role of aspartate 60 , and crystal structure of the aspartate $60->$ asparagine mutant. Biochemistry 1997;36:13979-13988.

[123] Weichsel A, Gasdaska JR, Powis G, Montfort WR. Crystal structures of reduced, oxidized, and mutated human thioredoxins: evidence for a regulatory homodimer. Structure 1996;4:735-751.

[124] Wang P, Wu Y, Li X, Ma X, Zhong L. Thioredoxin and thioredoxin reductase control tissue factor activity by thiol redox-dependent mechanism. J Biol Chem 2013;288:3346-3358.

[125] Lee S, Kim SM, Lee RT. Thioredoxin and thioredoxin target proteins: from molecular mechanisms to functional significance. Antioxid Redox Signal 2013;18:1165-1207.

[126] Atkinson HJ, Babbitt PC. An atlas of the thioredoxin fold class reveals the complexity of function-enabling adaptations. PLoS Comput Biol 2009;10:e1000541.

[127] Berndt $\mathrm{C}$, Lillig $\mathrm{CH}$, Holmgren A. Thioredoxins and glutaredoxins as facilitators of protein folding. Biochim Biophys Acta 2008;1783:641-650.

[128] Holmgren A. Hydrogen donor system for Escherichia coli ribonucleoside-diphosphate reductase dependent upon glutathione. Proc Natl Acad Sci USA 1976;73:2275-2279.

[129] Askelöf P, Axelsson K, Eriksson S, Mannervik B. Mechanism of action of enzymes catalyzing thiol-disulfide interchange. Thioltransferases rather than transhydrogenases. FEBS Lett 1974;38:263-267.

[130] Gallogly MM, Starke DW, Mieyal JJ. Mechanistic and kinetic details of catalysis of thiol-disulfide exchange by glutaredoxins and potential mechanisms of regulation. Antioxid Redox Signal 2009;11:1059-1081.

[131] Lillig $\mathrm{CH}$, Berndt C. Glutaredoxins in thiol/disulfide exchange. Antioxid Redox Signal 2013;18:1654-1665.

[132] Bushweller JH, Billeter M, Holmgren A, Wüthrich K. The nuclear magnetic resonance solution structure of the mixed disulfide between Escherichia coli glutaredoxin (C14S) and glutathione. J Mol Biol 1994;235:1585-1597.

[133] Håkansson KO, Winther JR. Structure of glutaredoxin Grx1p C30S mutant from yeast. Acta Crystallogr D Biol Crystallogr 2007;63:288-294.

[134] Nordstrand K, Asslund F, Holmgren A, Otting G, Berndt KD. NMR structure of Escherichia coli glutaredoxin 3glutathione mixed disulfide complex: implications for the enzymatic mechanism. J Mol Biol 1999;286:541-552.

[135] Yang Y, Jao SC, Nanduri S, Starke DW, Mieyal JJ, Qin J. Reactivity of the human thioltransferase (glutaredoxin) C7S, C25S, C78S, C82S mutant and NMR solution structure of its glutathionyl mixed disulfide intermediate reflect catalytic specificity. Biochemistry 1998;37: 17145-17156.
[136] Yu J, Zhang NN, Yin PD, Cui PX, Zhou CZ. Glutathionylation-triggered conformational changes of glutaredoxin Grx1 from the yeast Saccharomyces cerevisiae. Proteins 2008;72:1077-1083.

[137] Deponte M. Glutathione catalysis and the reaction mechanisms of glutathione-dependent enzymes. Biochim Biophys Acta 2013;1830:3217-3266.

[138] Collet JF, D'Souza JC, Jakob U, Bardwell JC. Thioredoxin 2 , an oxidative stress-induced protein, contains a high affinity zinc binding site. J Biol Chem 2003;278:45325-45332.

[139] Bushweller JH, Åslund F, Wüthrich K, Holmgren A. Structural and functional characterization of the mutant Escherichia coli glutaredoxin (C14-S) and its mixed disulfide with glutathione. Biochemistry 1992;31:9288-9293.

[140] Berardi MJ, Bushweller JH. Binding specificity and mechanistic insight into glutaredoxin-catalyzed protein disulfide reduction. J Mol Biol 1999;292:151-161.

[141] Bräutigam L, Schütte LD, Godoy JR, Prozorovski T, Gellert M, Hauptmann G, et al. Vertebrate-specific glutaredoxin is essential for brain development. Proc Natl Acad Sci USA 2011;108:20532-20537.

[142] Gellert M, Venz S, Mitlöhner J, Cott C, Hanschmann EM, Lillig $\mathrm{CH}$. Identification of a dithiol-disulfide switch in collapsin response mediator protein 2 (CRMP2) that is toggled in a model of neuronal differentiation. J Biol Chem 2013;288:35117-35125.

[143] Gallogly MM, Starke DW, Leonberg AK, Ospina SM, Mieyal JJ. Kinetic and mechanistic characterization and versatile catalytic properties of mammalian glutaredoxin 2: implications for intracellular roles. Biochemistry 2008;47:11144-11157.

[144] Rouhier N, Gelhaye E, Jacquot JP. Exploring the active site of plant glutaredoxin by site-directed mutagenesis. FEBS Lett 2002;511:145-149.

[145] Yang YF, Wells WW. Catalytic mechanism of thioltransferase. J Biol Chem 1991;266:12766-12771.

[146] Johansson C, Kavanagh KL, Gileadi O, Oppermann U. Reversible sequestration of active site cysteines in a $2 \mathrm{Fe}-$ 2S-bridged dimer provides a mechanism for glutaredoxin 2 regulation in human mitochondria. J Biol Chem 2007;282:3077-3082.

[147] Lundberg $M$, Holmgren $A$, Johansson $M$. Human glutaredoxin 2 affinity tag for recombinant peptide and protein purification. Protein Expr Purif 2006;45:37-42.

[148] Bräutigam L, Jensen LD, Poschmann G, Nyström S, Bannenberg S, Dreij K, et al. Glutaredoxin regulates vascular development by reversible glutathionylation of sirtuin 1. Proc Natl Acad Sci USA 2013;110:20057-20062.

[149] Berndt C, Poschmann G, Stühler K, Holmgren A, Bräutigam L. Zebrafish heart development is regulated via glutaredoxin 2 dependent migration and survival of neural crest cells. Redox Biol 2014;2:673-678.

[150] Gravina SA, Mieyal JJ. Thioltransferase is a specific glutathionyl mixed disulfide oxidoreductase. Biochemistry 1993;32:3368-3376.

[151] Jensen KS, Pedersen JT, Winther JR, Teilum K. The $\mathrm{pK}_{a}$ value and accessibility of cysteine residues are key determinants for protein substrate discrimination by glutaredoxin. Biochemistry 2014;53:2533-2540. 
[152] Srinivasan U, Mieyal PA, Mieyal JJ. pH profiles indicative of rate-limiting nucleophilic displacement in thioltransferase catalysis. Biochemistry 1997;36:3199-3206.

[153] Holmgren A, Åslund F. Glutaredoxin. Methods Enzymol 1995;252:283-292.

[154] Begas P, Staudachera V, Deponte M. Systematic reevaluation of the bis(2-hydroxyethyl)disulfide (HEDS) assay reveals an alternative mechanism and activity of glutaredoxins. Chem Sci 2015;6;3788-3796.

[155] Eckers E, Bien M, Stroobant V, Herrmann JM, Deponte M. Biochemical characterization of dithiol glutaredoxin 8 from Saccharomyces cerevisiae: the catalytic redox mechanism redox. Biochemistry 2009;48:1410-1423.

[156] Johansson C, Lillig $\mathrm{CH}$, Holmgren A. Human mitochondrial glutaredoxin reduces $\mathrm{S}$-glutathionylated proteins with high affinity accepting electrons from either glutathione or thioredoxin reductase. J Biol Chem 2004;279:7537-7543.

[157] Netto LES, Oliveira MA. Site-directed mutagenesis as a tool to characterize specificity in thiol based redox interactions between proteins and substrates. In: Figurski D, ed. Genetic manipulation of DNA and protein - examples from current research. Croatia: InTech; 2013:91-106.

[158] Fernandes AP, Holmgren A. Glutaredoxins: glutathionedependent redox enzymes with functions far beyond a simple thioredoxin backup system. Antioxid Redox Signal 2004;6:63-74.

[159] Jao SC, English Ospina SM, Berdis AJ, Starke DW, Post $\mathrm{CB}$, Mieyal JJ. Computational and mutational analysis of human glutaredoxin (thioltransferase): probing the molecular basis of the low $\mathrm{pK}_{\mathrm{a}}$ of cysteine 22 and its role in catalysis. Biochemistry 2006;45:4785-4796.

[160] Sun C, Berardi MJ, Bushweller JH. The NMR solution structure of human glutaredoxin in the fully reduced form. J Mol Biol 1998;280:687-701.

[161] Demasi M, Netto LE, Silva GM, Hand A, de Oliveira CL, Bicev RN, et al. Redox regulation of the proteasome via S-glutathionylation. Redox Biol 2013;2:44-51.

[162] Gallogly MM, Mieyal JJ. Mechanisms of reversible protein glutathionylation in redox signaling and oxidative stress. Curr Opin Pharmacol 2007;7:381-391.

[163] Grek CL, Zhang J, Manevich Y, Townsend DM, Tew KD. Causes and consequences of cysteine S-glutathionylation. J Biol Chem 2013;288:26497-26504.

[164] Couturier J, Przybyla-Toscano J, Roret T, Didierjean C, Rouhier $\mathrm{N}$. The roles of glutaredoxins ligating Fe-S clusters: sensing, transfer or repair functions? Biochim Biophys Acta 2015;1853:1513-1527.

[165] Flohé L. The trypanothione system and the opportunities it offers to create drugs for the neglected kinetoplast diseases. Biotechnol Adv 2012;30:294-301.

[166] Krauth-Siegel RL, Comini MA. Redox control in trypanosomatids, parasitic protozoa with trypanothione-based thiol metabolism. Biochem Biophys Acta 2008;1780:1236-1248.

[167] Fairlamb AH, Blackburn P, Ulrich P, Chait BT, Cerami A. Trypanothione: a novel bis (glutathionyl) spermidine cofactor for glutathione reductase in trypanosomatids. Science 1985;227:1485-1487.

[168] Moutiez M, Meziane-Cherie D, Aumercier M, Sergheraert C, Tartar A. Compared reactivities of trypanothione and glutathione in conjugation reactions. Chem Pharm Bull 1994;42:2641-2644.

[169] Hofmann B, Budde H, Bruns K, Guerrero SA, Kalisz HM, Menge $U$, et al. Structures of tryparedoxins revealing interaction with trypanothione. Biol Chem 2001;382:459-471.

[170] Montemartini $M$, Kalisz HM, Kiess $M$, Nogoceke $E$, Singh $M$, Steinert $P$, Flohé $L$. Sequence, heterologous expression and functional characterization of a novel tryparedoxin from Crithidia fasciculata. Biol Chem 1998;379:1137-1142.

[171] Krumme D, Budde $H$, Hecht HJ, Menge U, Ohlenschlager $O$, Ross $A$, et al. NMR studies of the interaction of tryparedoxin with redox-inactive substrate homologues. Biochemistry 2003;42:14720-14728.

[172] Steinert P, Plank-Schumacher K, Montemartini M, Hecht HJ, Flohé L. Permutation of the active site motif of tryparedoxin 2. Biol Chem 2000;381:211-219.

[173] Budde H, Flohé L, Hecht HJ, Hofmann B, Stehr M, Wissing $\mathrm{J}$, Lünsdorf $\mathrm{H}$. Kinetics and redox-sensitive oligomerisation reveal negative subunit cooperativity in tryparedoxin peroxidase of Trypanosoma brucei brucei. Biol Chem 2003;384:619-633.

[174] Piñeyro MD, Pizarro JC, Lema F, Pritsch O, Cayota A, Bentley GA, Robello C. Crystal structure of the tryparedoxin peroxidase from the human parasite Trypanosoma cruzi. J Struct Biol 2005;150:11-22.

[175] Xiao R, Lundström-Ljung J, Holmgren A, Gilbert HF. Catalysis of thiol/disulfide exchange. Glutaredoxin 1 and protein-disulfide isomerase use different mechanisms to enhance oxidase and reductase activities. J Biol Chem 2005;280:21099-21106.

[176] Hernández G, Anderson JS, LeMaster DM. Electrostatic stabilization and general base catalysis in the active site of the human protein disulfide isomerase a domain monitored by hydrogen exchange. Chembiochem 2008;9:768-778.

[177] Guddat LW, Bardwell JC, Martin JL. Crystal structures of reduced and oxidized DsbA: investigation of domain motion and thiolate stabilization. Structure 1998;6:757-767.

[178] Wang C, Li W, Ren J, Fang J, Ke H, Gong W, et al. Structural insights into the redox-regulated dynamic conformations of human protein disulfide isomerase. Antioxid Redox Signal 2013;19:36-45.

[179] Depuydt M, Messens J, Collet JF. How proteins form disulfide bonds. Antioxid Redox Signal 2011;15:49-66.

[180] Joelson T, Sjöberg BM, Eklund H. Modifications of the active center of T4 thioredoxin by site-directed mutagenesis. J Biol Chem 1990;265:3183-3188.

[181] Krause G, Lundström J, Barea JL, Pueyo de la Cuesta C, Holmgren A. Mimicking the active site of protein disulfide-isomerase by substitution of proline 34 in Escherichia coli thioredoxin. J Biol Chem 1991;266:9494-9500.

[182] Chivers PT, Prehoda KE, Raines RT. The CXXC motif: a rheostat in the active site. Biochemistry 1997;36:4061-4066.

[183] Ren G, Stephan D, Xu Z, Zheng Y, Tang D, Harrison RS, et al. Properties of the thioredoxin fold superfamily are modulated by a single amino acid residue. J Biol Chem 2009;284:10150-10159. 
[184] Kadokura H, Tian H, Zander T, Bardwell JC, Beckwith J. Snapshots of DsbA in action: detection of proteins in the process of oxidative folding. Science 2004;303:534-537.

[185] Su D, Berndt C, Fomenko DE, Holmgren A, Gladyshev VN. A conserved cis-proline precludes metal binding by the active site thiolates in members of the thioredoxin family of proteins. Biochemistry 2007;46:6903-6910.

[186] Inaba K, Murakami S, Suzuki M, Nakagawa A, Yamashita E, Okada K, Ito K. Crystal structure of the DsbB-DsbA complex reveals a mechanism of disulfide bond generation. Cell 2006;127:789-801.

[187] Bewley KD, Dey M, Bjork RE, Mitra S, Chobot SE, Drennan $\mathrm{CL}$, Elliott $\mathrm{SJ}$. Rheostat re-wired: alternative hypotheses for the control of thioredoxin reduction potentials. PLoS One 2015;10:e0122466.

[188] Flohé L. The fairytale of the GSSG/GSH redox potential. Biochim Biophys Acta 2013;1830:3139-3142.

[189] Debarbieux L, Beckwith J. On the functional interchangeability, oxidant versus reductant, of members of the thioredoxin superfamily. J Bacteriol 2000;182:723-727.

[190] Stewart EJ, Åslund F, Beckwith J. Disulfide bond formation in the Escherichia coli cytoplasm: an in vivo role reversal for the thioredoxins. EMBO J 1998;17:5543-5550.

[191] Ortenberg R, Beckwith J. Functions of thiol-disulfide oxidoreductases in E. coli: redox myths, realities, and practicalities. Antioxid Redox Signal 2003;54:403-411.

[192] Hudson DA, Gannon SA, Thorpe C. Oxidative protein folding: from thiol-disulfide exchange reactions to the redox poise of the endoplasmic reticulum. Free Radic Biol Med 2015;80:171-182.

[193] Denoncin K, Collet JF. Disulfide bond formation in the bacterial periplasm: major achievements and challenges ahead. Antioxid Redox Signal 2013;19:63-71.

[194] Anfinsen CB. Principles that govern the folding of protein chains. Science 1973;181:223-230.

[195] Creighton TE. Kinetic study of protein unfolding and refolding using urea gradient electrophoresis. J Mol Biol 1980;137:61-80.

[196] Zito E, Melo EP, Yang Y, Wahlander Å, Neubert TA, Ron D. Oxidative protein folding by an endoplasmic reticulum-localized peroxiredoxin. Mol Cell 2010;40: 787-797.

[197] Tavender TJ, Springate JJ, Bulleid NJ. Recycling of peroxiredoxin IV provides a novel pathway for disulphide formation in the endoplasmic reticulum. EMBO J 2010;29:4185-4197.

[198] Zito E, Hansen HG, Yeo GS, Fujii J, Ron D. Endoplasmic reticulum thiol oxidase deficiency leads to ascorbic acid depletion and noncanonical scurvy in mice. Mol Cell 2012;48:39-51.

[199] Monteiro G, Horta BB, Pimenta DC, Augusto O, Netto LES. Reduction of 1-Cys peroxiredoxins by ascorbate changes the thiol-specific antioxidant paradigm, revealing another function of vitamin C. Proc Natl Acad Sci USA 2007;104:4886-4891.

[200] Laurindo FR, Pescatore LA, Fernandes Dde C. Protein disulfide isomerase in redox cell signaling and homeostasis. Free Radic Biol Med 2012;52:1954-1969.

[201] Darby NJ, Creighton TE. Characterization of the active site cysteine residues of the thioredoxin-like domains of protein disulfide isomerase. Biochemistry 1995;34: 16770-16780.

[202] Hudson DA, Thorpe C. Mia40 is a facile oxidant of unfolded reduced proteins but shows minimal isomerase activity. Arch Biochem Biophys 2015;579:1-7.

[203] Reed L. A trail of research from lipoic acid to alpha-keto acid dehydrogenase complexes. J Biol Chem 2001;276:38329-38336.

[204] Bunik VI. 2-Oxo acid dehydrogenase complexes in redox regulation. Eur J Biochem 2003;270:1036-1042.

[205] Cussiol JR, Alegria TG, Szweda LI, Netto LES. Ohr (organic hydroperoxide resistance protein) possesses a previously undescribed activity, lipoyl-dependent peroxidase. J Biol Chem 2010;285:21943-21950.

[206] Si M, Wang J, Xiao X, Guan J, Zhang Y, Ding W, et al. Ohr protects Corynebacterium glutamicum against organic hydroperoxide induced oxidative stress. PLoS One 2015;10:e0131634.

[207] Bryk R, Lima CD, Erdjument-Bromage H, Tempst P, Nathan C. Metabolic enzymes of mycobacteria linked to antioxidant defense by a thioredoxin-like protein. Science 2002;295:1073-1077.

[208] Beckwith J. Genetic suppressors and recovery of repressed biochemical memory. J Biol Chem 2009;284:12585-12592.

[209] Björnberg O, Ostergaard H, Winther JR. Measuring intracellular redox conditions using GFP-based sensors. Antioxid Redox Signal 2006;8:354-361.

[210] Meyer AJ, Dick TP. Fluorescent protein-based redox probes. Antioxid Redox Signal 2010;13:621-650.

[211] Østergaard H, Tachibana C, Winther JR. Monitoring disulfide bond formation in the eukaryotic cytosol. J Cell Biol 2004;166:337-345.

[212] Morgan B, Ezerina D, Amoako TN, Riemer J, Seedorf M, Dick TP. Multiple glutathione disulfide removal pathways mediate cytosolic redox homeostasis. Nat Chem Biol 2013;9:119-125.

[213] Schwarzländer M, Dick TP, Meye AJ, Morgan B. Dissecting redox biology using fluorescent protein sensors. Antioxid Redox Signal 2015. [Epub ahead of print]. doi: 10.1089/ars.2015.6266.

[214] Imlay JA. The molecular mechanisms and physiological consequences of oxidative stress: lessons from a model bacterium. Nat Rev Microbiol 2013;11:443-454.

[215] Loi VV, Rossius M, Antelmann H. Redox regulation by reversible protein S-thiolation in bacteria. Front Microbiol 2015;6:187.

[216] Luebke JL, Giedroc DP. Cysteine sulfur chemistry in transcriptional regulators at the host-bacterial pathogen interface. Biochemistry 2015;54:3235-3249.

[217] Green J, Paget MS. Bacterial redox sensors. Nat Rev Microbiol 2004;2:954-966.

[218] Antelmann H, Helmann JD. Thiol-based redox switches and gene regulation. Antioxid. Redox Signal 2011;14:1049-1063.

[219] Chen PR, Brugarolas P, He C. Redox signaling in human pathogens. Antioxid Redox Signal 2011;14:1107-1118.

[220] Vázquez-Torres A. Redox active thiol sensors of oxidative and nitrosative stress. Antioxid Redox Signal 2012;17:1201-1214.

[221] Imlay JA. Transcription factors that defend bacteria against reactive oxygen species. Annu Rev Microbiol 2015;69:93-108. 
[222] Jo I, Chung IY, Bae HW, Kim JS, Song S, Cho YH, Ha NC. Structural details of the OxyR peroxide-sensing mechanism. Proc Natl Acad Sci USA 2015;112:6443-6448.

[223] Lee C, Lee SM, Mukhopadhyay P, Kim SJ, Lee SC, Ahn WS, et al. Redox regulation of OxyR requires specific disulfide bond formation involving a rapid kinetic reaction path. Nat Struct Mol Biol 2004;11:1179-1185.

[224] Zheng M, Åslund F, Storz G. Activation of the OxyR transcription factor by reversible disulfide bond formation. Science 1998;279:1718-1721.

[225] Choi H, Kim S, Mukhopadhyay P, Cho S, Woo J, Storz G, Ryu SE. Structural basis of the redox switch in the OxyR transcription factor. Cell 2001;105:103-113.

[226] Tao K. In vivo oxidation-reduction kinetics of OxyR, the transcriptional activator for an oxidative stressinducible regulon in Escherichia coli. FEBS Lett 1999;457:90-92.

[227] Åslund F, Zheng M, Beckwith J, Storz G. Regulation of the OxyR transcription factor by hydrogen peroxide and the cellular thiol-disulfide status. Proc Natl Acad Sci USA 1999;96:6161-6165.

[228] Wei Q, Minh PN, Dötsch A, Hildebrand F, Panmanee W, Elfarash $A$, et al. Global regulation of gene expression by OxyR in an important human opportunistic pathogen. Nucleic Acids Res 2012;40:4320-4333.

[229] Kim SO, Merchant K, Nudelman R, Beyer WF, JrKeng T, DeAngelo J, et al. OxyR: a molecular code for redoxrelated signaling. Cell 2002;109:383-396.

[230] Seth D, Hausladen A, Wang YJ, Stamler JS. Endogenous protein S-Nitrosylation in E. coli: regulation by OxyR. Science 2012;336:470-473.

[231] Lee JW, Helmann JD. The PerR transcription factor senses $\mathrm{H}_{2} \mathrm{O}_{2}$ by metal-catalysed histidine oxidation. Nature 2006;440:363-367.

[232] Cussiol JRR, Alves SV, Oliveira MA, Netto LES. Organic hydroperoxide resistance gene encodes a thiol-dependent peroxidase. J Biol Chem 2003;278:11570-11578.

[233] Dubbs JM, Mongkolsuk S. Peroxide-sensing transcriptional regulators in bacteria. J Bacteriol 2012;194:5495-5503.

[234] Panmanee W, Vattanaviboon P, Poole LB, Mongkolsuk S. Novel organic hydroperoxide-sensing and responding mechanisms for OhrR, a major bacterial sensor and regulator of organic hydroperoxide stress. J Bacteriol 2006;188:1389-1395.

[235] Fuangthong M, Helmann JD. The OhrR repressor senses organic hydroperoxides by reversible formation of a cysteine-sulfenic acid derivative. Proc Natl Acad Sci USA 2002;99:6690-6695.

[236] Lee JW, Soonsanga S, Helmann JD. A complex thiolate switch regulates the Bacillus subtilis organic peroxide sensor OhrR. Proc Natl Acad Sci USA 2007;104:87438748.

[237] Chi BK, Gronau K, Mäder U, Hessling B, Becher D, Antelmann H. S-bacillithiolation protects against hypochlorite stress in Bacillus subtilis as revealed by transcriptomics and redox proteomics. Mol Cell Proteomics 2011;10:M111.009506.

[238] Gaballa A, Chi BK, Roberts AA, Becher D, Hamilton CJ, Antelmann $\mathrm{H}$, Helmann JD. Redox regulation in Bacillus subtilis: the bacilliredoxins $\mathrm{BrxA}(\mathrm{YphP})$ and $\mathrm{BrxB}(\mathrm{YqiW})$ function in de-bacillithiolation of S-bacillithiolated OhrR and MetE. Antioxid Redox Signal 2014;21:357-367.
[239] da Silva Neto JF, Negretto CC, Netto LES. Analysis of the organic hydroperoxide response of Chromobacterium violaceum reveals that $\mathrm{OhrR}$ is a cys-based redox sensor regulated by thioredoxin. PLoS One 2012;7:e47090.

[240] Kang JG, Paget MS, Seok YJ, Hahn MY, Bae JB, Hahn JS, et al. RsrA, an anti-sigma factor regulated by redox change. EMBO J 1999;18:4292-4298.

[241] Jung YG, Cho YB, Kim MS, Yoo JS, Hong SH, Roe JH. Determinants of redox sensitivity in RsrA, a zinc-containing anti-sigma factor for regulating thiol oxidative stress response. Nucleic Acids Res 2011;39: 7586-7597.

[242] Paget MS, Bae JB, Hahn MY, Li W, Kleanthous C, Roe JH, Buttner MJ. Mutational analysis of RsrA, a zinc-binding anti-sigma factor with a thiol-disulphide redox switch. Mol Microbiol 2001;39:1036-1047.

[243] Li W, Bottrill AR, Bibb MJ, Buttner MJ, Paget MS, Kleanthous $C$. The role of zinc in the disulphide stressregulated anti-sigma factor RsrA from Streptomyces coelicolor. J Mol Biol 2003;333:461-472.

[244] Kim MS, Dufour YS, Yoo JS, Cho YB, Park JH, Nam GB, et al. Conservation of thiol-oxidative stress responses regulated by SigR orthologues in actinomycetes. Mol Microbiol 2012;85:326-344.

[245] Park JH, Roe JH. Mycothiol regulates and is regulated by a thiol-specific antisigma factor RsrA and sigma(R) in Streptomyces coelicolor. Mol Microbiol 2008;68:861-870.

[246] Nakamura K, Hihara Y. Photon flux density-dependent gene expression in Synechocystis sp. PCC 6803 is regulated by a small, redox-responsive, LuxR-type regulator. J Biol Chem 2006;281:36758-36766.

[247] Horiuchi M, Nakamura K, Kojima K, Nishiyama $Y$, Hatakeyama W, Hisabori T, Hihara Y. The PedR transcriptional regulator interacts with thioredoxin to connect photosynthesis with gene expression in cyanobacteria. Biochem J 2010;431:135-140.

[248] Boronat $S$, Domènech $A$, Paulo $E$, Calvo IA, GarcíaSantamarina $S$, García $P$, et al. Thiol-based $\mathrm{H}_{2} \mathrm{O}_{2}$ signalling in microbial systems. Redox Biol 2014;2:395-399.

[249] Izawa S, Maeda K, Sugiyama K, Mano J, Inoue Y, Kimura A. Thioredoxin deficiency causes the constitutive activation of Yap1, an AP-1-like transcription factor in Saccharomyces cerevisiae. J Biol Chem 1999;274:2845928465.

[250] Marinho HS, Real C, Cyrne L, Soares H, Antunes F. Hydrogen peroxide sensing, signaling and regulation of transcription factors. Redox Biol 2014;2:535-562.

[251] Lee J, Godon C, Lagniel G, Spector D, Garin J, Labarre J, Toledano MB. Yap1 and Skn7 control two specialized oxidative stress response regulons in yeast. J Biol Chem 1999;274:16040-16046.

[252] Delaunay A, Isnard AD, Toledano $M B . \mathrm{H}_{2} \mathrm{O}_{2}$ sensing through oxidation of the Yap1 transcription factor. EMBO J 2000;19:5157-5166.

[253] Delaunay A, Pflieger D, Barrault MB, Vinh J, Toledano MB. A thiol peroxidase is an $\mathrm{H}_{2} \mathrm{O}_{2}$ receptor and redoxtransducer in gene activation. Cell 2002;111:471-481.

[254] Yan C, Lee LH, Davis LI. Crm1p mediates regulated nuclear export of a yeast AP-1-like transcription factor. EMBO J 1998;17:7416-7429. 
[255] Okazaki S, Tachibana T, Naganuma A, Mano N, Kuge S. Multistep disulfide bond formation in Yap1 is required for sensing and transduction of $\mathrm{H}_{2} \mathrm{O}_{2}$ stress signal. Mol Cell 2007;27:675-688.

[256] Wood MJ, Storz G, Tjandra N. Structural basis for redox regulation of Yap1 transcription factor localization. Nature 2004;430:917-921.

[257] Veal EA, Ross SJ, Malakasi P, Peacock E, Morgan BA. Ybp1 is required for the hydrogen peroxide-induced oxidation of the Yap1 transcription factor. J Biol Chem 2003;278:30896-30904.

[258] Azevedo D, Tacnet F, Delaunay A, Rodrigues-Pousada C, Toledano MB. Two redox centers within Yap1 for $\mathrm{H}_{2} \mathrm{O}_{2}$ and thiol-reactive chemicals signaling. Free Radic Biol Med 2003;35:889-900.

[259] Fomenko DE, Koc A, Agisheva N, Jacobsen M, Kaya A, Malinouski $M$, et al. Thiol peroxidases mediate specific genome-wide regulation of gene expression in response to hydrogen peroxide. Proc Natl Acad Sci USA 2011;108:2729-2734.

[260] Winterbourn CC, Hampton MB. Thiol chemistry and specificity in redox signaling. Free Radic Biol Med 2008;45:549-561.

[261] Day AM, Brown JD, Taylor SR, Rand JD, Morgan BA, Veal EA. Inactivation of a peroxiredoxin by hydrogen peroxide is critical for thioredoxin-mediated repair of oxidized proteins and cell survival. Mol Cell 2012;45:398-408.

[262] Matthews JR, Wakasugi N, Virelizier JL, Yodoi J, Hay RT. Thioredoxin regulates the DNA binding activity of NFkappa $\mathrm{B}$ by reduction of a disulphide bond involving cysteine 62. Nucleic Acids Res 1992;20:3821-3830.

[263] Schenk H, Klein M, Erdbrügger W, Dröge W, SchulzeOsthoff K. Distinct effects of thioredoxin and antioxidants on the activation of transcription factors NF-kappa B and AP-1. Proc Natl Acad Sci USA 1994;91:1672-1676.

[264] Baldwin AS, Jr. The NF-kappa B and I kappa B proteins: new discoveries and insights. Annu Rev Immunol 1996;14:649-683.

[265] Qin J, Clore GM, Kennedy WM, Huth JR, Gronenborn AM. Solution structure of human thioredoxin in a mixed disulfide intermediate complex with its target peptide from the transcription factor NF kappa B. Structure 1995;15:289-297.

[266] Hirota K, Murata M, Sachi Y, Nakamura H, Takeuchi J, Mori K, Yodoi J. Distinct roles of thioredoxin in the cytoplasm and in the nucleus. A two-step mechanism of redox regulation of transcription factor NF-kappaB. J Biol Chem 1999;274:27891-27897.

[267] Curran T, Franza BR Jr. Fos and Jun: the AP-1 connection. Cell 1998;55:395-397.
[268] Abate C, Patel L, Rauscher FJ, Curran T. Redox regulation of Fos and Jun DNA-binding activity in vitro. Science 1990;249:1157-1161.

[269] Xanthoudakis S, Miao G, Wang F, Pan YC, Curran T. Redox activation of Fos-Jun DNA binding activity is mediated by a DNA repair enzyme. EMBO J 1992;11:3323-3335.

[270] Georgiadis MM, Luo M, Gaur RK, Delaplane S, Li X, Kelley MR. Evolution of the redox function in mammalian apurinic/apyrimidinic endonuclease. Mutat Res 2008;643:54-63.

[271] Kelley MR, Georgiadis MM, Fishel ML. APE1/Ref-1 role in redox signaling: translational applications of targeting the redox function of the DNA repair/redox protein APE1/Ref-1. Curr Mol Pharmacol 2012;5:36-53.

[272] Luo M, Zhang J, He H, Su D, Chen Q, Gross ML, et al. Characterization of the redox activity and disulfide bond formation in apurinic/apyrimidinic endonuclease. Biochemistry 2012;51:695-705.

[273] Qin J, Clore GM, Kennedy WP, Kuszewski J, Gronenborn AM. The solution structure of human thioredoxin complexed with its target from Ref- 1 reveals peptide chain reversal. Structure 1996;15:613-620.

[274] Sobotta MC, Liou W, Stöcker S, Talwar D, Oehler M, Ruppert T, et al. Peroxiredoxin-2 and STAT3 form a redox relay for $\mathrm{H}_{2} \mathrm{O}_{2}$ signaling. Nat Chem Biol 2015;11:64-70.

[275] Cao J, Schulte J, Knight A, Leslie NR, Zagozdzon A, Bronson $\mathrm{R}$, et al. Prdx1 inhibits tumorigenesis via regulating PTEN/AKT activity. EMBO J 2009;28:15051517.

[276] Jarvis RM, Hughes SM, Ledgerwood EC. Peroxiredoxin 1 functions as a signal peroxidase to receive, transduce, and transmit peroxide signals in mammalian cells. Free Radic Biol Med 2012;53:1522-1530.

[277] Yan Y, Sabharwal P, Rao M, Sockanathan S. The antioxidant enzyme Prdx1 controls neuronal differentiation by thiol-redox-dependent activation of GDE2. Cell 2009;138:1209-1221.

[278] Flohé L. The impact of thiol peroxidases on redox regulation. Free Radic Res 2015;30:1-17.

[279] Saitoh M, Nishitoh H, Fujii M, Takeda K, Tobiume K, Sawada $Y$, et al. Mammalian thioredoxin is a direct inhibitor of apoptosis signal-regulating kinase (ASK) 1. EMBO J 1998;17:2596-2606.

[280] Kundumani-Sridharan V, Subramani J, Das KC. Thioredoxin activates MKK4-NFKB pathway in a redoxdependent manner to control manganese superoxide dismutase gene expression in endothelial cells. J Biol Chem 2015;290:17505-17519. 